\title{
TÉCNICAS DE REPLICAÇÃO EM ANÁLISE DE DADOS DE INQUÉRITOS DOMICILIARES
}

MARIA CECILIA GOI PORTO ALVES

Tese de Doutorado apresentada ao Departamento de Epidemiologia da Faculdade de Saúde Pública da Universidade de São Paulo para obtenção do Grau de Doutor. Área de concentração: Epidemiologia

Orientadora: Profa. Associada Dra. Nilza Nunes da Silva

São Paulo

2002

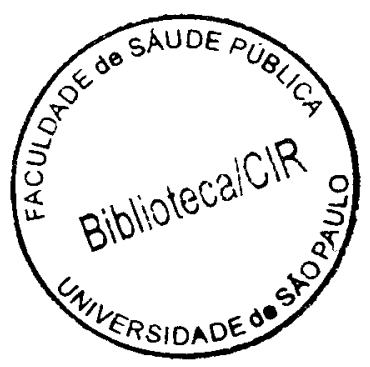


Autorizo, exclusivamente para fins acadêmicos e científicos, a reprodução total ou parcial desta tese, por processos fotocopiadores.

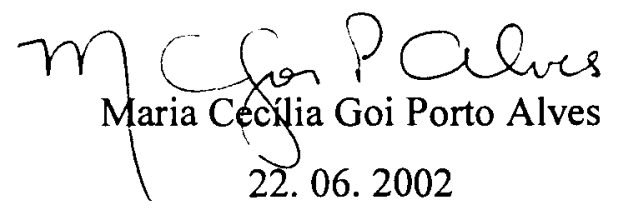

$+260212002 d x$ 
Aos meus pais, Orlando (in memorian) e Yole, que cultivaram em mim o desejo de aprender.

Ao Marcio, Renata, Beatriz e Fernanda, que são o meu apoio em todos os passos da vida.

Às minhas irmãs, Laura, Tereza e Luisa, que são o meu exemplo de amizade e solidariedade. 


\section{AGRADECIMENTOS}

Sou grata a muitos que colaboraram comigo na realização deste trabalho. À Prof. Dra. Nilza Nunes da Silva, pelo estímulo e orientação. Aos membros da banca examinadora, professores Benedito Benze, Chester Luiz Galvão César, Jair Lício dos Santos, Rosana Fiorini Puccini e Linda Lee Ho, pelas críticas e sugestões dadas ao trabalho. À Fundação SEADE e aos pesquisadores que gentilmente me cederam os arquivos de dados utilizados neste estudo. Aos meus amigos da SUCEN, pelo auxílio em várias etapas do trabalho. À amiga Mariza, pela disponibilidade e pelo apoio constantes. Devo, ainda, um agradecimento especial a Tarcísio Neves da Cunha, pelo suporte nas atividades de computação. 


\section{RESUMO}

Alves MCGP. Técnicas de replicação em análise de dados de inquéritos domiciliares. São Paulo; 2002. [Tese de doutorado - Faculdade de Saúde Pública da Universidade de São Paulo].

Objetivos. Estimativas de variância são necessárias à avaliação da qualidade dos dados coletados em inquéritos por amostragem. Buscando alternativas que simplifiquem o processo de estimação, foi estudada a aplicação de técnicas de replicação na análise de dados de inquéritos domiciliares em saúde pública. Avaliaram-se as técnicas BRR e Jackknife quanto à acurácia dos estimadores de variância, ao desempenho no cálculo de intervalos de confiança para proporções e médias e à análise de associação entre variáveis expressas por tabelas de contingência. Métodos. Para o estudo de acurácia, foram construídas distribuições de amostragem dos estimadores BRR e Jackknife para 3 delineamentos, sorteando-se 2000 amostras da população de estudo. As medidas de erro quadrático médio dessas distribuições e as coberturas dos intervalos de confiança foram comparadas às do Método de Linearização de Taylor. O desempenho dos estimadores Jackknife e BRR na construção de intervalos de confiança e em estudos de associação foi avaliado em quatro inquéritos realizados no Estado de São Paulo. Resultados. Com amostras de mais de 40 unidades primárias de amostragem, o desempenho dos estimadores BRR e Jackknife no cálculo de intervalos de confiança equipararam-se a Taylor. Com amostras menores, os intervalos calculados por Jackknife foram mais amplos. Os testes de associação realizados sob delineamentos complexos, por meio de técnicas de replicação, 
levaram à rejeição da hipótese de não associação com freqüência menor do que sob a Amostragem Aleatória Simples, por incorporarem correções referentes ao efeito do delineamento. Pelo mesmo motivo, os intervalos de confiança de odds ratio, construídos com estimativas por replicação, incluíram a unidade com freqüência maior que os obtidos sob a Amostragem Aleatória Simples. Conclusões. As técnicas de replicação mostraram-se adequadas à realização de inferências com dados provenientes de inquéritos de saúde, em especial BRR, que permitiu obter resultados mais precisos que Jackknife, quando aplicada a amostras com poucas unidades primárias de amostragem. A aplicação das técnicas de replicação na construção de intervalos de confiança e na realização de estudos de associação entre variáveis, por permitir considerar os delineamentos complexos adotados, deve ser estimulada na área de saúde pública.

Descritores: Técnicas de replicação. Estimação de variância. Delineamentos complexos. Inquéritos de saúde. BRR. Jackknife. 


\section{SUMMARY}

Alves MCGP. Replication techniques for analyzing household survey data. São Paulo; 2002. [PhD Thesis - Faculdade de Saúde Pública da Universidade de São Paulo].

Objectives. Variance estimates are necessary in order to assess the quality of data collected in sample surveys. Replication techniques for analyzing household survey data in public health were studied aiming at finding alternatives to simplify the estimating process. The BRR and Jackknife techniques were assessed in relation to accuracy of variance estimators, performance for calculating confidence intervals for proportions and averages, and association analysis between variables expressed by contingency tables. Methods. In order to study accuracy, sample distributions of BRR and Jackknife estimators for three sample designs were constructed by drawing 2,000 samples of the study population. The mean square error measurements and the coverage of confidence intervals were compared to those of the Taylor Linearization Method. The performance of the Jackknife and BRR estimators for constructing confidence intervals and for association studies was assessed in 4 surveys carried out in the State of São Paulo. Results. The performance of the BRR and Jackknife estimators was comparable to Taylor, for samples over 40 primary sample units, in relation to the size of the confidence intervals calculated. The intervals for BRR were smaller than Jackknife for smaller samples. In health surveys, association tests performed under complex delineations, by means of replication techniques, resulted in the rejection of the non-association hypothesis more frequently than under Simple Random Sampling, because they incorporate corrections attaining to the design effect. Odds ratio confidence 
intervals, constructed with replication estimates, included the unit less frequently than those obtained under Simple Random Sampling for the same reason. Conclusions. Replication techniques proved themselves adequate for performing inferences with data from health surveys, especially BRR that allowed reaching more precise results than Jackknife, when used for samples with a small number of primary sample units. Using replication techniques for constructing confidence intervals for studying association between variables should be encouraged in public health because they allow considering the complex sample designs adopted.

Keywords: Replication Techniques. Variance Estimation. Complex Design. Health Survey's. BRR. Jackknife. 


\section{ÍNDICE}

1 INTRODUÇÃO 1

2 OBJETIVOS 14

3 REFERENCIAL TEÓRICO 15

3.1 Técnica de Replicação BRR 15

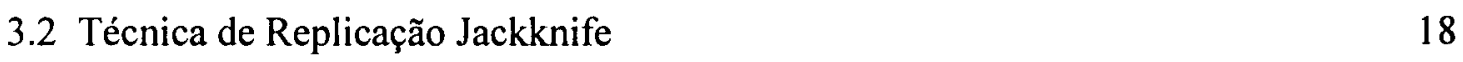

3.3 Estudo de associação sob delineamentos complexos 20

4 METODOLOGIA 25

4.1 Acurácia dos estimadores de variância 25

4.2 Aplicação de técnicas de replicação em inquéritos de saúde 32

4.2.1 Técnicas de replicação no cálculo de intervalos de confiança 33

4.2.2 Técnicas de replicação em estudos de associação 35

5 RESULTADOS 39

5.1 Acurácia dos estimadores de variância 39

5.2 Aplicação de técnicas de replicação em inquéritos de saúde 48

5.2.1 Técnicas de replicação no cálculo de intervalos de confiança 48

5.2.2 Técnicas de replicação em estudos de associação 62

6 DISCUSSÃO

7 CONCLUSÕES $\quad 86$

8 REFERÊNCIAS BIBLIOGRÁFICAS

ANEXO 1 Al

ANEXO $2 \ldots$ A3

$\begin{array}{ll}\text { ANEXO } 3 & \text { A10 }\end{array}$ 


\section{LISTA DE TABELAS}

Tabela 1. Municípios ou distritos, setores censitários e domicílios, segundo estratos da Pesquisa de Emprego e Desemprego. Região Metropolitana de São Paulo, agosto a novembro de 1998.

Tabela 2. Números de estratos, setores censitários e domicílios, segundo delineamento adotado no estudo de acurácia dos estimadores de variância.

Tabela 3. Média e vício do estimador razão $\mathrm{r}$, segundo número de amostras e delineamento de amostragem.

Tabela 4. Média e erro padrão da distribuição amostral do estimador $r$, construída com 2000 amostras, segundo delineamento.

Tabela 5. Média da distribuição amostral da variância do estimador $r$, construída com 2000 amostras, segundo estimadores de variância e delineamento.

Tabela 6. Erro padrão EP[var(r)] e coeficiente de variação CV[var(r)] da variância de r, calculados com 2000 amostras, segundo estimador de variância e delineamento de amostragem .

Tabela 7. Vícios absoluto e relativo, $\operatorname{Vic}[\operatorname{var}(r)]$ e $V R[\operatorname{var}(r)]$, e razão de vício $R V$ [var(r)], da variância de r, calculados com 2000 amostras, segundo estimador de variância e delineamento de amostragem.

Tabela 8. Erro quadrático médio, EQM[var(r)], e erro quadrático médio relativo, EQMR[var(r)], da variância de r, calculados com 2000 amostras, segundo estimador de variância e delineamento de amostragem.

Tabela 9. Cobertura dos intervalos de confiança com coeficientes da distribuição t-Student e Normal, calculada com 2000 amostras, segundo estimadores de variância e delineamento de amostragem.

Tabela 10. Porcentagens estimadas (p) e intervalos de confiança $\left(\mathrm{IC}_{95 \%}\right)$ calculados pelo Método de Linearização de Taylor (TY) e pela técnica Jackknife (JN), segundo estrato. Pesquisa "Morbidade infantil e utilização de serviços de saúde no Município de Embu", 1996. 
Tabela 11. Porcentagens (p) e erros padrão [dp(p)] estimados pela técnica Jackknife (JN) e pelo Método de Linearização de Taylor (TY), segundo estrato. Pesquisa "Morbidade infantil e utilização de serviços de saúde no Município de Embu", 1996.

Tabela 12. Razões entre estimativas de erro padrão Jackknife (JN) e Taylor (TY). Pesquisa "Morbidade infantil e utilização de serviços de saúde no Município de Embu", 1996.

Tabela 13. Porcentagens estimadas (p) e intervalos de confiança $\left(\mathrm{IC}_{95 \%}\right)$ calculados pela técnica Jackknife (JN) e pelo Método de Linearização de Taylor (TY), segundo área. Pesquisa "Morbidade referida e utilização de serviços de saúde na região sudeste da Grande São Paulo", 1989-90.

Tabela 14. Porcentagens e erros padrão estimados pela técnica Jackknife (JN) e pelo Método de Linearização de Taylor (TY), segundo área. Pesquisa' "Morbidade referida e utilização de serviços de saúde na região sudeste da GSP”, 1989-90.

Tabela 15. Razões entre estimativas de erro padrão Jackknife (JN) e Taylor (TY). Pesquisa "Morbidade referida e utilização de serviços de saúde na região sudeste da Grande São Paulo", 1989 e 1990.

Tabela 16. Índices de Breteau ( $I \hat{B}$ ) estimados e intervalos de confiança (IC $95 \%$ ) calculados pela técnica Jackknife (JN) e pelo Método de Linearização de Taylor (TY), por mês e bairro. Estudo "Produtividade dos habitats de Aedes aegypti", Santos, 2000.

Tabela 17. Índices de Breteau $(I \hat{B})$ e erros padrão $d p(I \hat{B})$ estimados pela técnica Jackknife (JN) e pelo Método de Linearização de Taylor (TY), por mês e bairro. Estudo "Produtividade dos habitats de Aedes aegypti", Santos, 2000.

Tabela 18. Porcentagens estimadas $(p)$ e intervalos de confiança $\left(\mathrm{IC}_{95 \%}\right)$ calculados pela técnica Jackknife (JN) e pelo Método de Linearização de Taylor (TY). "Pesquisa de Condições de Vida - 1998", Região Metropolitana de São Paulo.

Tabela 19. Porcentagens e erros padrão estimados pela técnica Jackknife (JN) e pelo Método de Linearização de Taylor (TY). "Pesquisa de Condições de Vida - 1998", Região Metropolitana de São Paulo.

Tabela 20. Porcentagens estimadas e intervalos de confiança calculados pelas técnicas BRR e Jackknife (JN) e pelo Método de Linearização de Taylor (TY). "Pesquisa de Condições de Vida - 1998", Região Metropolitana de Santos. 
Tabela 21. Porcentagens e erros padrão estimados pelas técnicas BRR e Jackknife (JN) e pelo Método de Linearização de Taylor (TY). "Pesquisa de Condições de Vida - 1998", Região Metropolitana de Santos.

Tabela 22. Razões entre erros padrão de estimativas Jackknife (JN), BRR e Taylor (TY), "Pesquisa de Condições de Vida - 1998”, Região Metropolitana de Santos.

Tabela 23. Níveis descritivos dos testes de associação entre estrato e variáveis da pesquisa, segundo delineamento de amostragem. "Morbidade infantil e utilização de serviços de saúde no Município de Embu”, 1996.

Tabela 24. Níveis descritivos dos testes de associação entre escolaridade e variáveis, segundo delineamento de amostragem. Pesquisa "Morbidade referida e utilização de serviços de saúde na região sudoeste da Grande São Paulo", 1989 e 1990.

Tabela 25. Níveis descritivos dos testes de associação entre escolaridade e variáveis, segundo delineamento de amostragem. Pesquisa "Morbidade referida e utilização de serviços de saúde na região sudoeste da Grande São Paulo", 1989 e 1990.

Tabela 26. Níveis descritivos dos testes de associação entre renda média familiar e variáveis, segundo delineamento de amostragem. "Pesquisa de Condições de Vida - 1998", Região Metropolitana de São Paulo.

Tabela 27. Estimativas do efeito do delineamento (deff), estatísticas de Pearson, com e sem correção de Rao-Scott, para testes de associação entre renda média familiar e variáveis da "Pesquisa de Condições de Vida - 1998", Região Metropolitana de São Paulo.

Tabela 28. Estimativas de odds ratio para desmame precoce, dada a apresentação de características de interesse ${ }^{(1)}$, e intervalos de confiança $\left(\mathrm{IC}_{95 \%}\right)$, segundo delineamento de amostragem. Pesquisa "Morbidade infantil e utilização de serviços de saúde no Município de Embu", 1996.

Tabela 29. Estimativas de odds ratio para doenças, dado o gểnero ${ }^{(1)}$, e intervalos de confiança ( $\mathrm{IC}_{95 \%}$ ), segundo delineamento de amostragem. Pesquisa "Morbidade referida e utilização de serviços de saúde na região sudoeste da Grande São Paulo", 1989 e 1990. 71

Tabela 30. Dados da amostra e pesos das réplicas criadas pela técnica Jackknife.

Tabela 31. Dados da amostra e pesos das réplicas criadas pela técnica BRR.

Tabela 32. Unidades de amostragem, quarteirões e edificações, na pesquisa "Produtividade dos habitats de Aedes aegypti", Município de Santos, 2000. 


\section{LISTA DE QUADROS E FIGURAS}

Figura 1. Distribuição de amostragem do estimador razão.

Figura 2. Distribuição de amostragem da variância do estimador razão, sob delineamento com 8 estratos e 16 unidades primárias de amostragem, segundo técnica de estimação de variância.

Figura 3. Distribuição de amostragem da variância do estimador razão, sob delineamento com 16 estratos e 32 unidades primárias de amostragem, segundo técnica de estimação de variância.

Figura 4. Distribuição de amostragem da variância do estimador razão, sob delineamento com 24 estratos e 48 unidades primárias de amostragem, segundo técnica de estimação de variância

Quadro 1. Dados de matriz ortogonal para definição de réplicas.

Quadro 2. Freqüências de indivíduos na amostra, segundo categorias das variáveis.

Quadro 3. Estimadores das freqüências de indivíduos na amostra, segundo categorias das variáveis.

Quadro 4. Tabela de contingência $2 \times 2$.

Quadro 5. Valores da constante c, empregada na estimação de variância, segundo técnica de replicação.

Quadro 6. Graus de liberdade segundo técnica de replicação.

Quadro 7. Modelo do Arquivo 1, com dados da Pesquisa de Emprego e Desemprego, por domicílio.

Quadro 8. Modelo do Arquivo 2, com dados da Pesquisa de Emprego e Desemprego, por setor censitário.

Quadro 9. Modelo da Matriz Hadamard (8x8).

Quadro 10. Frações de amostragem por estrato e estágio de seleção. Pesquisa "Morbidade referida e utilização de serviços de saúde na região sudoeste da Grande São Paulo". 


\section{INTRODUÇÃO}

Inquéritos domiciliares têm sido mundialmente utilizados em saúde pública, no planejamento e avaliação de serviços de saúde. Desde as primeiras experiências realizadas no início do século passado, década de 20 , vem aumentando a freqüência com que estudos de morbidade e de uso de serviços têm sido feitos por meio de amostra de domicílios (KROEGER 1983).

Esse crescimento decorre do reconhecimento das vantagens da realização de diagnósticos de saúde a partir de levantamentos domiciliares, entre elas:

- inclusão da parcela da população que não tem acesso ao sistema de saúde (LEBRÃO 1991);

- facilidade de atingir usuários de diferentes instituições prestadoras de serviços (CARVALHEIRO 1981);

- superação das limitações que dados de fontes secundárias apresentam, em especial a que se refere à seleção de casos de maior gravidade, em estudos de morbidade (CESAR 1997);

- possibilidade de coletar informações referentes a variáveis que se relacionam com os fenômenos sob investigação, aumentando a compreensão sobre sua ocorrência e a capacidade de determinar intervenções apropriadas (WHITE 1985).

Inquéritos domiciliares têm sido usados também, como ocorre no estado de São Paulo, para acompanhar a densidade de vetores existentes em áreas urbana e rural, subsidiando a avaliação do risco de transmissão de doenças e das estratégias de vigilância c controle adotadas (ALVES 1989, ALVES 1991). 
Embora cresça o reconhecimento da importância dos inquéritos domiciliares para a área de saúde pública, pouca atenção se tem dado à propriedade das inferências efetuadas. A divulgação dos resultados dos inquéritos geralmente é feita sem a inclusão de informações sobre erros de amostragem, que permitam avaliar a precisão das estimativas. Esse aspecto tem sido constantemente negligenciado também em outros países. KISH e FRANKEL (1974) afirmaram que cálculos de erros ainda ocorriam como raras exceções e não como complementos naturais de amostras probabilísticas.

O conhecimento dos erros de amostragem, além de ser necessário para a correta interpretação dos resultados do levantamento, possibilita avaliar e aprimorar os delineamentos de amostras adotados. Além disso, a descrição de características populacionais deixou, há muito, de ser o objetivo primordial de levantamentos por amostragem, buscando-se, com freqüência cada vez maior, fazer comparações entre subgrupos populacionais, testar hipóteses sobre parâmetros e estabelecer relações entre as variáveis dimensionadas. Para quaisquer desses fins, as estimativas de variância são igualmente necessárias.

Vários aspectos presentes em inquéritos domiciliares fazem com que os delineamentos de amostragem sejam complexos e, conseqüentemente, a estimação de erros de amostragem deixe de ser tarefa simples.

$\mathrm{Na}$ Amostragem Aleatória Simples (AAS), em que as unidades têm iguais probabilidades de seleção e são independentes, a variância do estimador da média de uma variável "y", caso o sorteio seja com reposição, é expressa por $\frac{s^{2}}{n}=\frac{\sum_{i=1}^{n}\left(y_{i}-\bar{y}\right)^{2}}{n(n-1)}$, onde n é o número de elementos da amostra, $y_{i}$ são os valores 
desses elementos e $\bar{y}=\frac{\sum_{i=1}^{n} y_{i}}{n}$ sua média (KISH 1965). Em inquéritos domiciliares, dificilmente tais condições são satisfeitas, permitindo o uso de estimador tão simples.

A adoção de planos complexos de amostragem é ditada basicamente por duas considerações. Há sempre informações sobre elementos da população ou de subgrupos dela, que podem ser usadas no delineamento ou na estimação, para aumentar a precisão. Surgem assim: estratificação, pós-estratificação, sorteio de conglomerados com probabilidade proporcional ao tamanho, uso de estimadores razão e regressão. Além disso, geralmente os elementos da população estão dispersos em área geográfica extensa e conglomerados de elementos podem ser identificados antes do sorteio da amostra, o que leva à sua adoção para diminuir os custos da amostra.

Há também outras alternativas de delineamentos que se pode ter interesse em adotar, tais como a amostragem em duas fases (em que uma subamostra é sorteada de uma amostra inicial), de painéis (amostras das quais elementos são medidos em duas ou mais ocasiões) e seleção controlada (em que número de estratos é muito grande em relação ao numero de unidades), às quais correspondem estimadores complexos.

Mesmo que a amostragem seja a aleatória simples, a existência de unidades sem resposta influencia a estimação e, com freqüência, leva à adoção de ajustes para corrigir vícios possivelmente introduzidos. Ajustes de pós-estratificação também podem ser incorporados na tentativa de ajustar a distribuição da amostra à da população, em relação a características importantes, diminuindo o vício das estimativas. 
$\mathrm{Na}$ amostragem por conglomerados de tamanhos desiguais, o número de elementos da amostra passa a ser uma variável aleatória, o que transforma a média em uma razão de variáveis aleatórias, com conseqüências na estimação de seu erro de amostragem. Dessa forma, a maior parte dos estimadores utilizados em inquéritos constituem em razões, que são estimadores não-lineares, complexos. Os pesos utilizados nos ajustes de não resposta e pós-estratificação são, eles próprios, razões de variáveis aleatórias, e ainda, quando da utilização de ajustes concomitantes, aparece o produto, combinação não-linear, dessas razões.

Além desses fatores referentes a delineamentos e ajustes, há que se referir ainda às estatísticas utilizadas na análise de dados, tais como coeficientes de regressão e de correlação, que são naturalmente complexas.

Os aspectos mencionados levam à utilização de aproximações ajustadas à natureza complexa do delineamento da amostra, dos parâmetros e do processo de estimação. Os métodos conhecidos para se obterem estimadores alternativos aproximados de estimadores não lineares são: linearização de Taylor e replicação.

O método de linearização de Taylor fornece uma aproximação linear para o estimador não-linear de interesse, por meio da Série de Taylor. A essa aproximação são aplicadas as fórmulas usuais de estimadores lineares.

No caso do estimador razão, a aproximação feita pelo método tem sido amplamente utilizada na área de amostragem. Na literatura estatística, constam aproximações lineares para inúmeros estimadores não-lineares, tais como: diferenças de razões, razão de razões (ponderada ou não), produto de razões, soma ponderada de razões, coeficientes de regressão, e outros. 
Para que a aproximação da variância de um estimador razão pela Série de Taylor seja adequada, o tamanho da amostra (denominador da razão) não pode estar sujeito a grande variação, o que ocorre quando os conglomerados selecionados diferem muito em tamanho. A dificuldade em manter sob controle a variabilidade do denominador aumenta quando a estimação é dirigida para subclasses. A necessidade de estimar parâmetros em subpopulações (subclasses) surge com freqüência em inquéritos domiciliares, sendo que o cálculo de diferenças de médias entre subclasses é uma das técnicas mais comuns de avaliar relações. Muitas vezes, o aparecimento, na amostra, de unidades dessas subclasses não pode ser controlado, em especial para caracteristicas raras e/ou distribuidas desıgualmente pelos conglomerados.

Pela utilização do Mćtodo de Linearização de Taylor, a expressão de variância do estimador razão, $r=\frac{y}{x}, \quad$ é da forma (KISH 1965): $\operatorname{var}(r)=\frac{1}{x^{2}}\left[\operatorname{var}(y)+r^{2} \operatorname{var}(x)-2 r \operatorname{cov}(x y)\right]$. Apesar de ser apresentada com freqüência na literatura estatística, essa expressão, que envolve as variâncias do numerador, $\operatorname{var}(y)$, do denominador, $\operatorname{var}(x)$, além da covariância entre eles, $\operatorname{cov}(x y)$, não pode ser considerada simples.

As técnicas de replicação surgem como uma alternativa de simplificação do processo de estimação de variância. Consistem em se obterem subconjuntos da amostra (réplicas), repetir o processo de estimação para cada um dos subconjuntos e calcular a variância a partir dessas estimativas. Às distintas formas de retirá-los da amostra, correspondem distintas técnicas de replicação.

A mais antiga delas é a de Grupos Aleatórios, segundo denominação utilizada por WOLTER (1985), na qual a amostra é composta por um conjunto de réplicas que 
têm a mesma estrutura da amostra toda, diferindo desta só pelo tamanho. Para formálas, são retiradas da população várias amostras, utilizando-se mesmo delineamento e mesmo procedimento de coleta de dados.

O esquema é o seguinte. Uma amostra de tamanho n é construída pela união de $\mathrm{K}$ amostras (réplicas) de tamanho $\mathrm{n} / \mathrm{K}$. Sendo $\theta$ o parâmetro de interesse e $\hat{\theta}$ o seu estimador, são obtidas estimativas para cada réplica utilizando $\hat{\theta}_{k}(k=1, \ldots, K)$. $\hat{\bar{\theta}}=\frac{1}{K} \sum_{k=1}^{K} \hat{\theta}_{k} \quad$ é estimador de $\theta$ e $\quad \operatorname{var}(\hat{\bar{\theta}})=\frac{1}{K(K-1)} \sum_{k=1}^{K}\left(\hat{\theta}_{k}-\hat{\bar{\theta}}\right)^{2}$ é estimador da variância de $\hat{\bar{\theta}}$ (WOLTER 1985).

Essa construção segue a simplicidade da estimação da média na Amostragem Aleatória Simples, na qual o estimador do parâmetro é dado pela média aritmética das observações e a variância utiliza-se dos desvios das observações em relação à média.

A idéia básica foi dada por Mahalanobis, em trabalhos de 1939, 1944 e 1946, nos quais as réplicas, denominadas "interpenetrating samples", foram propostas para investigar erros não amostrais (KALTON 1977). Trabalhos posteriores exploraram a técnica e outras denominações surgiram, como "replicated samples", adotada por DEMING (1956), que defendeu seu uso para simplificar cálculos de erros de amostragem.

Um dos objetivos com que a técnica de Grupos Aleatórios é mais comumente utilizada diz respeito ao estudo de erros não amostrais, tais como vícios relacionados a entrevistadores. Destinando distintas réplicas para distintos entrevistadores e comparando as estimativas correspondentes, é possível ter indicações sobre erros introduzidos (KISH 1965). 
A técnica é ainda uma alternativa adequada à estimação de variância em amostras sistemáticas (WOLTER 1985), que, a rigor, por ser constituída por um único conglomerado, não dispõe de estimador para a variância. A existência de estimativas feitas para várias subamostras sistemáticas, selecionadas a partir do sorteio de vários inícios casuais, permite que se disponha de aproximação para a variância, sem que seja necessário fazer suposições sobre a organização dos elementos da população nos sistemas de referência, como é prática comum. É com essa abordagem que KISH (1965), em seu livro de amostragem, introduz o tema de replicação.

Os grupos aleatórios devem ser criados utilizando-se sempre o mesmo procedimento. Dessa forma, o sorteio deve ser feito com o mesmo delineamento (sistema de referência, tipo de unidade, estratificação); a coleta de dados deve ser feita da mesma forma (treinamento e recrutamento de pessoal, instrumentos de registro de dados, codificação de respostas, entrada de dados); e também os estimadores e as etapas envolvidas no cálculo de estimativas (tratamento de não resposta, ponderação) devem ser os mesmos.

Para que as réplicas sejam independentes, é necessário que sejam sorteadas com reposição, sendo que a coleta de dados deve ser realizada por diferentes equipes nas distintas réplicas e as etapas de estimação aplicadas separadamente em cada uma delas. Tais exigências restringem a utilização de grupos independentes, fazendo com que na prática, a amostra seja repartida em subamostras, após o sorteio. As réplicas referem-se, então, a grupos aleatórios dependentes, correlacionados, para as quais os estimadores definidos para grupos independentes tornam-se aproximações (WOLTER 1985). 
Mesmo assim, há grande dificuldade na utilização da técnica de Grupos Aleatórios, em função da necessidade de amostras muito grandes, que permitam a formação de réplicas em número suficiente para que estimativas de variância não sejam demasiadamente instáveis. Em amostragem estratificada em estágios múltiplos, o número necessário de unidades primárias de amostragem por estrato é, em geral, proibitivo.

Em função dessas limitações, a opção recai sobre técnicas denominadas de pseudo-replicação, nas quais as réplicas são obtidas por amostragem repetida ("resampling"), ou seja, construídas retirando-se, repetidamente, subamostras da amostra toda. As mais comuns são: "Balanced Repeated Replication" (BRR) e "Jackknife".

A técnica BRR surgiu como uma alternativa de estimação em delineamentos que, por considerações de eficiência, utilizam um número muito grande de estratos e, consequentemente, o menor número possível de unidades primárias de amostragem por estrato: duas unidades. Se fosse utilizada a técnica de Grupos Aleatórios com esse delineamento, seriam obtidas somente duas réplicas, e conseqüentemente estimativas de variância não alcançariam níveis adequados de precisão.

Para superar essa dificuldade, o "US Bureau of the Census" originou um esquema de pseudo-replicação, que foi denominado "half-sample replication" (WOLTER 1985). O esquema foi adaptado e modificado pelos técnicos do "National Center of Health Statistics", sendo que em 1966, McCARTHY (1966) introduziu o balanceamento a que se refere o nome da técnica.

A premissa básica é muito simples. De uma amostra estratificada são retiradas meias amostras (réplicas), formadas por uma das unidades de cada estrato. 
Para cada réplica, obtém-se a estimativa de primeira ordem de interesse e o quadrado da diferença entre essa estimativa e a da amostra toda constitui uma estimativa da variância. A média de todas essas estimativas é utilizada como estimador da variância.

Embora GURNEY e JEWETT (1975) tenham sugerido a possibilidade de utilização da técnica com outros números de unidades primárias por estrato (desde que constantes), BRR é empregado de maneira geral com seleções pareadas. Esse delineamento pode também ser consequiência de alterações feitas na estrutura da amostra, não sendo portanto tão restritivo como parece. É possível, por exemplo, unir duas a duas as unidades de amostras sistemáticas, unir estratos que tenham só uma unidade ou unir unidades dentro de estratos quando há mais do que duas (UNITED NATIONS 1993).

Procedimentos de estimação Jackknife foram concebidos, originalmente, com o objetivo de reduzir o vício de um estimador de coeficiente de correlação em séries temporais, por Quenouille, em 1949. Na década de 50, suas propriedades de redução de vício foram exploradas, ainda no contexto de populações infinitas, tornando-se aplicável à ampla classe de problemas estatísticos nos quais os estimadores propostos sejam viciados (COCHRAN 1977). TUKEY (1958) sugeriu que os estimadores individuais das sub-amostras criados pela técnica poderiam ser vistos como variáveis aleatórias independentes e identicamente distribuídas, levando-se a um estimador muito simples de variância e a uma estatística aproximada de t para teste e estimação de intervalos de confiança. Deu-lhe o nome de Jackknife para fazer referência a um instrumento de múltiplos usos, o canivete. Sua utilização no contexto de populações 
finitas parece ter sido considerada, pela primeira vez, por Durbin, em 1959, associada ao estimador razão (WOLTER 1985).

$\mathrm{Na}$ técnica Jackknife de estimação de variância, réplicas são obtidas retirando-se geralmente uma unidade amostral de cada estrato. A contribuição de cada replicação na amostra, ou equivalentemente, de cada unidade e estrato, é medida pela diferença entre o total da amostra estimado com e sem a inclusão da réplica. Os estimadores do parâmetro e de sua variância são dados pelas médias dessas contribuições.

A estimação de variância por meio das técnicas Jackknife e BRR tornou-se procedimento comum na análise de dados de inquéritos em outros países, como fica atestado pela verificação de que três das maiores organizações de pesquisa dos Estados Unidos: "US Bureau of the Census", "National Center for Health Statistics" e "Survey Research Center" da Universidade de Michigan as empregam rotineiramente (BEAN 1975).

RUST (1986) afirma que a utilização de técnicas de replicação passou a ser norma em surveys, particularmente após sua utilidade ficar demonstrada por KISH e FRANKELL (1974), em trabalho que se tornou um marco na discussão de amostras complexas. Com dados do "Current Population Survey" do "US Bureau of the Census", os autores avaliaram o desempenho das técnicas Jackknife, BRR e do método de linearização de Taylor, para várias estatísticas e concluíram que todas apresentam resultados adequados, nenhuma se mostrando consistentemente melhor ou pior, frente aos vários critérios adotados.

A avaliação que se tem hoje dessas técnicas de estimação de variância é, em grande medida, baseada nos resultados empíricos de estudos referentes a inúmeros 
parâmetros, delineamentos, estimadores e populações finitas (KISH e FRANKEL 1974, BEAN 1975, CAMPBELL e MEYER 1978, MULRY e WOLTER 1981, KOVAR et al. 1988, BURKE e RUST 1995). Em geral, os resultados das análises, mesmo apresentando variações em função dos aspectos específicos de cada estudo, confirmaram a indicação de que os estimadores de variância de todas as técnicas podem ser usados para fazer inferências.

Considerando essa conclusão, a escolha entre as técnicas parece depender de vantagens e desvantagens de outra ordem, tais como considerações administrativas (disponibilidade de "softwares" e custo) e compatibilidade do delineamento e estimador com as distintas alternativas.

Nesse aspecto, uma das vantagens das técnicas de replicação em relação ao método de linearização de Taylor refere-se à facilidade com que a sua idéia básica pode ser entendida pelos profissionais interessados nas informações provenientes de inquéritos domiciliares. Essa facilidade fica realçada quando se considera que o procedimento de análise, dado um determinado delineamento, é o mesmo para todo tipo de estatística. Tanto a variância de um estimador razão como a de uma estatística definida como função não linear de várias razões são estimadas com a mesma expressão, ou seja, aquela que mede aos desvios das estimativas das réplicas em relação à média geral, calculada sobre toda a amostra.

Em inquéritos de saúde, embora as estimativas mais freqüentemente desejadas sejam do tipo razão, não é raro surgir outras estatísticas para as quais seja difícil determinar expressões de variância. O método de linearização tem sido considerado adequado quando delineamento e estimadores são usados repetidamente, porém a abordagem não é reconhecida como prática quando estimadores não 
lineares, que devem ser aproximados, serão usados uma única vez ou mesmo poucas vezes (FLYER et al. 1989, BRICK et al. 1998).

Para SKINNER (1989), a maior vantagem das técnicas de replicação é criar condições para que usuários de dados secundários possam estimar erros de amostragem, sem conhecer pormenores relacionados ao delineamento. Caso as réplicas sejam anexadas aos arquivos de dados pelos pesquisadores envolvidos no inquérito, torna-se possível, em estudos posteriores, estimar erros de amostragem, "desconsiderando" o delineamento e utilizando as réplicas.

As vantagens citadas das técnicas de replicação, em especial a que se refere à simplificação do processo de estimação de variância, apontam para a importância de estudar sua utilização, contribuindo para superar as dificuldades que hoje são observadas na avaliação dos erros de amostragem em inquéritos realizados em nosso meio.

O presente estudo pretende contribuir na compreensão de aspectos relacionados à sua aplicação, desde os que se referem à acurácia de seus estimadores até a identificação de situações em que sua utilização seja mais conveniente que a de métodos tradicionais.

Atualmente, uma das dificuldades presentes na avaliação dos dados provenientes de levantamentos por amostragem diz respeito ao estudo de associação entre variáveis, levando-se em consideração o delineamento da amostra. Isto porque, ainda predomina em nosso meio o uso de softwares estatísticos de análise de dados que pressupõem a utilização de Amostragem Aleatória Simples, o que pode levar a conclusões equivocadas. A partir da década de 70 , têm surgido ferramentas para 
análise de dados provenientes de delineamentos complexos (CARLSON 1998, LEPKOWSKI e BOWES 1996), cuja implementação deve ser estimulada.

Utilizando técnicas de replicação, pretende-se com este estudo contribuir também para que sejam incorporadas novas práticas na análise de dados na área de saúde pública, nas quais os aspectos referentes à complexidade do processo de amostragem sejam considerados. 


\section{OBJETIVOS}

\subsection{Objetivo geral}

Estudar a aplicação de técnicas de replicação na análise de dados de inquéritos domiciliares em saúde pública.

\subsection{Objetivos Específicos}

Avaliar as técnicas de replicação Jackknife e BRR, quanto:

- à acurácia dos estimadores de variância;

- ao desempenho no cálculo de intervalos de confiança para proporções e médias estimadas em inquéritos epidemiológicos, realizados sob delineamentos complexos de amostragem;

- à análise de distribuições bivariadas expressas por tabelas de contingência. 


\section{REFERENCIAL TEÓRICO}

\section{Técnicas de replicação para estimar erros de amostragem}

\subsection{BRR (WOLTER 1985)}

Seja uma população de $\mathrm{N}$ elementos dividida em $\mathrm{H}$ estratos, com $N_{h}$ elementos em cada estrato. De cada estrato, são retiradas amostras com reposição, de $n_{h}=2$ elementos, sendo que $y_{h 1}$ e $y_{h 2}$ denotam as observações do estrato $\mathrm{h}$ $(h=1, \ldots, H)$.

São formadas réplicas, selecionando-se uma unidade de cada estrato. O estimador de $\bar{Y}$ em cada réplica $\alpha$ é:

$$
\bar{y}_{\alpha}=\sum_{h=1}^{H} W_{h}\left(\delta_{h 1 \alpha} \cdot y_{h 1}+\delta_{l 12 \alpha} \cdot y_{h 2}\right) \text {, }
$$

onde $\delta_{l 1 \alpha}=1$ se a unidade $(\mathrm{h}, 1)$ pertence à $\alpha$-ésima réplica e $\delta_{m \alpha \alpha}=0$, se não pertence; $\delta_{h 2 \alpha}=1-\delta_{h 1 \alpha} ;$ e $W_{h}=N_{h} / N$. Há $2^{H}$ réplicas para uma dada amostra e cada uma delas fornece estimativas para a média populacional e para sua variância. Há, portanto, $2^{H}$ estimativas $\bar{y}_{\alpha}$ de $\bar{Y}$ e $2^{H}$ estimativas $\left(\bar{y}_{\alpha}-\bar{y}\right)^{2}$ de $\operatorname{var}(\bar{y})$.

Estimadores da média e variância populacionais são tomados considerando-se o conjunto das réplicas e são expressos, respectivamente, por: $\bar{y}=\sum_{\alpha=1}^{2^{\prime \prime}} \frac{\bar{y}_{\alpha}}{2^{H}}$, onde a igualdade ocorre em função de cada unidade da amostra aparecer exatamente em metade das réplicas criadas, e $\operatorname{var}(\bar{y})=\sum_{\alpha=1}^{2^{\prime \prime}} \frac{\left(\bar{y}_{\alpha}-\bar{y}\right)^{2}}{2^{H}}$, estimador não viciado de $\operatorname{Var}(\bar{y})$. 
Caso o número de estratos seja grande, o cálculo dessa média torna-se proibitivo. É possível, porém, selecionar um conjunto $\mathrm{k}$ de réplicas dentre as $2^{H}$ existentes, de tal forma que $\operatorname{var}_{k}(\bar{y})=\operatorname{var}(\bar{y})$. Esse conjunto é dito balanceado (McCARTHY 1966).

Para tanto, é necessário que $\sum_{\alpha=1}^{k} \varepsilon_{h \alpha} \varepsilon_{h^{\prime} \alpha}=0$ para todo $h<h^{\prime}=1, \ldots, H$, definindo-se $\varepsilon_{h \alpha}=2 \delta_{h 1 \alpha}-1 ; \varepsilon_{h \alpha}=1$, se a unidade (h,1) estiver na $\alpha$-ésima réplica e $\varepsilon_{h \alpha}=-1$, se a unidade $(h, 2)$ estiver na $\alpha$-ésima réplica.

Matrizes ortogonais construídas por PLACKETT e BURMAN (1946), denominadas matrizes Hadamard, possuem colunas que satisfazem essa igualdade. São matrizes $\mathrm{k}$ x k, onde $\mathrm{k}$ é um múltiplo de 4 . Adotam-se valores de $\mathrm{k}$ equivalentes ao primeiro múltiplo de 4 que seja igual ou maior que $H$. A figura abaixo corresponde à matriz $8 \times 8$, que deve ser utilizada, portanto, para amostras com 5,6 , 7 ou 8 estratos.

Quadro 1. Dados de matriz ortogonal para definição de réplicas.

\begin{tabular}{lcccccccc}
\hline REPLICA & & \multicolumn{7}{c}{ ESTRATO (h) } \\
$(\alpha)$ & 1 & 2 & 3 & 4 & 5 & 6 & 7 & 8 \\
\hline$\varepsilon_{h 1}$ & +1 & -1 & -1 & +1 & -1 & +1 & +1 & -1 \\
$\varepsilon_{h 1}$ & +1 & +1 & -1 & -1 & +1 & -1 & +1 & -1 \\
$\varepsilon_{h 1}$ & +1 & +1 & +1 & -1 & -1 & +1 & -1 & -1 \\
$\varepsilon_{h 1}$ & -1 & +1 & +1 & +1 & -1 & -1 & +1 & -1 \\
$\varepsilon_{h 1}$ & +1 & -1 & +1 & +1 & +1 & -1 & -1 & -1 \\
$\varepsilon_{h 1}$ & -1 & +1 & -1 & +1 & +1 & +1 & -1 & -1 \\
$\varepsilon_{h 1}$ & -1 & -1 & +1 & -1 & +1 & +1 & +1 & -1 \\
$\varepsilon_{h 1}$ & -1 & -1 & -1 & -1 & -1 & -1 & -1 & -1 \\
\hline
\end{tabular}


Cada linha da matriz corresponde a uma réplica $\alpha$, sendo que +1 indica a inclusão da unidade $(h, 1)$ na réplica e -1 , da unidade $(h, 2)$. Para amostras com cinco, seis ou sete estratos, qualquer conjunto de cinco, seis ou sete colunas pode ser utilizado.

Considerando o delineamento mais freqüentemente utilizado em inquéritos domiciliares (por conglomerados) e os estimadores razão, não-lineares, tem-se que:

O estimador de interesse é $\hat{R}=\hat{Y} / \hat{X}$ e o estimador a partir da $\alpha$-ésima réplica é $\hat{R}_{\alpha}=\hat{Y}_{\alpha} / \hat{X}_{\alpha}$

$$
\hat{Y}_{\alpha}=\sum_{h=1}^{H}\left(\delta_{h 1 \alpha} \hat{Y}_{h 1} / p_{h 1}+\delta_{h 2 \alpha} \hat{Y}_{h 2} / p_{h 2}\right) \text { e } \hat{X}_{\alpha}=\sum_{h=1}^{H}\left(\delta_{h 1 \alpha} \hat{X}_{h 1} / p_{h 1}+\delta_{h 2 \alpha} \hat{X}_{h 2} / p_{h 2}\right)
$$

sendo $\hat{Y}_{h i}$ e $\hat{X}_{h i}$ os estimadores dos totais da (h,i)-ésima unidade primária de amostragem; $p_{h i}$ a probabilidade de seleção dessa unidade; $\hat{Y}_{h i} / p_{h i}$ e $\hat{X}_{h i} / p_{h i}$ os estimadores (devidamente ponderados) dos totais do estrato $h$, a partir da unidade $i$ das replicações $(\mathrm{i}=1,2)$.

$$
\text { O estimador de } \mathrm{R} \text { com as } \mathrm{K} \text { réplicas é } \hat{\bar{R}}=\frac{1}{K} \sum_{\alpha=1}^{K} \hat{R}_{\alpha} \text {, }
$$

e o estimador da variância $\operatorname{var}(\hat{R})=\frac{\sum_{\alpha=1}^{K}\left(\hat{R}_{\alpha}-\hat{R}\right)^{2}}{K}$.

Com estimadores não lineares, há também outros estimadores de variância,

$\left.\operatorname{var}^{c}(\hat{R})=\frac{\sum_{\alpha=1}^{K}\left(\hat{R}_{\alpha}^{c}-\hat{R}\right)^{2}}{K}, \overline{\operatorname{var}} \overline{\hat{R}}\right)=\frac{\left[\operatorname{var}(\hat{R})+\operatorname{var}^{c}(\hat{R})\right]}{2}, \operatorname{var}^{+}(\hat{R})=\frac{\sum_{\alpha=1}^{K}\left(\hat{R}_{\alpha}-\hat{R}_{\alpha \alpha}^{c}\right)^{2}}{4 K}$, sendo $\hat{R}_{\alpha}^{c}$ é o estimador calculado com a réplica complementar de $\alpha$. 


\subsection{Jackknife (WOLTER 1985)}

Sejam $Y_{1}, \ldots, Y_{n}$ variáveis aleatórias independentes e identicamente distribuidas, com função distribuição $\mathrm{F}(\mathrm{y})$ e seja $\hat{\theta}$ um estimador do parâmetro populacional de interesse $\theta$, calculado com todos os elementos da amostra.

Divide-se a amostra em $k$ grupos com $m$ observações cada $(n=m k, n, m, k$ inteiros). Seja $\hat{\theta}_{(\alpha)}$ um estimador com a mesma forma funcional de $\hat{\theta}$, mas calculado com amostra de $\mathrm{m}(\mathrm{k}-1)$ elementos, omitindo-se o $\alpha$-ésimo grupo, e seja $\hat{\theta}_{\alpha}=k \hat{\theta}-(k-1) \hat{\theta}_{(\alpha)}$, chamado de pseudo-valor.

O estimador de Quenouille é a média dos pseudo-valores $\hat{\theta}_{\alpha}, \hat{\bar{\theta}}=\frac{\sum_{\alpha=1}^{k} \hat{\theta}_{\alpha}}{k}$.

Seguindo a sugestão de Tukey, os pseudo-valores $\hat{\theta}_{\alpha}$ podem ser vistos como estimativas de $\theta$, independentes e igualmente distribuídas. O estimador Jackknife de variância é então $\quad v_{1}(\hat{\bar{\theta}})=\frac{1}{k(k-1)} \sum_{\alpha=1}^{k}\left(\hat{\theta}_{\alpha}-\hat{\bar{\theta}}^{2}\right.$.

Esse estimador pode também ser escrito como $v_{1}(\hat{\bar{\theta}}=) \frac{(k-1)}{k} \sum_{\alpha=1}^{k}\left(\hat{\theta}_{(\alpha)}-\hat{\theta}_{(\bullet)}\right)^{2}$,

uma vez que, $\hat{\theta}_{\alpha}-\hat{\bar{\theta}}=-(k-1)\left(\hat{\theta}_{(\alpha)}-\hat{\theta}_{(\bullet)}\right)$, onde $\hat{\theta}_{(\bullet)}=\frac{\sum_{\alpha=1}^{k} \hat{\theta}_{(\alpha)}}{k}$

O número de grupos em que se divide a amostra e o número de observações por grupo $(k, m)$ são geralmente $(n, 1)$, de forma a se ter estimadores mais precisos. Ou seja, forma-se o número máximo de grupos, com uma única unidade em cada. 
Considerando que inquéritos domiciliares, em geral, utilizam amostras por conglomerados, estratificadas, os estimadores Jackknife referentes a esse delineamento estão descritos abaixo.

Seja $\hat{\theta}_{(h i)}$ o estimador da mesma forma funcional de $\hat{\theta}$, obtido após extrair da amostra a i-ésima unidade do h-ésimo estrato. Por se tratar de conglomerados, as unidades a serem retiradas não se referem às unidades primárias e sim aos "ultimate clusters", conjunto de unidades incluídas na amostra a partir de uma unidade primária (HANSEN et al. 1953).

O estimador Jackknife de $\theta$ é $\hat{\theta}_{1}=\sum_{h}^{L} \sum_{i}^{n_{h}} \frac{\hat{\theta}_{l i}}{L \cdot n_{h}}$

ou $\hat{\theta}_{1}=\left[1+\sum_{h}^{l}\left(n_{h}-1\right)\right] \hat{\theta}-\sum_{h}^{l}\left(n_{h}-1\right) \theta_{(l \cdot)}$,

sendo L o número de estratos e $\hat{\theta}_{(l \cdot \bullet)}=\sum_{i}^{n_{h}} \frac{\hat{\theta}_{(l i)}}{n_{h}}$.

A variância é $v_{1}(\hat{\theta})=\sum_{h=1}^{L} \frac{n_{h}-1}{n_{h}} \sum_{i=1}^{n_{h}}\left(\hat{\theta}_{(h i)}-\hat{\theta}_{(h \bullet)}\right)^{2}$

ou ainda $v_{1}^{\prime}(\hat{\theta})=\sum_{h=1}^{l} \frac{n_{h}-1}{n_{h}} \sum_{i=1}^{n_{h}}\left(\hat{\theta}_{(h i)}-\hat{\theta}_{(\bullet \bullet)}\right)^{2}$, sendo $\hat{\theta}_{(\bullet)}=\sum_{h}^{L} \sum_{i}^{n_{h}} \frac{\hat{\theta}_{(l i)}}{n}$.

Considerando-se o estimador mais utilizado em inquéritos de saúde, o

estimador razão combinado $\hat{\theta}=\frac{\sum_{h=1}^{L} N_{h} \bar{y}_{h}}{\sum_{h=1}^{L} N_{h} \bar{x}_{h}}$,

a expressão matemática para $\hat{\theta}_{(h i)}$ é: $\hat{\theta}_{(h i)}=\frac{\sum_{h \neq h}^{l} N_{h h^{\prime}} \bar{y}_{h^{\prime}}+N_{h} \sum_{j \neq i}^{n_{h}} \frac{y_{h i}}{n_{h l}-1}}{\sum_{h i \neq h}^{l} N_{h} \bar{x}_{h^{\prime}}+N_{h} \sum_{j \neq i}^{n_{h}} \frac{x_{h i}}{n_{h}-1}}$. 


\section{3 Estudo de associação sob delineamentos complexos de amostragem}

Verificar a existência de associação entre variáveis é objetivo freqüente em inquéritos de saúde. Também usualmente, tais variáveis são categóricas e as frequêencias de elementos da amostra que são identificados no cruzamento de categorias de duas variáveis quaisquer podem ser dispostas em tabelas de contingência, como ilustrado pelo Quadro 2.

Quadro 2. Frequiências de indivíduos na amostra, segundo categorias das variáveis.

\begin{tabular}{|c|c|c|c|c|c|c|c|}
\hline \multirow[t]{2}{*}{ VARIÁVEL 1} & \multicolumn{6}{|c|}{$\overline{\text { VARIÁVEL } 2}$} & \multirow[t]{2}{*}{ Total } \\
\hline & 1 & 2 & $\ldots$ & $\mathrm{c}$ & & $\mathrm{C}$ & \\
\hline 1 & $n_{11}$ & $n_{12}$ & $\ldots$ & $n_{1 c}$ & $\cdots$ & $n_{1 c:}$ & $n_{1}$. \\
\hline $\begin{array}{l}2 \\
:\end{array}$ & $n_{21}$ & $\begin{array}{c}n_{22} \\
:\end{array}$ & $\ldots$ & $\begin{array}{c}n_{2 c} \\
:\end{array}$ & ... & $n_{2 C}$ & $n_{2}$ \\
\hline l & $n_{n}$ & $n_{12}$ & $\ldots$ & $\begin{array}{c}: \\
n_{l c}\end{array}$ & $\ldots$ & $n_{k}$ & $\begin{array}{c}: \\
n_{l}\end{array}$ \\
\hline$\vdots$ & $\pi$ & $\vdots$ & & $\vdots$ & & $\vdots$ & $\vdots$ \\
\hline $\mathrm{L}$ & $n_{L, 1}$ & $n_{L, 2}$ & $\ldots$ & $n_{l, c}$ & $\ldots$ & $n_{L C}$ & $n_{L}$. \\
\hline Total & $n_{.1}$ & $n_{.2}$ & $\ldots$ & $n_{\bullet c}$ & $\ldots$ & $n_{\circ \mathrm{c}:}$ & $n$ \\
\hline
\end{tabular}

* $n_{l c}$ é o número de elementos amostrais na linha l e coluna c

Quando o delineamento utilizado para sorteio da amostra é o aleatório simples, estimativas não viciadas das proporções de indivíduos em cada casela podem ser obtidas por meio do estimador: $p_{l c}=\frac{n_{l c}}{n}$, sendo $n=\sum_{l=1}^{l} \sum_{c=1}^{C} n_{l c}$. 
Testes de associação entre variáveis são conduzidos considerando-se a

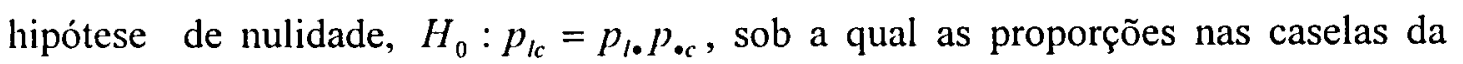
tabela de contingência podem ser escritas em função das proporções marginais, $p_{\iota_{\bullet}}=\frac{n_{\iota_{\bullet}}}{n} \quad$ e $\quad p_{\bullet c}=\frac{n_{\bullet c}}{n}, \quad \mathrm{e} \quad$ utilizando-se a estatística de Pearson, $X_{p}^{2}(I)=n \sum \sum \frac{\left(p_{l c}-p_{1 .} p_{\bullet c}\right)^{2}}{p_{1 .} p_{\bullet c}}($ PESSOA e NASCIMENTO-SILVA 1998).

$\mathrm{Na}$ Amostragem Aleatória Simples (AAS) e sob a hipótese nula, essa estatística tem distribuição amostral assintótica qui-quadrado com (C-1)(L-1) graus de liberdade.

No contexto de inquéritos domiciliares, é comum que os individuos sejam incluídos na amostra com probabilidades distintas, sendo necessário considerá-las na estimação das proporções de elementos nas caselas da tabela de contingência. Dessa forma, tais tabelas devem ser construídas com os valores padronizados das estimativas de freqüência das caselas, $\hat{n}_{l c}=\frac{\hat{N}_{l c}}{\hat{N}} \cdot n$

onde $\mathrm{n}$ é o tamanho da amostra, $\hat{N}_{l c}=\sum_{k} w_{l c k}$ é o estimador do número de observações na casela $(1, \mathrm{c}), w_{l c k}$ é o peso associado ao indivíduo $\mathrm{k}$ na casela $(1, \mathrm{c})$, dado pelo inverso de sua fração de amostragem e $\hat{N}=\sum_{l=1}^{l} \sum_{c=1}^{c} \hat{N}_{l c}$ é o total de indivíduos na população (PESSOA e NASCIMENTO-SILVA 1998), conforme esquema do Quadro 3. 
Quadro 3. Estimadores das frequiências de indivíduos na amostra, segundo categorias das variáveis.

\begin{tabular}{|c|c|c|c|c|c|c|c|}
\hline \multirow[t]{2}{*}{ VARIÁVEL 1} & \multicolumn{6}{|c|}{ VARIÁVEL 2} & \multirow[t]{2}{*}{ Total } \\
\hline & 1 & 2 & $\ldots$ & $c$ & $\ldots$ & $\mathrm{C}$ & \\
\hline 1 & $\hat{n}_{11}$ & $\hat{n}_{12}$ & $\ldots$ & $\hat{n}_{1 c}$ & $\ldots$ & $\hat{n}_{1 C}$ & $\hat{\hat{n}_{1}}$ \\
\hline 2 & $\hat{n}_{21}$ & $\hat{n}_{22}$ & $\ldots$ & $\hat{n}_{2 c}$ & $\ldots$ & $\hat{n}_{2 C}$ & $\hat{n}_{2}$ \\
\hline$\vdots$ & $\vdots$ & $\vdots$ & & $\vdots$ & & $\vdots$ & $\vdots$ \\
\hline$l$ & $\hat{n}_{n 1}$ & $\hat{n}_{12}$ & .. & $\hat{n}_{l c}$ & $\ldots$ & $\hat{n}_{k:}$ & $\hat{n}_{l \bullet}$ \\
\hline$\vdots$ & $\vdots$ & $\vdots$ & & $\vdots$ & & $\vdots$ & $\vdots$ \\
\hline $\mathrm{L}$ & $\hat{n}_{L 1}$ & $\hat{n}_{l, 2}$ & $\ldots$ & $\hat{n}_{l . c}$ & $\ldots$ & $\hat{n}_{l c}$ & $\hat{n}_{l \cdot}$ \\
\hline Total & $\hat{n}_{.1}$ & $\hat{n}_{.2}$ & $\ldots$ & $\hat{n}_{\cdot c}$ & $\ldots$ & $\hat{n}_{\cdot c}$ & $n$ \\
\hline
\end{tabular}

O estimador da proporção de população na casela $(1, c)$ passa a ser expresso por: $\hat{p}_{l c}=\frac{\hat{n}_{l c}}{n}$.

Essa proporção é uma razão de variáveis aleatórias, pois distintos aspectos presentes nesses levantamentos não permitem que o denominador se mantenha fixo. Estão entre eles: a existência de unidades de amostragem sem resposta, a mudança do foco da análise para subgrupos populacionais, e principalmente, o sorteio de conglomerados de tamanhos desiguais. Sua variância é, via de regra, maior que aquela que seria obtida pela Amostragem Aleatória Simples, significando um efeito de delineamento - razão entre as variâncias sob o delineamento de amostragem efetivamente adotado e sob a Amostragem Aleatória Simples, para amostras de mesmo tamanho (KISH, 1965) - maior que a unidade.

Ao se abandonar a Amostragem Aleatória Simples, a propriedade assintótica padrão da estatística não se mantém válida, como conseqüência dos dados não serem 
mais independentes. Para testar associação entre variáveis sob a amostragem por conglomerados, devem ser introduzidas correções na expressão algébrica da estatística de Pearson, a fim de que ela tenha distribuição de referência qui-quadrado. Há inúmeras alternativas para se obter uma estatística corrigida, sendo que a idéia básica é dividir o qui-quadrado de Pearson por uma média ponderada do efeito do delineamento, $X^{2} \mathrm{c}=\frac{X^{2} p}{\bar{d}}$

como sugerido por FELLEGI (1980).

Além de se testar a existência de associação entre variáveis, pode haver interesse em se obter uma medida dessa associação. Odds ratio tem sido intensamente usada em investigações epidemiológicas como uma medida de associação entre doenças e fatores de risco (KAHN e SEMPOS, 1989). Segundo FREEMAN (1987), a estimação de odds ratio é a forma mais comum de resumir a dependência existente entre duas variáveis dicotômicas.

Odds ratio é baseada na relação entre as chances de ocorrer um determinado evento (variável B) dado que um fator antecedente (variável A) está presente e de ocorrer o evento quando o fator está ausente. Mais especificamente, é a razão entre essas chances, e pode ser escrita como:

$$
O R=\frac{P(B / A) / P(\bar{B} / A)}{P(B / \bar{A}) / P(\bar{B} / \bar{A})}
$$

onde $P(B / A)$ e $P(\bar{B} / A)$ são, respectivamente, as probabilidades de ocorrer $\mathrm{B}$ e de não ocorrer $\mathrm{B}$, dado que A está presente; $P(B / \bar{A})$ e $P(\bar{B} / \bar{A})$ são as probabilidades de ocorrer B e de não ocorrer B, dado que A está ausente (FLEISS 1981). 
A tabela de contingência em que estão descritas as freqüências de elementos da amostra está ilustrada no Quadro 4.

Quadro 4. Tabela de contingência $2 \times 2$

\begin{tabular}{ccc}
\hline VARIÁVEL & \multicolumn{2}{c}{ VARIÁVEL B } \\
A & Sim & Não \\
\hline Sim & $n_{11}$ & $n_{12}$ \\
Não & $n_{21}$ & $n_{22}$ \\
\hline
\end{tabular}

Por meio das probabilidades empíricas, dadas pelas proporções $\mathrm{p}_{\mathrm{ij}}$, OR é estimado por: $o r=\frac{p_{11} / p_{12}}{p_{21} / p_{22}}=\frac{p_{11} \cdot p_{22}}{p_{12} \cdot p_{21}}$.

$$
p_{i j}=n_{i j} / n, \quad \mathrm{i}, \mathrm{j}=1,2 ; \quad n=\sum_{i=1}^{2} \sum_{j=1}^{2} n_{i j}
$$

Sob a Amostragem Aleatória Simples, o erro padrão é estimado por (FLEISS 1981):

$$
e p(o r)=\frac{o r}{\sqrt{n}} \sqrt{\frac{1}{p_{11}}+\frac{1}{p_{12}}+\frac{1}{p_{21}}+\frac{1}{p_{22}}}
$$

Sob delineamentos complexos, cada proporção passa a ser uma razão e o estimador or uma razão de duplas razões, para a qual não se aplica a expressão de erro padrão acima. É preciso que se obtenha uma aproximação, por meio de algum método de estimação de variância. 


\section{METODOLOGIA}

\subsection{Acurácia dos estimadores de variância}

Para o estudo da acurácia dos estimadores de variância, dados coletados na Pesquisa de Emprego e Desemprego tornaram-se a população de estudo, da qual foram retiradas repetidas amostras. Essa pesquisa é realizada mensalmente no Estado de São Paulo, pela Fundação Sistema Estadual de Análise de Dados Estatísticos SEADE. A cada mês, são sorteadas amostras independentes, de forma a permitir que estimativas trimestrais sejam feitas com base em dados acumulados em três meses consecutivos.

Para compor a população deste estudo, foram tomados os 3708 domicílios visitados em agosto, setembro e outubro de 1998, nos municípios da Região Metropolitana de São Paulo, obtendo-se os números de setores censitários e domicílios indicados na TABELA 1. A Região Metropolitana de São Paulo está dividida em estratos, constituídos por áreas homogêneas, quanto à ocupação da população em setores de atividade econômica e criados em estudo realizado com informações adicionais do Censo Demográfico de 1980 (BUSSAB e DINI 1985). São seis estratos compostos pelos distritos do Município de São Paulo e outros cinco, pelos demais municípios. 
Tabela 1. Municípios ou distritos, setores censitários e domicílios, segundo estratos da Pesquisa de Emprego e Desemprego. Região Metropolitana de São Paulo, agosto a novembro de 1998.

\begin{tabular}{cccc}
\hline ESTRATO & $\begin{array}{c}\text { MUNICIPIOS/ } \\
\text { DISTRITOS }\end{array}$ & $\begin{array}{c}\text { SETORES } \\
\text { CENSITÁRIOS }\end{array}$ & DOMICILIOS \\
\hline 1 & 8 & 68 & 487 \\
2 & 14 & 69 & 646 \\
3 & 9 & 19 & 185 \\
4 & 4 & 1 & 7 \\
5 & 2 & 1 & 2 \\
6 & 14 & 63 & 266 \\
7 & 8 & 55 & 286 \\
8 & 17 & 94 & 587 \\
9 & 7 & 89 & 792 \\
10 & 2 & 3 & 11 \\
11 & 8 & 46 & 439 \\
\hline Total & 93 & 508 & 3708 \\
\hline
\end{tabular}

Fonte: Fundação SEADE.

Dessa população, foram retiradas amostras mediante amostragem estratificada, por conglomerados em dois estágios. Os setores censitários constituíram as unidades primárias de amostragem (UPAs) e os domicílios, as secundárias. Em cada estrato, dois setores censitários foram sorteados com probabilidade proporcional ao seu número de domicílios. E em cada um desses setores, cinco domicílios foram sorteados, perfazendo o total de dez domicílios por estrato.

O sorteio com probabilidade proporcional ao tamanho foi adotado por se constituir no tipo de sorteio mais utilizado em inquéritos domiciliares. Pelo mesmo motivo, foram utilizados como unidades de amostragem, setores censitários e domicílios. 
As frações de amostragem referentes a esse delineamento são:

$f_{1 h}=\frac{2 \cdot M_{h \alpha}}{M_{h}} \rightarrow$ fração de amostragem no $1^{0}$. estágio

$f_{2 h}=\frac{5}{M_{h \alpha}} \rightarrow$ fração de amostragem no $2^{\circ}$. estágio

$f_{h}=f_{1 h} \cdot f_{2 h}=\frac{10}{M_{h}} \rightarrow$ fração de amostragem global

sendo $M_{h}$ o número de domicílios do estrato h e $M_{h \alpha}$ o número de domicílios do setor censitário $\alpha$ do estrato h.

Para avaliar a acurácia dos estimadores Jackknife e BRR em função do aumento do número de unidades primárias de amostragem, foram definidos três delineamentos, mantendo-se o modelo geral anteriormente apresentado.

- $1^{\mathrm{o}}$. delineamento

Os estratos originais da Pesquisa de Emprego e Desemprego muito pequenos, com um a três setores censitários, foram agrupados a outros, utilizando-se como critério a proximidade das rendas médias. E para viabilizar o sorteio de cinco domicílios por setor, as UPAs que tinham menos de seis domicílios foram também agrupadas a outras. A população passou a ser composta de oito estratos e as amostras de 16 UPAs, das quais foram sorteados 80 domicílios.

$-2^{\circ}$ delineamento

Os municípios e distritos foram ordenados segundo a renda familiar e os estratos com mais de 50 UPAs do delineamento anterior foram divididos em dois ou 
três novos estratos. Foram construídos, dessa forma, 16 estratos e as amostras passaram a ter 32 UPAs, sendo sorteados 160 domicílios.

$-3^{\circ}$. delineamento

Os estratos do $1^{\circ}$. delineamento foram divididos em dois, três ou quatro novos estratos, de tamanhos semelhantes em número de UPAs, ainda com os municípios e distritos ordenados por renda familiar média. Criaram-se 24 estratos, que geraram amostras com 48 UPAs.

A TABELA 2 apresenta algumas das características dos delineamentos utilizados.

Tabela 2. Números de estratos, setores censitários e domicílios, segundo delineamento adotado no estudo de acurácia dos estimadores de variância.

\begin{tabular}{lccc}
\hline DELINEAMENTO & No. ESTRATOS & No. SETORES & No. DOMICÍLIOS \\
\hline 1 & 8 & 16 & 80 \\
2 & 16 & 32 & 160 \\
3 & 24 & 48 & 240 \\
\hline
\end{tabular}

Com cada um dos delineamentos, foram sorteadas 2000 amostras mediante procedimentos descritos no Anexo 1. Em cada amostra, foi obtido o estimador razão, empregado na estimação de médias e proporções em delineamentos sob conglomerados. A variável utilizada neste estudo foi renda familiar e o estimador foi expresso por: 
$r=\frac{\sum_{h} w_{h} \sum_{\alpha} \sum_{\beta} y_{h \alpha \beta}}{\sum_{h} w_{h} \sum_{\alpha} \sum_{\beta} x_{h \alpha \beta}}$

sendo $y_{h \alpha \beta}$ a renda familiar do domicílio $\beta$, do setor $\alpha$, do estrato $\mathrm{h} ; x_{h \alpha \beta}=1$, para os domicílios com informação e $x_{h \alpha \beta}=0$ para aqueles sem resposta; $w_{h}=1 / f_{h}$, o peso de cada domicílio, dado pelo inverso da fração amostral do estrato a que pertence o domicílio, $f_{h}=10 / M_{n}$.

Foi construída a distribuição de amostragem de r, com o objetivo de fornecer um valor para a variância populacional, sob o delineamento fixado:

$S^{2}=\frac{\sum_{i=1}^{2000}\left[r_{i}-E(r)\right]^{2}}{2000}$,

sendo $E(r)$ o valor esperado de $r$, correspondente à média de sua distribuição de amostragem, $E(r)=\frac{\sum_{i=1}^{2000} r_{i}}{2000}$,

e $r_{i}$ a estimativa razão na amostra $i$.

As estimativas de variância pelas técnicas de replicação Jackknife e BRR foram obtidas por meio do software WesVar, versão 4.0 (WESTAT 2000), submetendo as amostras às suas rotinas. A partir das estimativas de variância, foram construídas as distribuições de amostragem para obtenção das medidas de precisão e vício dos estimadores Jackknife e BRR. No ANEXO 2, foram incluídas tabelas que ilustram como foram criadas as réplicas referentes a uma das amostras.

Os resultados obtidos pelos estimadores de variância foram comparados com os de Taylor, que tradicionalmente são utilizados em inquéritos. Por esse motivo, foi 
também construída sua distribuição de amostragem. As estimativas de variância pelo método de linearização de Taylor, foram obtidas pelas expressões (KISH 1965):

$$
\begin{aligned}
& \operatorname{var}(r)=\frac{1}{x^{2}}\left[\sum_{h} \operatorname{var}\left(y_{h}\right)+r^{2} \sum_{h} \operatorname{var}\left(x_{h}\right)-2 r \sum_{h} \operatorname{cov}\left(y_{h}, x_{h \prime}\right)\right] \\
& \operatorname{var}\left(y_{h}\right)=\frac{1}{a_{h}-1}\left[a_{h} \sum_{\alpha}\left(w_{h \alpha} y_{h \alpha}\right)^{2}-\left(\sum_{\alpha} w_{h \alpha} y_{h \alpha}\right)^{2}\right] \\
& \operatorname{var}\left(x_{h}\right)=\frac{1}{a_{h}-1}\left[a_{h} \sum_{\alpha}\left(w_{h \alpha} x_{h \alpha}\right)^{2}-\left(\sum_{\alpha} w_{h \alpha} x_{h \alpha}\right)^{2}\right] \\
& \operatorname{cov}\left(y_{h}, x_{h}\right)=\frac{1}{a_{h}-1}\left[a_{h} \sum_{\alpha}\left(w_{h \alpha} y_{h \alpha}\right)\left(w_{h \alpha} x_{h \alpha}\right)-\left(\sum_{\alpha} w_{h \alpha} y_{h \alpha}\right)\left(\sum_{\alpha} w_{h \alpha} x_{h \alpha}\right)\right]
\end{aligned}
$$

sendo $a_{h}=2 \quad$ o número de unidades primárias de amostragem; $w_{h \alpha}$ o peso no domicílio $\alpha$ do estrato $\mathrm{h} ; y_{h_{\alpha}}$ o valor da variável em estudo no domicílio $\alpha$ do estrato $\mathrm{h} ; x_{h \alpha}=1$ se domicílio tem informação e $x_{h \alpha}=0$, caso contrário.

A precisão dos estimadores de variância foi avaliada pela variância de sua distribuição de amostragem, expressa por:

$$
\operatorname{Var}[\operatorname{var}(r)]=\frac{\sum_{i=1}^{2000}\left\{\operatorname{var}\left(r_{i}\right)-E[\operatorname{var}(r)]\right\}^{2}}{2000},
$$

sendo $E[\operatorname{var}(r)]$ o valor esperado da variância de $r$, correspondente à média de sua distribuição de amostragem, $E[\operatorname{var}(r)]=\frac{\sum_{i=1}^{2000} \operatorname{var}\left(r_{i}\right)}{2000}$.

A comparação entre as medidas de precisão dos estimadores foi feita pelo coeficiente de variação, medida relativa mais utilizada para esse fim, expressa por:

$$
C V[\operatorname{var}(r)]=\frac{\sqrt{\operatorname{Var}[\operatorname{var}(r)]}}{E[\operatorname{var}(r)]}
$$


O vício dos estimadores, medido pela distância entre os valores médios, da distribuição de amostragem e da população, foi expresso por:

$\operatorname{Vic}[\operatorname{var}(r)]=E[\operatorname{var}(r)]-S^{2}$

sendo $S^{2}$ conforme (29).

A comparação entre as medidas de vício foi feita por meio do vício relativo (BEAN 1975):

$$
V R[\operatorname{var}(r)]=\frac{V i c[\operatorname{var}(r)]}{E[\operatorname{var}(r)]}
$$

Foi ainda obtida a razão de vício, que mede o vício em unidades de desvio padrão (KISH e FRANKEL 1974):

$$
R V[\operatorname{var}(r)]=\frac{\operatorname{Vic}[\operatorname{var}(r)]}{\sqrt{\operatorname{Var}[\operatorname{var}(r)]}}
$$

Considerando que a acurácia refere-se a pequenos erros totais, incluindo vício e variabilidade amostral (KISH 1965), a acurácia dos estimadores foi avaliada por meio do erro quadrático médio:

$$
E Q M[\operatorname{var}(r)]=\operatorname{Var}[\operatorname{var}(r)]+\operatorname{Vic}^{2}[\operatorname{var}(r)]
$$

e por sua medida relativa:

$$
E Q M R=\frac{E Q M[\operatorname{var}(r)]}{E[\operatorname{var}(r)]^{2}}
$$

Com o objetivo de verificar o real nível de confiança dos intervalos de confiança construídos, foi estudada a distribuição da razão padronizada $\frac{r-E(r)}{\sqrt{\operatorname{var}(r)}}$

sendo a $\sqrt{\operatorname{var}(r)}$ determinada pelos estimadores de BRR, Jackknife e Taylor. Calculou-se a proporção de vezes que essa razão padronizada pertenceu aos limites 
$[-2,306 ;+2,306],[-2,120 ;+2,120]$ e $[-2,064 ;+2,064]$, correspondentes a valores da distribuição t-Student, com 8, 16 e 24 graus de liberdade, respectivamente, verificando sua proximidade a 0,95 . Foram também calculadas as proporções de vezes que a razão pertenceu ao intervalo $[-1,96 ;+1,96]$, escollhido para comparação com a distribuição normal.

\subsection{Aplicação de técnicas de replicação em inquéritos de saúde}

Foram aplicadas as técnicas de replicação Jackknife e BRR nos seguintes inquéritos domiciliares:

- "Morbidade infantil e utilização de serviços de saúde" - Estudo realizado no município de Embu, por profissionais da Faculdade de Saúde Pública, da Universidade Federal de São Paulo e da Prefeitura da Estância Turística de Embu, no periodo de junho a novembro de 1996. Objetivando avaliar o Programa de Atenção à Saúde da Criança no município de Embu, o estudo buscou conhecer o perfil de morbidade da população menor de cinco anos e seu padrão de uso do sistema local de saúde, bem como identificar grupos de risco e estudar a atitude da familia diante das queixas e sinais referentes às patologias responsáveis pela maior parte dos óbitos infantis ocorridos após o período neonatal (SILVA et al. 1997).

- "Morbidade referida e utilização de serviços de saúde na região sudoeste da Grande São Paulo" - Estudo realizado pela Faculdade de Saúde Pública e Secretaria de Estado da Saúde de São Paulo, no período de julho de 1989 a junho 
de 1990. Foi realizado com o objetivo de conhecer o perfil epidemiológico e o padrão de uso de serviços de saúde das populações dos municípios de Taboão da Serra, Embu, Itapecerica da Serra, São Lourenço da Serra, Embu-Guaçu, Juquitiba, Cotia e Vargem Grande Paulista (CESAR et al. 1992).

- "Produtividade dos habitats de Aedes aegypti" - Estudo realizado em Santos, no periodo de dezembro de 1999 a abril de 2000. O trabalho buscou aprofundar os conhecimentos sobre os recipientes presentes no ambiente urbano, freqüientemente ocupados por Aedes aegypti, com o intuitó de contribuir para o aprimoramento de programas de controle de dengue. Foi estudada, em condições naturais, a produtividade dos habitats de Aedes aegypti, que além de serem dimensionados e caracterizados quanto ao tipo, localização, material, volume e reposição de água, foram comparados quanto à quantidade de exemplares e biomassa das pupas de Aedes aegypti (PEREIRA 2001).

- "Pesquisa de Condições de Vida - 1998" na Região Metropolitana de São Paulo e na Região Metropolitana de Santos - Pesquisa quadrienal realizada no Estado de São Paulo, pela Fundação Sistema de Análise de Dados Estatísticos. A pesquisa tem por objetivos produzir e divulgar indicadores que permitam avaliar as condições de vida e a situação sócio-econômica da população residente no Estado de São Paulo, além de coletar dados que permitam às demais instituições e pesquisadores, dispor de informações referentes à educação, habitação, inserção no mercado de trabalho, utilização de serviços de saúde, renda e patrimônio faniliar (FUNDAÇÃO SEADE 1995). 


\subsubsection{Técnicas de replicação no cálculo de intervalos de confiança.}

Em cada um dos inquéritos, foram identificados os parâmetros populacionais de interesse (médias e proporções), apresentados e discutidos nos respectivos relatórios ou nos trabalhos subseqüentes que utilizaram seus arquivos de dados. Pelas técnicas de replicação, Jackknife e BRR, foram obtidos as estimativas desses parâmetros e os correspondentes intervalos de confiança.

As estimativas das proporções e médias foram obtidas por meio do estimador

razão, da forma: $r=\frac{\sum_{i}^{n} w_{i} y_{i}}{\sum_{i}^{n} w_{i}}$

onde $n$ é o número total de elementos da amostra; $y_{i}$ é o valor da variável de interesse no elemento i, para o caso de médias e $y_{i}$ é variável dicotômica para o caso de proporções, assumindo os valores 1 ou 0 se o elemento $\mathrm{i}$ tem ou não a característica em estudo; $w_{i}$ é o peso de cada elemento da amostra, dado pelo inverso de sua fração de amostragem.

A fração de amostragem de cada inquérito está descrita, junto com seu delineamento de amostragem, no ANEXO 2.

As estimativas de variância foram obtidas por técnicas de replicação, pela

expressão (WESTAT 2000): $\operatorname{var}(r)=\frac{\sum_{g=1}^{g}\left(r_{(g)}-r\right)^{2}}{c}$ 
sendo $r$ a estimativa com base na amostra toda, $r_{(g)}$ a estimativa referente a g-ésima replicação, $\mathrm{G}$ o número de replicações e c uma constante que depende da técnica de replicação, conforme QUADRO 5.

Quadro 5. Valores da constante c, empregada na estimação de variância, segundo técnica de replicação.

\begin{tabular}{lc}
\hline Técnica de replicação & $c$ \\
\hline BRR & $\mathrm{G}$ \\
Jackknife sem estratificação & $\mathrm{G} /(\mathrm{G}-1)$ \\
Jackknife com estratificação & 1 \\
\hline
\end{tabular}

Foram calculados os intervalos de confiança por (WESTAT 2000):

$I C_{95 \%}:\left[r-t_{1-\alpha / 2}(g l) \cdot \sqrt{\operatorname{var}(r)} ; r+t_{1-\alpha / 2}(g l) \cdot \sqrt{\operatorname{var}(r)}\right]$

sendo $t_{1-\alpha / 2}(g l)$ um valor tabelado da distribuição t-Student com $g l$ graus de liberdade, conforme indicado no Quadro 6, no qual L é o número de estratos e G é o número de réplicas.

Quadro 6. Graus de liberdade $(g l)$, segundo técnica de replicação.

\begin{tabular}{lc}
\hline Técnica de replicação & $g l$ \\
\hline BRR & $\mathrm{L}$ \\
Jackknife sem estratificação & $\mathrm{G}-1$ \\
Jackknife com duas UPAs por estrato & $\mathrm{L}$ \\
Jackknife com mais de duas UPAs por estrato & $\mathrm{G}-\mathrm{L}$ \\
\hline
\end{tabular}


Estimativas do efeito do delineamento, deff, foram obtidas por (WESTAT 2000): $d e f f=\frac{\operatorname{var}(r)}{\operatorname{var}_{A . S S}}$

sendo que a var(r) está definida em (44) e $\operatorname{var}_{A A S}=\frac{\sum_{i=1}^{n} w_{i}\left(y_{i}-\bar{y}\right)^{2}}{n \sum_{i=1}^{n} w_{i}}$,

$\bar{y}=\frac{\sum_{i=1}^{n} w_{i} y_{i}}{\sum_{i=1}^{n} w_{i}}$

As estimativas de erro padrão obtidas com a aplicação das técnicas de replicação Jackknife e BRR foram comparadas com as do Método de Linearização de Taylor, obtidas por meio do programa CSAMPLE, do software EpiInfo (CDC 1995). A comparação foi feita pela razão entre os erros padrão estimados.

\subsubsection{Técnicas de replicação em estudos de associação}

Pela aplicação de técnicas de replicação, foi verificada a existência de associação entre variáveis categóricas expressas em tabelas de contingência.

Foram realizados testes qui-quadrado, sendo que, a expressão da estatística de Pearson, apresentada em (21), sofreu duas alterações:

- foi calculada utilizando-se proporções ponderadas, em que os pesos originaramse das probabilidades distintas de seleção dos elementos da amostra e das correções para a não-resposta e pela pós-estratificação; 
- foi dividida pela média ponderada do efeito do delineamento, $\bar{d}$, segundo a correção de $1^{a}$. ordem de Rao-Scott (WESTAT 2000):

$\bar{d}=\frac{1}{(L-1)(C-1)}\left[\sum_{l=1}^{L} \sum_{c=1}^{c} \frac{\hat{p}_{l c} \cdot\left(1-\hat{p}_{l c}\right)}{\hat{p}_{l \bullet} \hat{p}_{\bullet c}} \cdot d_{l c}-\sum_{l=1}^{L}\left(1-\hat{p}_{l_{\bullet}}\right) \cdot d_{l \bullet}-\sum_{c=1}^{C}\left(1-\hat{p}_{\bullet c}\right) d_{\bullet c}\right]$

$d_{l c}=\frac{\operatorname{var}\left(\hat{p}_{l c}\right)}{\hat{p}_{l c}\left(1-\hat{p}_{l c}\right) / n}$ é o efeito do delineamento da proporção da lc-ésima casela; $d_{l \bullet}=\frac{\operatorname{var}\left(\hat{p}_{l}\right)}{\hat{p}_{l_{\bullet}}\left(1-\hat{p}_{l_{\bullet}}\right) / n}$ e $d_{\bullet c}=\frac{\operatorname{var}\left(\hat{p}_{\bullet c}\right)}{\hat{p}_{\bullet c}\left(1-\hat{p}_{\bullet c}\right) / n}$ são os efeitos do delineamento das proporções marginais $\hat{p}_{l_{\bullet}}$ e $\hat{p}_{{ }_{c}}$, respectivamente; $\operatorname{var}\left(\hat{p}_{l c}\right), \operatorname{var}\left(\hat{p}_{l_{\bullet}}\right)$ e $\operatorname{var}\left(\hat{p}_{\bullet c}\right)$ são os estimadores das variâncias das razões $\hat{p}_{l c}, \hat{p}_{l_{\bullet}}$ e $\hat{p}_{\bullet c}$.

As estimativas de variância foram obtidas por técnicas de replicação, $\operatorname{var}\left(\hat{p}_{l c}\right)=\frac{\sum_{g=1}^{G}\left(\hat{p}_{l c(g)}-\hat{p}_{l c}\right)^{2}}{c}$

sendo $\hat{p}_{l c}$ a estimativa com base na amostra toda, $\hat{p}_{l c(g)}$ a estimativa referente a gésima réplica, $\mathrm{G}$ o número de réplicas e c conforme Quadro 5.

Os resultados dos testes de associação realizados sob a amostragem por conglomerados, utilizando técnicas de replicação na estimação de erro padrão, foram comparados com aqueles que seriam obtidos sob a Amostragem Aleatória Simples.

Fixou-se que a probabilidade de cometer erro tipo I, referente à rejeição incorreta da hipótese verdadeira, deveria ser no máximo de 0,05 . Dessa forma, foram consideradas associadas as variáveis para as quais a probabilidade de ocorrer valores de estatística de Pearson mais extremos do que o observado, sendo verdadeira a hipótese nula, foi menor que 0,05 (HENKEL 1986). 
A comparação entre os delineamentos foi feita pela probabilidade estimada de erro tipo I, referida como "probabilidade associada ao teste" (CHOW 1996), "P-valor" ou "nível descritivo do teste" (BUSSAB 1987). Foram testadas somente as variáveis cujas tabelas de contingência tinham caselas com 5 observações, no mínimo (WESTAT 2000)

Para variáveis categóricas expressas em tabelas de contingência $2 \times 2$, foi medida a associação entre variáveis, por meio da odds ratio. Considerando-se o delineamento por conglomerados, o seu erro padrão foi estimado por meio de técnicas de replicação (WESTAT 2000):

$e p(o r)_{c}=\sqrt{\operatorname{var}(o r)} ; \operatorname{var}(o r)=\frac{\sum_{k=1}^{(j}\left(o r_{(g)}-o r\right)^{2}}{c}$,

sendo or $=\frac{\hat{p}_{11} \cdot \hat{p}_{22}}{\hat{p}_{12} \cdot \hat{p}_{21}}=\frac{\hat{n}_{11} \cdot \hat{n}_{22}}{\hat{n}_{12} \cdot \hat{n}_{21}}$, o estimador com base na amostra toda,

$o r_{(g)}$ o estimador referente a g-ésima replicação, G e c conforme Quadro 5.

Foram construídos intervalos de confiança, nível de confiança $95 \%$, da forma: $I C:[L I ; L S]$, sendo

$$
L I=\exp \left[o r-t_{1-\alpha / 2}(g l) \sqrt{\operatorname{var}(o r)}\right] \text { e } L S=\exp \left[o r+t_{1-\alpha / 2}(g l) \sqrt{\operatorname{var}(o r)}\right]
$$

e sendo ainda $t_{1-\alpha / 2}(g l)$, o percentil $(1-\alpha / 2)$ é-simo da distribuição t-Student com gl graus de liberdade, conforme Quadro 6.

A existência de associação foi verificada pela não inclusão da unidade nos intervalos de confiança, uma vez que valores de $O R$ iguais a um indicam independência entre duas variáveis (FLEISS 1981).

Os resultados obtidos sob a amostragem por conglomerados foram comparados aos da Amostragem Aleatória Simples. 


\section{RESULTADOS}

\subsection{Acurácia dos estimadores de variância}

$\mathrm{O}$ número de amostras sorteadas sob cada um dos delineamentos propostos permitiu que as estimativas da média da renda familiar tivessem vícios (em módulo) menores que a unidade. Sob o primeiro delineamento, os vícios, medidos pelas distâncias entre a média da população $(1353,676)$ e a média do conjunto das amostras, tornaram-se menores que 1 com o sorteio de 1900 amostras e assim se mantiveram com 2000 (TABELA 3). Como esperado, sob os delineamentos com maiores números de estratos, 16 e 24 estratos, esses resultados foram observados a partir de números menores de amostras, 1700 e 1200, respectivamente.

Com essas 2000 amostras foram construidas distribuições de amostragem. A distribuição de amostragem de um estimador, dado um delineamento aplicado a uma população fixada, refere-se à distribuição teórica de todos os possiveis valores de estimativas, cada um com sua probabilidade de ocorrência (KISH 1965). Neste estudo, considerou-se que a distribuição das médias estimadạs nas 2000 amostras ficou suficientemente próxima da distribuição de amostragem "verdadeira", podendo ser tomada como tal. Ao se admitir que a forma da distribuição das 2000 médias estimadas é estável o suficiente para ser considerada a distribuição de amostragem, adotou-se sua variância como sendo a variância real da média para o delineamento fixado, assim como fizeram BEAN (1975) e KISH e FRANKELL (1974) em seus 
estudos. Dessa forma, o vício da média foi calculado a partir do valor populacional, mas, o da variância, foi determinado com base nesses valores.

Tabela 3. Média e vício do estimador razão, segundo número de amostras e delineamento de amostragem.

\begin{tabular}{|c|c|c|c|c|c|c|}
\hline \multirow[t]{2}{*}{$\begin{array}{l}\text { No. de } \\
\text { amostras }\end{array}$} & \multicolumn{2}{|c|}{$\begin{array}{c}1^{\circ} . \text { delineamento } \\
8 \text { estratos - } 16 \text { UPAs }\end{array}$} & \multicolumn{2}{|c|}{$\begin{array}{c}2^{\circ} . \text { delineamento } \\
16 \text { estratos - } 32 \text { UPAs }\end{array}$} & \multicolumn{2}{|c|}{$\begin{array}{c}3^{\circ} . \text { delineamento } \\
24 \text { estratos - } 48 \text { UPAs }\end{array}$} \\
\hline & média & vício & média & vício & média & vício \\
\hline 500 & 1345,753 & $-7,923$ & 1358,497 & 4,821 & 1355,800 & 2,124 \\
\hline 600 & 1349,673 & $-4,003$ & 1353,808 & 0,132 & 1352,760 & $-0,916$ \\
\hline 700 & 1345,914 & $-7,762$ & 1353,183 & $-0,493$ & 1354,677 & 1,001 \\
\hline 800 & 1350,037 & $-3,639$ & 1353,232 & $-0,444$ & 1354,428 & 0,752 \\
\hline 900 & 1352,381 & $-1,295$ & 1354,865 & 1,189 & 1353,747 & 0,071 \\
\hline 1000 & 1356,534 & 2,858 & 1354,887 & 1,211 & 1352,021 & $-1,655$ \\
\hline 1100 & 1357,956 & 4,280 & 1356,011 & 2,335 & 1353,422 & $-0,254$ \\
\hline 1200 & 1353,994 & 0,318 & 1356,407 & 2,731 & 1355,040 & 1,364 \\
\hline 1300 & 1352,469 & $-1,207$ & 1355,023 & 1,347 & 1354,505 & 0,829 \\
\hline 1400 & 1354,027 & 0,351 & 1353,414 & $-0,262$ & 1354,668 & 0,992 \\
\hline 1500 & 1352,420 & $-1,256$ & 1351,815 & $-1,861$ & 1354,240 & 0,564 \\
\hline 1600 & 1349,397 & $-4,279$ & 1349,724 & $-3,952$ & 1354,274 & 0,598 \\
\hline 1700 & 1349,749 & $-3,927$ & 1351,074 & $-2,602$ & 1354,028 & 0,352 \\
\hline 1800 & 1350,661 & $-3,015$ & 1353,502 & $-0,174$ & 1353,505 & $-0,171$ \\
\hline 1900 & 1353,155 & $-0,521$ & 1354,609 & 0,933 & 1353,580 & $-0,096$ \\
\hline 2000 & 1353,955 & 0,279 & 1353,767 & 0,091 & 1353,107 & $-0,569$ \\
\hline
\end{tabular}


As distribuições de amostragem da média da renda familiar, construídas com 2000 amostras, estão ilustradas na FIGURA 1, sendo que suas médias e erros padrão estão indicados na TABELA 4.

Tabela 4. Média e erro padrão da distribuição amostral do estimador razão $r$, construída com 2000 amostras, segundo delineamento.

\begin{tabular}{lcc}
\hline DELINEAMENTO & MÉDIA & ERRO PADRÃO \\
\hline 8 estratos - 16 UPAs & 1353,955 & 256,760 \\
16 estratos -32 UPAs & 1353,767 & 171,616 \\
24 estratos -48 UPAs & 1353,107 & 137,564 \\
\hline
\end{tabular}

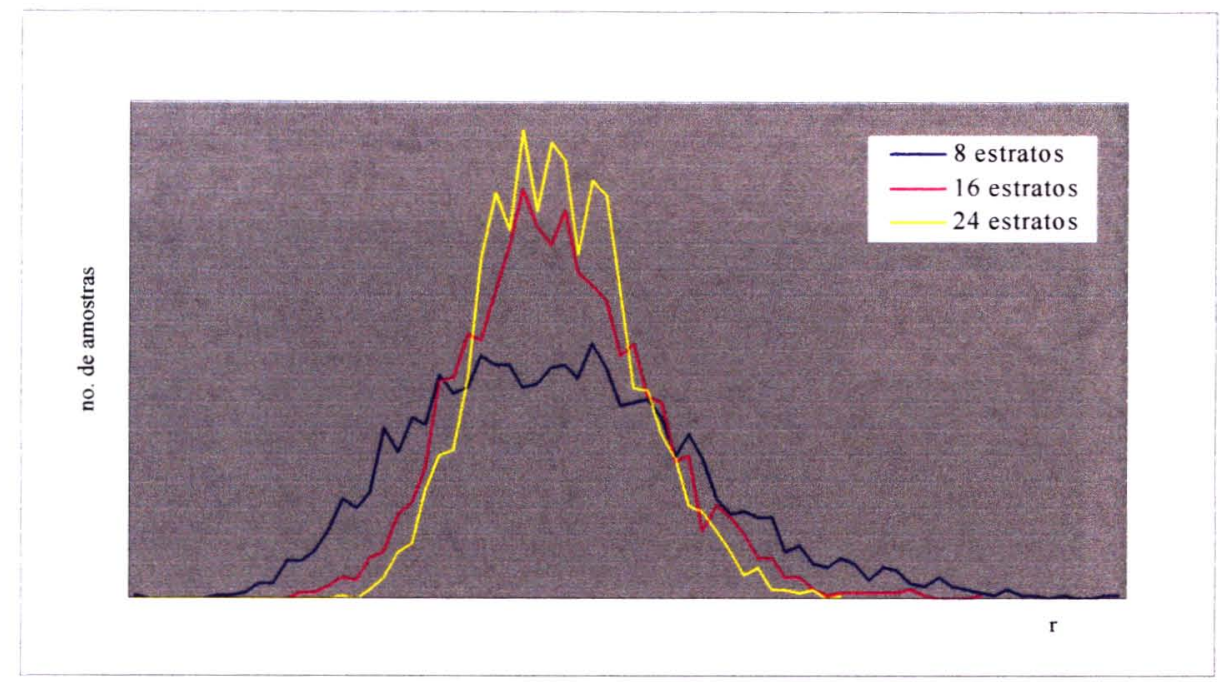

Figura 1. Distribuição de amostragem do estimador r.

Face o objetivo de estudar a acurácia dos estimadores de variância Jackknife e BRR, comparando-os com Taylor, foram construídas suas distribuições de amostragem, ilustradas nas FIGURAS 2 a 4. Cada uma delas se refere a um delineamento de amostragem. 


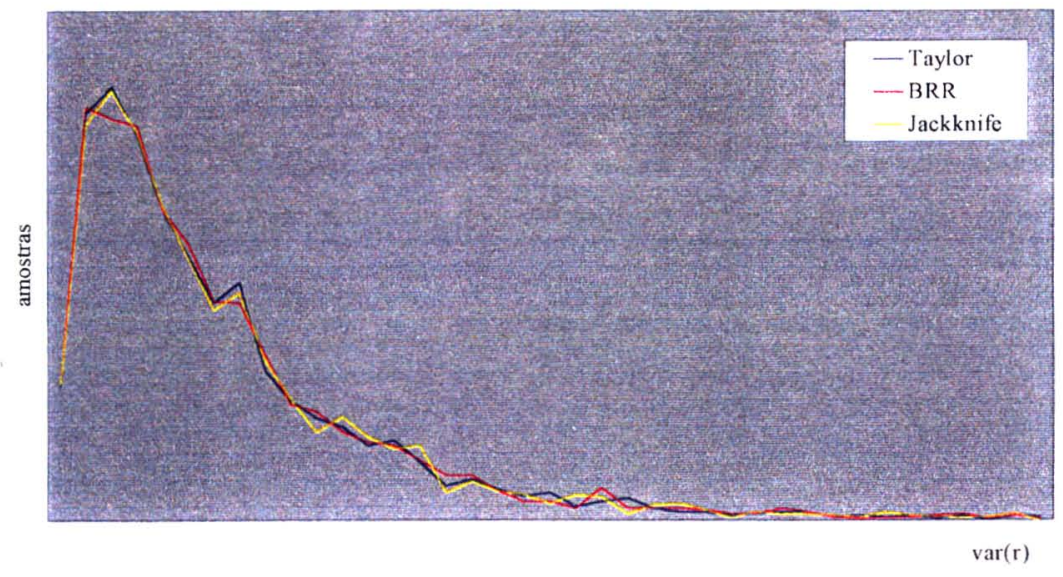

Figura 2. Distribuição de amostragem da variância do estimador $r$, sob delineamento com 8 estratos e 16 unidades primárias de amostragem, segundo técnica de estimação de variância.

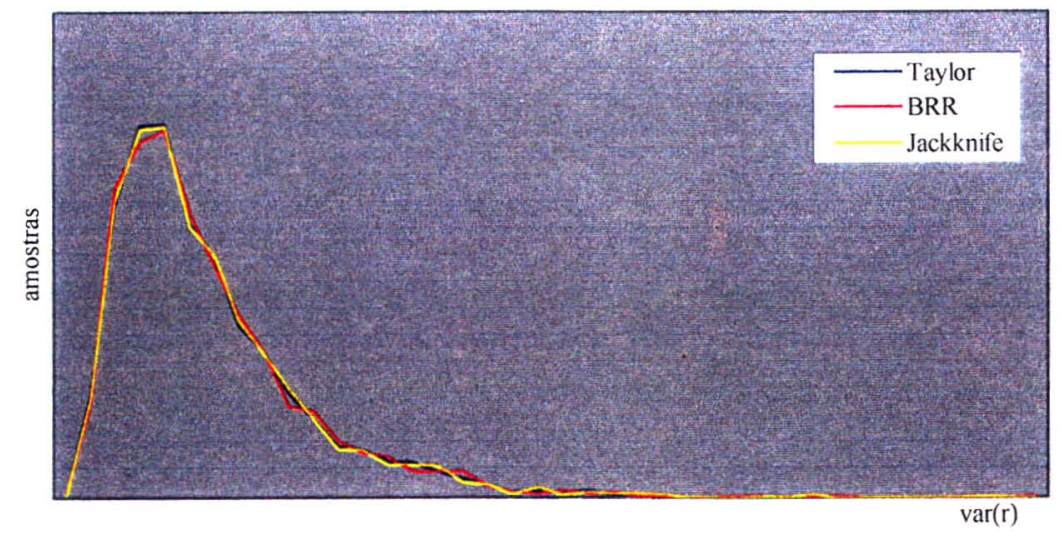

Figura 3. Distribuição de amostragem da variância do estimador $r$, sob delineamento com 16 estratos e 32 unidades primárias de amostragem, segundo técnica de estimação de variância. 


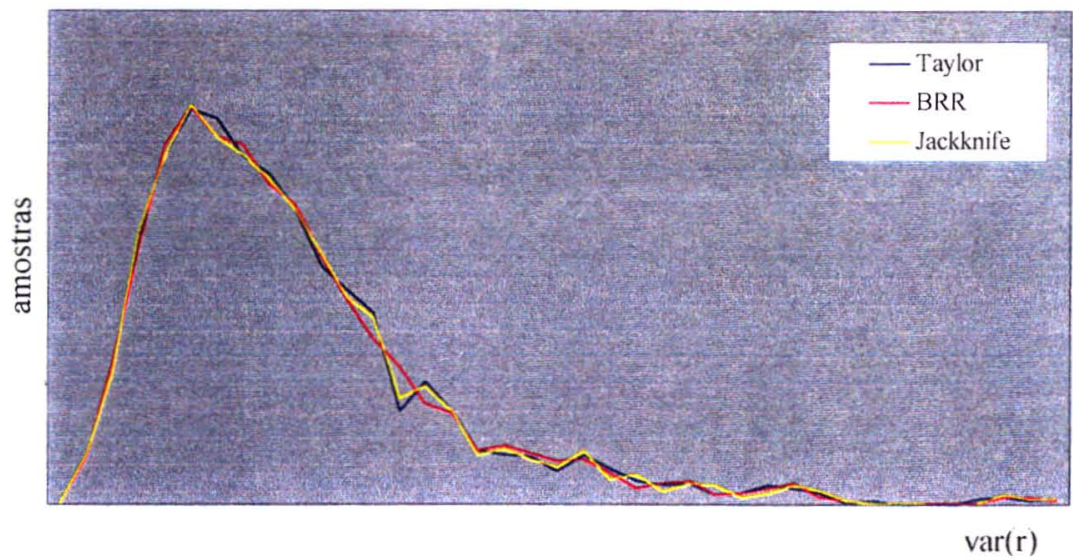

Figura 4. Distribuição de amostragem da variância do estimador r, sob delineamento com 24 estratos e 48 unidades primárias de amostragem, segundo técnica de estimação de variância.

Os valores esperados dessas distribuições constam na TABELA 5. A esperança do estimador BRR foi igual à de Taylor em um dos delineamentos, o de 32 UPAs, e maior, quando foram utilizadas 16 e 48 UPAs. Jackknife apresentou os maiores valores esperados em todos os delineamentos. As diferenças entre os estimadores por replicação e Taylor foram maiores para o primeiro delineamento.

Tabela 5. Média da distribuição amostral da variância do estimador r, construída com 2000 amostras, segundo estimadores de variância e delineamento.

\begin{tabular}{lccc}
\hline ESTIMADOR & \multicolumn{3}{c}{ DELINEAMENTO } \\
& 8 estratos & 16 estratos & 24 estratos \\
& 16 UPAs & 32 UPAs & 48 UPAs \\
\hline Taylor & $7,242 \times 10^{4}$ & $3,198 \times 10^{4}$ & $2,100 \times 10^{4}$ \\
BRR & $7,293 \times 10^{4}$ & $3,198 \times 10^{4}$ & $2,105 \times 10^{4}$ \\
Jackknife & $7,345 \times 10^{4}$ & $3,207 \times 10^{4}$ & $2,107 \times 10^{4}$ \\
\hline
\end{tabular}


Os valores encontrados para o erro padrão dos estimadores de variância estão incluídos na TABELA 6. A comparação entre esses valores, feita por meio do coeficiente de variação, indicou que, em relação a Taylor, BRR apresentou menor ou igual variabilidade. Como na comparação anterior, Jackknife apresentou os piores resultados. As diferenças, embora sempre pequenas, foram maiores para o delineamento que definiu amostras de 16 UPAs e praticamente deixaram de existir sob amostras de 48 UPAs.

Tabela 6. Erro padrão EP[var(r)] e coeficiente de variação CV[var(r)] da variância de $r$, calculados com 2000 amostras, segundo estimador de variância e delineamento de amostragem.

\begin{tabular}{llccc}
\hline & ESTIMADOR & \multicolumn{3}{c}{ DELINEAMENTO } \\
& & $\begin{array}{c}\text { 8 estratos } \\
16 \text { UPAs }\end{array}$ & $\begin{array}{c}\text { 16 estratos } \\
\text { 32 UPAs }\end{array}$ & $\begin{array}{c}\text { 24 estratos } \\
48 \text { UPAs }\end{array}$ \\
\hline EP[var(r)] & Taylor & $7,260 \times 10^{4}$ & $2,222 \times 10^{4}$ & $1,211 \times 10^{4}$ \\
& BRR & $7,303 \times 10^{4}$ & $2,219 \times 10^{4}$ & $1,214 \times 10^{4}$ \\
& Jackknife & $7,398 \times 10^{4}$ & $2,233 \times 10^{4}$ & $1,217 \times 10^{4}$ \\
\hline CV $[\operatorname{var}(\mathrm{r})]$ & Taylor & 1,003 & 0,695 & 0,577 \\
& BRR & 1,001 & 0,694 & 0,577 \\
& Jackknife & 1,007 & 0,696 & 0,578 \\
\hline
\end{tabular}

O vício dos estimadores de variância está apresentado na TABELA 7, por meio de seus valores absolutos e relativos. Comparado ao estimador de Taylor, BRR apresentou igual vício relativo, ao serem sorteadas amostras com 32 UPAs e, vício 
maior, ao serem utilizadas 16 e 48 UPAs. Para Jackknife, os valores foram sempre os maiores, em qualquer situação.

Constam, ainda, na TABELA 7, as razões de vício, em que a relação entre vício e erro padrão pode ser observada. Sob o primeiro delineamento, de 16 UPAs, ficaram em torno de 0,10 , indicando que o vício correspondeu a $10 \%$ do erro padrão da variância. Diminuíram para valores próximos a 0,04 e 0,06 , sob os delineamentos com 32 e 48 UPAs, respectivamente. Resultados referentes às técnicas de replicação foram pouco maiores que os do Método de Linearização de Taylor.

Tabela 7. Vícios absoluto e relativo, Vic[var(r)] e VR[var(r)], e razão de vício RV[var(r)], da variância de r, calculados com 2000 amostras, segundo estimador de variância e delineamento de amostragem.

\begin{tabular}{|c|c|c|c|c|}
\hline & \multirow[t]{3}{*}{ ESTIMADOR } & \multicolumn{3}{|c|}{ DELINEAMENTO } \\
\hline & & 8 estratos & 16 estratos & 24 estratos \\
\hline & & 16 UPAs & 32 UPAs & 48 UPAs \\
\hline \multirow[t]{3}{*}{$\operatorname{Vic}[\operatorname{var}(r)]$} & Taylor & $6,493 \times 10^{3}$ & $2,533 \times 10^{3}$ & $2,079 \times 10^{3}$ \\
\hline & BRR & $7,003 \times 10^{3}$ & $2,525 \times 10^{3}$ & $2,129 \times 10^{3}$ \\
\hline & Jackknife & $7,522 \times 10^{3}$ & $2,622 \times 10^{3}$ & $2,147 \times 10^{3}$ \\
\hline \multirow[t]{3}{*}{$\operatorname{VR}[\operatorname{var}(\mathrm{r})]$} & Taylor & 0,090 & 0,079 & 0,099 \\
\hline & BRR & 0,096 & 0,079 & 0,101 \\
\hline & Jackknife & 0,102 & 0,082 & 0,102 \\
\hline \multirow[t]{3}{*}{$R V[\operatorname{var}(r)]$} & Taylor & 0,089 & 0,036 & 0,054 \\
\hline & BRR & 0,096 & 0,036 & 0,055 \\
\hline & Jackknife & 0,102 & 0,037 & 0,056 \\
\hline
\end{tabular}


As medidas para o erro quadrático médio estão na TABELA 8, pela qual verificou-se, mais uma vez, que o estimador BRR aproximou-se de Taylor, apresentando valores menores em dois dos delineamentos e igual em um deles.

Como indicado pelas razões de vício, os vícios foram irrelevantes frente às dimensões do erro padrão. Pesou, portanto, na magnitude do erro quadrático médio, a contribuição das variâncias determinadas em função dos graus de liberdade existentes.

Tabela 8. Erro quadrático médio, EQM[var(r)], e erro quadrático médio relativo, EQMR[var(r)], da variância de r, calculados com 2000 amostras, segundo estimador de variância e delineamento de amostragem.

\begin{tabular}{llccc}
\hline ESTATÍSTICA & ESTIMADOR & \multicolumn{3}{c}{ DELINEAMENTO } \\
& & 8 estratos & 16 estratos & 24 estratos \\
& & 16 UPAs & 32 UPAs & 48 UPAs \\
\hline EQM[var(r)] & Taylor & $5,313 \times 10^{9}$ & $4,942 \times 10^{8}$ & $1,471 \times 10^{8}$ \\
& BRR & $5,383 \times 10^{9}$ & $4,929 \times 10^{8}$ & $1,478 \times 10^{8}$ \\
& Jackknife & $5,530 \times 10^{9}$ & $4,992 \times 10^{8}$ & $1,486 \times 10^{8}$ \\
\hline EQMR[var(r)] & Taylor & 1,013 & 0,483 & 0,333 \\
& BRR & 1,012 & 0,482 & 0,333 \\
& Jackknife & 1,025 & 0,485 & 0,335 \\
\hline
\end{tabular}

Em relação à cobertura dos parâmetros populacionais pelos intervalos de confiança, os resultados estão apresentados na TABELA 9. Os valores referentes às distintas técnicas utilizadas para a estimação do erro padrão foram muito próximos. Embora as diferenças tenham sido muito pequenas, observou-se que, com base na 
distribuição t-Student, as coberturas obtidas pelo estimador BRR ficaram mais distantes do nível de confiança fixado de $95 \%$ do que as de Taylor. Jackknife teve os mesmos resultados que Taylor, em um dos delineamentos, e cobertura pior nos outros dois.

Como esperado, as coberturas ficaram piores ao se utilizarem coeficientes da distribuição normal no cálculo das coberturas. Também, como esperado, as diferenças entre as coberturas pelas duas distribuições diminuíram à medida que aumentou o número de estratos e, conseqüentemente, o número de graus de liberdade.

Tabela 9. Cobertura dos intervalos de confiança com coeficientes da distribuição tStudent e Normal, calculada com 2000 amostras, segundo estimadores de variância e delineamento de amostragem.

\begin{tabular}{llccc}
\hline DISTRIBUIÇÃo & ESTIMADOR & \multicolumn{3}{c}{ DELINEAMENTO } \\
& & 8 estratos & 16 estratos & 24 estratos \\
& & 16 UPAs & 32 UPAs & 48 UPAs \\
\hline \multirow{2}{*}{-Student } & Taylor & 90,20 & 93,90 & 94,10 \\
& BRR & 90,10 & 93,85 & 93,95 \\
& Jackknife & 90,15 & 93,85 & 94,10 \\
\hline \multirow{2}{*}{ Normal } & Taylor & 86,45 & 92,55 & 92,70 \\
& BRR & 86,65 & 92,45 & 92,90 \\
& Jackknife & 86,55 & 92,50 & 92,70 \\
\hline
\end{tabular}




\subsection{Aplicação de técnicas de replicação em inquéritos de saúde}

\subsubsection{Cálculo de intervalos de confiança}

Para compor o presente estudo, foram selecionados da pesquisa "Morbidade e utilização de serviços de saúde no município de Embu" dados referentes às populações de crianças menores de 1 ano e de 3 anos, seguindo esquemas de apresentação constantes no relatório da FAPESP (SILVA et al. 1997) e na dissertação de mestrado "Prevalência do aleitamento materno no município de Embu", apresentada à Universidade Federal de São Paulo - Escola Paulista de Medicina (PEDROSO 1999).

Na primeira das tabelas utilizadas, estão estimadas porcentagens de crianças menores de um ano em categorias de interesse, fixadas como indicadores, segundo os objetivos da pesquisa. Considerando a intenção de identificar segmentos da população que demandassem atuação específica dos serviços de saúde, caracterizados como grupos de risco, as estimativas foram feitas para estratos definidos segundo condições de moradia e situação sócio-econômica das famílias. Esses estratos constituem agrupamentos homogêneos, construídos por meio da técnica de análise de agrupamentos (FREI 1998).

Seguindo essa forma de apresentação de resultados, na TABELA 10 estão indicadas as porcentagens amostrais de crianças menores de um ano, segundo os quatro estratos criados no Município de Embu, bem como os intervalos de confiança construídos com estimativas de erro padrão obtidas pela técnica Jackknife e pelo Método de Linearização de Taylor. 
Tabela 10. Porcentagens estimadas (p) e intervalos de confiança 95\% (IC) calculados pelo Método de Linearização de Taylor (TY) e pela técnica Jackknife $(J N)$, segundo estrato. Pesquisa "Morbidade infantil e utilização de serviços de saúde no Município de Embu”, 1996.

\begin{tabular}{|c|c|c|c|c|c|c|}
\hline \multirow[t]{2}{*}{ VARIÁVEL } & \multirow{2}{*}{$\begin{array}{c}\text { ESTA- } \\
\text { TÍSTICA }\end{array}$} & \multicolumn{5}{|c|}{ ESTRATO } \\
\hline & & 1 & 2 & 3 & 4 & Total \\
\hline Fez pré-natal no & $\mathrm{p}$ & 61,560 & 54,710 & 45,788 & 63,521 & 54,303 \\
\hline \multirow[t]{2}{*}{ Embu } & IC $-\mathrm{TY}$ & $51,830-71,290$ & $47,627-61,793$ & $26,073-65,502$ & $54,772-72,270$ & $48,105-60,500$ \\
\hline & $\mathrm{IC}-\mathrm{JN}$ & $51,483-71,637$ & $47,226-62,193$ & $22,131-69,444$ & $53,409-73,632$ & $47,797-60,808$ \\
\hline Iniciou pré-natal no & $\mathrm{p}$ & 69,719 & 64,619 & 67,919 & 56,653 & 64,643 \\
\hline \multirow[t]{2}{*}{ primeiro trimestre } & $\mathrm{IC}-\mathrm{TY}$ & $62,574-76,864$ & $52,994-76,244$ & $54,918-80.919$ & $50,781-62,525$ & $55,692-73,594$ \\
\hline & $\mathrm{IC}-\mathrm{JN}$ & $62,079-77,359$ & $50,593-78,644$ & $52,682-83,155$ & $50,354-62,953$ & $54,351-74,935$ \\
\hline Fez cinco ou mais & $\mathrm{p}$ & 84,853 & 79,790 & 83,842 & 77,212 & 80,342 \\
\hline \multirow[t]{2}{*}{ consultas } & $\mathrm{IC}-\mathrm{TY}$ & $72,195-97,511$ & $70,554-89,026$ & $73,766-93,918$ & $70,299-84,125$ & $73,204-87,480$ \\
\hline & $\mathrm{IC}-\mathrm{JN}$ & $64,110-94,615$ & $67,084-88,437$ & $70,114-91,985$ & $68,651-83,981$ & $71,160-87,129$ \\
\hline Teve mamas & $\mathrm{p}$ & 63,442 & 61,218 & 53,863 & 65,076 & 60,514 \\
\hline \multirow[t]{2}{*}{ examinadas } & $\mathrm{IC}-\mathrm{TY}$ & $46,254-80,631$ & $54,481-67,955$ & $44,168-63,557$ & $52,854-77,299$ & $55,176-65,852$ \\
\hline & $\mathrm{IC}-\mathrm{JN}$ & $43,434-83,451$ & $53,992-68,445$ & $42,487-65,238$ & $50,855-79,298$ & $54,861-66,168$ \\
\hline \multirow[t]{3}{*}{ Teve parto cesária } & $\mathrm{p}$ & 38,556 & 31,144 & 42,009 & 28,041 & 32,839 \\
\hline & $\mathrm{IC}-\mathrm{TY}$ & $30,433-46,678$ & $21,260-41,028$ & $28,771-55,248$ & $19,326-36,756$ & $24,801-40,877$ \\
\hline & $\mathrm{IC}-\mathrm{JN}$ & $30,023-47,089$ & $19,355-42,934$ & $26,545-57,473$ & $18,358-37,724$ & $23,727-41,951$ \\
\hline
\end{tabular}


O delineamento adotado na pesquisa, no que concerne ao sorteio de dez setores censitários em cada estrato, não permitiu o emprego da técnica $B R R$, que requer a seleção de duas unidades primárias de amostragem por estrato (WESTAT 2000). Em função da existência de quatro estratos e 40 UPAs na amostra do inquérito, as estimativas Jackknife foram feitas com base em 40 réplicas, com 36 graus de liberdade.

Verificou-se que os intervalos de confiança construídos com estimativas Jackknife foram mais amplos que os de Taylor. Isto porque, além das diferenças referentes aos múltiplos do erro padrão utilizados (2,022 para a técnica Jackknife e 1,96 para o Método de Linearização de Taylor), as estimativas de erro padrão Jackknife foram maiores que as de Taylor, como indicam os dados da Tabela 11 .

As razões entre as estimativas Jackknife e Taylor, apresentadas na TABELA 12, confirmam a observação anterior, pois foram maiores que a unidade, tendo somente um dos resultados como exceção. A média das razões foi de 1,09, significando que as estimativas Jackknife, calculadas com 36 graus de liberdade, foram, em média, 9\% maiores que as de Taylor. 
Tabela 11. Porcentagens (p) c erros padrão [dp(p)] estimados pela técnica Jackknife (JN) e pelo Método de Linearização de Taylor (TY), segundo estrato. Pesquisa “Morbidade infantil e utilização de serviços de saúde no Município de Embu”, 1996.

\begin{tabular}{|c|c|c|c|c|c|c|}
\hline \multirow[t]{2}{*}{ VARIÁVEL } & \multicolumn{2}{|l|}{ ESTATÍS } & \multicolumn{3}{|c|}{ ESTRATOS } & \multirow[b]{2}{*}{ Total } \\
\hline & TICA & 1 & 2 & 3 & 4 & \\
\hline Fez pré-natal no & $\mathrm{p}$ & 61,560 & 54,710 & 45,788 & 63,521 & 54,303 \\
\hline \multirow[t]{2}{*}{ Embu } & $d p(p)-T Y$ & 4,964 & 3,614 & 10,059 & 4,464 & 3,162 \\
\hline & $d p(p)-J N$ & 4,986 & 3,703 & 11,705 & 5,003 & 3,219 \\
\hline Iniciou pré-natal no & $\mathrm{p}$ & 69,719 & 64,619 & 67,919 & 56,653 & 64,643 \\
\hline \multirow[t]{2}{*}{ primeiro trimestre } & $d p(p)-T Y$ & 3,646 & 5,931 & 6,633 & 2,996 & 4,567 \\
\hline & $d p(p)-J N$ & 3,780 & 6,940 & 7,539 & 3,117 & 5,092 \\
\hline Fez cinco ou mais & $\mathrm{p}$ & 84,853 & 79,790 & 83,842 & 77,212 & 80,342 \\
\hline \multirow[t]{2}{*}{ consultas } & $d p(p)-T Y$ & 6,458 & 4,712 & 5,141 & 3,527 & 3,642 \\
\hline & $d p(p)-J N$ & 7,671 & 5,372 & 5,462 & 3,830 & 3,986 \\
\hline Teve mamas & $\mathrm{p}$ & 63,442 & 61,218 & 53,863 & 65,076 & 60,514 \\
\hline \multirow[t]{2}{*}{ examinadas } & $\mathrm{dp}(\mathrm{p})-\mathrm{TY}$ & 8,770 & 3,437 & 4,946 & 6,236 & 2,723 \\
\hline & $d p(p)-J N$ & 9,900 & 3,575 & 5,629 & 7,037 & 2,797 \\
\hline \multirow[t]{3}{*}{ Teve parto cesária } & $\mathrm{p}$ & 38,556 & 31,144 & 42,009 & 28,041 & 32,839 \\
\hline & $\mathrm{dp}(\mathrm{p})-\mathrm{TY}$ & 4,144 & 5,043 & 6,754 & 4,447 & 4,101 \\
\hline & $d p(p)-J N$ & 4,222 & 5,833 & 7,651 & 4,791 & 4,509 \\
\hline
\end{tabular}

Tabela 12. Razões entre estimativas de erro padrão Jackknife (JN) e Taylor (TY). Pesquisa "Morbidade infantil e utilização de serviços de saúde no Município de Embu", 1996.

\begin{tabular}{lccccc}
\hline VARIÁVEL & \multicolumn{5}{c}{ ESTRATO } \\
& 1 & 2 & 3 & 4 & Total \\
\hline Fez pré-natal no Embu & 1,004 & 1,025 & 1,164 & 1,121 & 1,018 \\
Pré-natal no 1 ${ }^{\circ}$ trimestre & 1,037 & 1,170 & 1,137 & 1,040 & 1,115 \\
5 ou mais consultas & 1,188 & 1,140 & 1,062 & 1,096 & 1,094 \\
Exame das mamas & 1,129 & 1,040 & 1,138 & 1,128 & 1,027 \\
Parto cesária & 1,019 & 1,157 & 1,133 & 1,077 & 1,099 \\
\hline
\end{tabular}


Na pesquisa "Morbidade referida e utilização de serviços de saúde na Região Sudoeste da Grande São Paulo", o perfil epidemiológico da população foi estudado por meio de referências dos entrevistados à morbidade ocorrida nos 15 dias anteriores à entrevista e às doenças crônicas e deficiências físicas portadas. Face ao interesse de instrumentar os serviços de saúde, as proporções de residentes que referiram alguma das questões citadas foram estimadas, em separado, para as distintas áreas geográficas em que foram agrupados os municípios da região.

Estão apresentados na TABELA 13, os percentuais de pessoas que referiram: doença nos 15 dias anteriores à entrevista, doenças crônicas (hipertensão, doença respiratória e problemas de nervosismo) e deficiência física (dificuldade de ver), segundo área de residência. As porcentagens amostrais estão acompanhadas dos intervalos de confiança construídos com estimativas de erro padrão Jackknife e Taylor. Pela aplicação da técnica Jackknife foram criadas 180 réplicas, correspondentes às 180 UPAs da amostra, sendo que os erros de amostragem foram estimados com 169 graus de liberdade. 
Tabela 13. Porcentagens estimadas (p) e intervalos de confiança (IC95\%) calculados pela técnica Jackknife (JN) e pelo Método de Linearização de Taylor (TY), segundo área. Pesquisa "Morbidade referida e utilização de serviços de saúde na região sudoeste da GSP", $1989-90$.

\begin{tabular}{|c|c|c|c|c|c|c|c|c|}
\hline \multirow{2}{*}{$\begin{array}{l}\text { VARIÁVEL } \\
\text { (referência a) }\end{array}$} & \multirow[t]{2}{*}{ IC } & \multicolumn{6}{|c|}{ ÁREA } & \multirow[b]{2}{*}{ Total } \\
\hline & & 1 & 2 & 3 & 4 & 5 & 6 & \\
\hline Doença & $\%$ & 27,262 & 21,564 & 21,385 & 35,722 & 28,824 & 22,576 & 25.329 \\
\hline \multirow[t]{2}{*}{ (qualquer) } & IC - TY & $23,543-30,981$ & $19,381-23,746$ & $18,397-24,374$ & $29,586-41,858$ & $25,961-31,722$ & $19,085-26,067$ & $23,749-26,909$ \\
\hline & $I C-J N$ & $23,486-31,038$ & $19,336-23,791$ & $18,354-24,417$ & $29,515-41,929$ & $25,939-31,744$ & $19,061-26,061$ & $23,736-26,922$ \\
\hline \multirow[t]{3}{*}{ Hipertensão } & $\%$ & 10,607 & 8,652 & 10,302 & 11,451 & 9,593 & 10,512 & 10,069 \\
\hline & IC $-\mathrm{TY}$ & $8,911-12,302$ & $6,973-10,330$ & $8,907-11,697$ & $9,952-12,951$ & $7,706-11,479$ & $8,707-12,316$ & $9,242-10,896$ \\
\hline & $I C-J N$ & $8,892-12,321$ & $6,923-10,380$ & $8,882-11,722$ & $9,938-12,965$ & $7,693-11,492$ & $8,682-12,341$ & $9,235-10,903$ \\
\hline \multirow{3}{*}{$\begin{array}{l}\text { Doença } \\
\text { respiratória }\end{array}$} & $\%$ & 6,854 & 6,059 & 5,240 & 5,739 & 6,61 & 6,582 & 6,466 \\
\hline & IC - TY & $5,067-8,640$ & $4,915-7,203$ & $3,802-6,678$ & $4,343-7,135$ & $5,205-8,017$ & $4,812-8,352$ & $5,700-7,231$ \\
\hline & IC $-\mathrm{JN}$ & $5,052-8,655$ & $4,907-7,211$ & $3,794-6,685$ & $4,329-7,149$ & $5,188-8,035$ & $4,793-8,372$ & $5,694-7,237$ \\
\hline \multirow{3}{*}{$\begin{array}{l}\text { Problema de } \\
\text { nervos }\end{array}$} & $\%$ & 11,403 & 9,124 & 9,103 & 9,261 & 13,687 & 4,802 & 9,498 \\
\hline & IC - TY & $9,249-13,557$ & $7,122-11,126$ & $7,507-10,699$ & $6,576-11,946$ & $9,954-17,420$ & $3,622-5,983$ & $8,416-10,580$ \\
\hline & IC $-\mathrm{JN}$ & $9,208-13,599$ & $7,091-11,157$ & $7,498-10,708$ & $6,536-11,986$ & $9,924-17,449$ & $3,618-5,987$ & $8,407-10,589$ \\
\hline \multirow{3}{*}{$\begin{array}{l}\text { Dificuldade de } \\
\text { ver }\end{array}$} & $\%$ & 19,752 & 17,675 & 20,461 & 24,199 & 24,337 & 25,180 & 22,042 \\
\hline & $\mathrm{IC}-\mathrm{TY}$ & $17,163-22,340$ & $14,917-20,433$ & $17,854-23,068$ & $21,727-26,672$ & $22,190-26,483$ & $22,094-28,266$ & $20,761-23,324$ \\
\hline & IC $-\mathrm{JN}$ & $17,139-22,364$ & $14,833-20,517$ & $17,818-23,104$ & $21,706-26,692$ & $22,167-26,507$ & $22,072-28,289$ & $20,750-23,334$ \\
\hline
\end{tabular}


Os intervalos obtidos pela técnica Jackknife foram mais amplos do que os obtidos pelo Método de Linearização de Taylor, porém as diferenças foram muito pequenas. As estimativas de erro padrão que originaram tais intervalos estão indicacias na Tabela 14.

Tabela 14. Porcentagens e erros padrão estimados pela técnica Jackknife (JN) e pelo Método de Linearização de Taylor (TY), segundo área. Pesquisa "Morbidade referida e utilização de serviços de saúde na região sudoeste da GSP”, 1989-90.

\begin{tabular}{llccccccc}
\hline $\begin{array}{l}\text { VARIÁVEL } \\
\text { (referência a) }\end{array}$ & ESTÁSTICA & 1 & 2 & 3 & 4 & 5 & 6 & Total \\
\hline Doença & $\%$ & 27,262 & 21,564 & 21,385 & 35,722 & 28,842 & 22,576 & 25.329 \\
(qualquer) & ep - TY & 1,897 & 1,113 & 1,525 & 3,131 & 1,470 & 1,781 & 0,806 \\
& ep - JN & 1,913 & 1,128 & 1,536 & 3,144 & 1,470 & 1,781 & 0,807 \\
\hline Hipertensão & $\%$ & 10,607 & 8,652 & 10,302 & 11,451 & 9,593 & 10,512 & 10,069 \\
& ep - TY & 0,865 & 0,856 & 0,712 & 0,765 & 0,963 & 0,921 & 0,422 \\
& ep - JN & 0,868 & 0,876 & 0,719 & 0,767 & 0,962 & 0,927 & 0,422 \\
\hline Doença & $\%$ & 6,854 & 6,059 & 5,240 & 5,739 & 6,611 & 6,582 & 6,466 \\
respiratória & ep - TY & 0,911 & 0,585 & 0,734 & 0,712 & 0,717 & 0,903 & 0,390 \\
& ep - JN & 0,913 & 0,584 & 0,732 & 0,714 & 0,721 & 0,907 & 0,391 \\
\hline Problema & $\%$ & 11,403 & 9,124 & 9,103 & 9,261 & 13,687 & 4,802 & 9,498 \\
de nervos & ep - TY & 1,099 & 1,022 & 0,814 & 1,370 & 1,905 & 0,602 & 0,552 \\
& ep - JN & 1,112 & 1,030 & 0,813 & 1,380 & 1,906 & 0,600 & 0,553 \\
\hline Dificuldade & $\%$ & 19,752 & 17,675 & 20,461 & 24,199 & 24,337 & 25,180 & 22,042 \\
de ver & ep - TY & 1,321 & 1,407 & 1,330 & 1,262 & 1,095 & 1,575 & 0,654 \\
& ep - JN & 1,323 & 1,440 & 1,339 & 1,263 & 1,099 & 1,575 & 0,654 \\
\hline
\end{tabular}


Para facilitar a comparação entre as estimativas de erro padrão pelas duas técnicas, foram calculadas as razões entre elas, apresentadas na Tabela 15. Observouse que as diferenças apareceram somente a partir da terceira casa decimal, sendo de 1,001 a médias das razões.

Tabela 15. Razões entre estimativas de erro padrão Jackknife (JN) e Taylor (TY). Pesquisa "Morbidade referida e utilização de serviços de saúde na região sudoeste da Grande São Paulo", 1989 e 1990.

\begin{tabular}{lccccccc}
\hline $\begin{array}{l}\text { VARIÁVEL } \\
\text { (referência a) }\end{array}$ & 1 & 2 & 3 & 4 & 5 & 6 & Total \\
\hline Doença & 1,008 & 1,013 & 1,007 & 1,004 & 1,000 & 1,000 & 1,001 \\
Hipertensão & 1,003 & 1,023 & 1,010 & 1,003 & 0,999 & 1,007 & 1,000 \\
D. Respiratória & 1,002 & 0,998 & 0,997 & 1,003 & 1,006 & 1,004 & 1,003 \\
Problema de nervos & 1,012 & 1,008 & 0,999 & 1,007 & 1,001 & 0,997 & 1,002 \\
Dificuldade de ver & 1,002 & 1,023 & 1,007 & 1,001 & 1,004 & 1,000 & 1,000 \\
\hline
\end{tabular}

Com os dados coletados na pesquisa "Produtividade dos habitats de Aedes aegypti", foram estimadas as médias de recipientes com larvas do mosquito em cada 100 edificações. Essa média define o Índice de Breteau, usado para medir a densidade larvária dos vetores de dengue e febre amarela (WHO 1972). Embora o objetivo do estudo realizado em Santos não tenha sido avaliar densidade larvária de Aedes aegypti, os índices foram estimados para contextualizar as discussões sobre produtividade de criadouros do mosquito.

As estimativas do Índice de Breteau estão apresentadas na TABELA 16, acompanhadas dos intervalos de confiança obtidos pelos métodos de replicação 
(técnica Jackknife) e linearização de Taylor. Os números de réplicas criadas para se obterem as estimativas de erro padrão por replicação, que originaram os intervalos criados, foram, para cada bairro: 11,18 e 11, no mês de janeiro; 15,15 e 12, no mês de fevereiro; e 15, 15 e 10, no mês de março. Esses valores, 'menos uma unidade, correspondem aos graus de liberdade disponíveis para a estimação.

Tabela 16. Índices de Breteau ( $I \hat{B}$ ) estimados e intervalos de confiança $\left(\mathrm{IC}_{95 \%}\right)$ calculados pela técnica Jackknife $(\mathrm{JN})$ e pelo Método de Linearização de Taylor (TY), por mês e bairro. Estudo "Produtividade dos habitats de Aedes aegypti", Santos, 2000.

\begin{tabular}{llccc}
\hline MÊS & BAIRRO & $I \hat{B}$ & Taylor & Jackknife \\
\hline Janeiro & & \multicolumn{2}{c}{$I C_{95 \%}$} \\
& V. São Jorge & 5,381 & $0,015-10,747$ & $-1,176-11,938$ \\
& Macuco & 14,575 & $7,635-21,514$ & $6,911-22,238$ \\
& Boqueirão & 5,771 & $1,765-9,777$ & $0,072-11,470$ \\
Fevereiro V. São Jorge & 14,270 & $4,431-24,108$ & $2,286-26,253$ \\
& Macuco & 8,354 & $5,564-11,143$ & $5,249-11,458$ \\
\multirow{5}{*}{ Março } & V. São Jorge & 13,002 & $4,535-21,468$ & $1,895-24,109$ \\
& Macuco & 16,398 & $8,870-23,925$ & $7,934-24,861$ \\
& Boqueirão & 11,033 & $5,824-16,242$ & $4,753-17,313$ \\
\hline
\end{tabular}

Na TABELA 17 constam as estimativas de erro padrão pela técnica de replicação, bem como as obtidas pelo Método de Linearização de Taylor. As razões entre elas, também incluídas na tabela, indicam que Jackknife produziu estimativas maiores e a diferença entre elas chegou a ser de $25,1 \%$. A média das razões foi de 1,08 . 
Tabela 17. Índices de Breteau $(I \hat{B})$ e erros padrão $d p(I \hat{B})$ estimados pela técnica Jackknife (JN) e pelo Método de Linearização de Taylor (TY), por mês e bairro. Estudo "Produtividade dos habitats de Aedes aegypti", Santos, 2000.

\begin{tabular}{|c|c|c|c|c|c|}
\hline \multirow[t]{2}{*}{ MÊS } & \multirow[t]{2}{*}{ BAIRRO } & \multirow[t]{2}{*}{$I \hat{B}$} & \multicolumn{2}{|c|}{$d p(\hat{I} B)$} & \multirow{2}{*}{$\begin{array}{c}\text { Razão } \\
\text { JN/Taylor }\end{array}$} \\
\hline & & & Taylor & $\mathrm{JN}$ & \\
\hline \multirow[t]{3}{*}{ Janeiro } & V. São Jorge & 5,381 & 2,738 & 2,943 & 1,075 \\
\hline & Macuco & 14,575 & 3,541 & 3,632 & 1,026 \\
\hline & Boqueirão & 5,771 & 2,044 & 2,558 & 1,251 \\
\hline \multirow[t]{3}{*}{ Fevereiro } & V. São Jorge & 14,270 & 5,020 & 5,587 & 1,113 \\
\hline & Macuco & 8,354 & 1,423 & 1,447 & 1,017 \\
\hline & Boqueirão & 8,108 & 1,293 & 1,295 & 1,001 \\
\hline \multirow[t]{3}{*}{ Março } & V. São Jorge & 13,002 & 4,320 & 5,179 & 1,199 \\
\hline & Macuco & 16,398 & 3,841 & 3,946 & 1,027 \\
\hline & Boqueirão & 11,033 & 2,657 & 2,776 & 1,045 \\
\hline
\end{tabular}

Para a realização da "Pesquisa de condições de vida - PCV-98", o Estado de São Paulo foi dividido em sete áreas, que constituíram domínios de estudo. Neste estudo, foram considerados dois desses domínios: a Região Metropolitana de São Paulo e a Região Metropolitana de Santos.

Os dados utilizados constam da "Base de Indicadores de Famílias e Domicílios", um dos arquivos que compõe a base de dados da pesquisa. Em relação aos indicadores, foram selecionados alguns dos propostos pela Fundação SEADE, no documento "Dicionário da Base de Dados da PCV-98" (FUNDAÇÃO SEADE 2000). São indicadores referentes a condições habitacionais, renda e patrimônio e porte de deficiências.

Na TABELA 18, estão listados os indicadores escolhidos e as porcentagens de indivíduos referentes a eles, estimadas na amostra da Região Metropolitana de 
São Paulo. Constam também os intervalos de confiança construídos com estimativas de erro padrão pelo Método de Linearização de Taylor e pela técnica Jackknife, que utilizou 508 réplicas e 498 graus de liberdade.

Tabela 18. Porcentagens estimadas (p) e intervalos de confiança (IC $95 \%$ ) calculados pela técnica Jackknife (JN) e pelo Método de Linearização de Taylor (TY). “Pesquisa de Condições de Vida - 1998”, Região Metropolitana de São Paulo.

\begin{tabular}{lccc}
\hline VARIÁVEL & $\mathrm{p}$ & \multicolumn{2}{c}{$\begin{array}{c}\text { INTERVALO DE CONFIANÇA } \\
\text { Taylor }\end{array}$} \\
\hline Fam. c/ vítimas de roubo ou furto & 19,921 & $18,421-21,420$ & $18,416-21,425$ \\
Fam. c/ portadores de dificuldades & 14,564 & $13,314-15,814$ & $13,310-15,818$ \\
Fam. em dom. c/ até 3 cômodos & 23,119 & $21,174-25,065$ & $21,167-25,072$ \\
Fam. em moradias auto-construídas & 16,086 & $14,452-17,720$ & $14,446-17,726$ \\
Fam. em moradias insalubres & 22,694 & $20,699-24,689$ & $20,691-24,697$ \\
Fam.em dom sem rede esgoto & 13,541 & $10,747-16,335$ & $10,734-16,347$ \\
\hline
\end{tabular}

Embora os intervalos de confiança calculados pela técnica Jackknife, com 498 graus de liberdade, tenham sido mais amplos que os do Método de Linearização de Taylor, as diferenças entre ambos foram insignificantes.

Estão apresentadas na TABELA 19, as estimativas de erro padrão com as quais os intervalos de confiança foram construídos, bem como as razões entre os resultados das duas técnicas, que mostram que diferenças praticamente inexistem. 
Tabela 19. Porcentagens e erros padrão estimados pela técnica Jackknife (JN) e pelo Método de Linearização de Taylor (TY). "Pesquisa de Condições de Vida - 1998”, Região Metropolitana de São Paulo.

\begin{tabular}{lcccc}
\hline VARIÁVEIS & Prop. & \multicolumn{2}{c}{ Erro padrão } & \multirow{2}{*}{ Razão } \\
& $\mathrm{p}$ & Taylor & $\mathrm{JN}$ & JN/TY \\
\hline Fam. com vítimas de roubo ou furto & 19,921 & 0,765 & 0,766 & 1,001 \\
Fam. com portadores de dificuldades & 14,564 & 0,638 & 0,638 & 1,000 \\
Fam. em dom. com até 3 cômodos & 23,119 & 0,993 & 0,994 & 1,001 \\
Fam. em moradias auto-construídas & 16,086 & 0,834 & 0,835 & 1,001 \\
Fam. em moradias insalubres & 22,694 & 1,018 & 1,019 & 1,001 \\
Fam. dom não ligados à rede esgoto & 13,541 & 1,426 & 1,428 & 1,001 \\
\hline
\end{tabular}

Na Região Metropolitana de Santos, a amostra da "Pesquisa de Condições de Vida - 1998" foi composta de estratos com duas unidades primárias de amostragem, o que possibilitou que, além da técnica Jackknife, fosse empregada BRR para estimação de variância.

$\mathrm{Na}$ TABELA 20, estão indicadas as estimativas de proporções e os respectivos intervalos de confiança, calculados pelas duas técnicas mencionadas e pelo Método de Linearização de Taylor.

Pelas técnicas de replicação, foram criadas 60 réplicas, correspondentes aos 60 estratos em que foi dividida a população de Santos, para o sorteio da amostra. 
Tabela 20. Porcentagens estimadas e intervalos de confiança calculados pelas técnicas BRR e Jackknife (JN) e pelo Método de Linearização de Taylor (TY). "Pesquisa de Condições de Vida - 1998", Região Metropolitana de Santos.

\begin{tabular}{lccc}
\hline VARIÁVEL & $\%$ & TÉCNICA & $\begin{array}{c}\text { INTERVALO DE } \\
\text { CONFIANÇA }\end{array}$ \\
\hline Fam. com vítimas de roubo ou furto & 19,343 & TY & $17,214-21,472$ \\
& & JN & $17,173-21,512$ \\
& & BRR & $17,169-21,517$ \\
\hline Fam. com portadores de dificuldades & \multirow{2}{*}{19,573} & TY & $17,005-22,142$ \\
& & JN & $16,982-22,164$ \\
& & BRR & $16,950-22,196$ \\
\hline Fam. em moradias auto-construídas & \multirow{2}{*}{14.720} & TY & $11,422-18,018$ \\
& & JN & $11,330-18.111$ \\
& & BRR & $11,350-18,090$ \\
\hline Fam. em moradias insalubres & 26,655 & TY & $23,260-30,050$ \\
& & JN & $23,202-30,107$ \\
& & BRR & $23,193-30,117$ \\
\hline Fam. sem acesso à pavimentação de rua & 26,195 & TY & $20,143-32,247$ \\
& & JN & $20,029-32,360$ \\
& & BRR & $20,010-32,380$ \\
\hline Fam. em dom não ligados à rede esgoto & 29,863 & TY & $23,606-36,120$ \\
& & JN & $23,463-36,263$ \\
& & BRR & $23,479-36,247$ \\
\hline
\end{tabular}

As estimativas de erro padrão estão indicadas na TABELA 21. Comparações entre Jackknife e Taylor repetiram as observações já apresentadas. Porém, comparações entre estimativas BRR e as outras não haviam sido ainda realizadas neste estudo. Os resultados indicaram que, para a maior parte das porcentagens, as estimativas de erro padrão foram menores que as de Taylor. A técnica Jackknife gerou estimativas de variância maiores que as de BRR. Essas observações estão ilustradas pelas razões entre erros padrão indicadas na TABELA 22. 
Tabela 21. Porcentagens e erros padrão estimados pelas técnicas BRR e Jackknife (IN) e pelo Método de Linearização de Taylor (TY). "Pesquisa de Condições de Vida - 1998", Região Metropolitana de Santos.

\begin{tabular}{lcccc}
\hline VARIÁVEL & $\%$ & \multicolumn{3}{c}{ ERRO PADRÃO } \\
& & Taylor & BRR & JN \\
\hline Famílias com vítimas de roubo ou furto & 19,343 & 1,086 & 1,085 & 1,087 \\
Famílias com portadores de dificuldades & 19,573 & 1,310 & 1,295 & 1,311 \\
Famílias em moradias auto-construídas & 14.720 & 1.683 & 1,695 & 1.685 \\
Famílias em moradias insalubres & 26,655 & 1,732 & 1,726 & 1,731 \\
Famílias sem acesso à pavimentação da rua & 26,195 & 3,088 & 3,082 & 3,092 \\
Famílias em dom não ligados à rede esgoto & 29,863 & 3,193 & 3,200 & 3,191 \\
\hline
\end{tabular}

Tabela 22. Razões entre erros padrão de estimativas Jackknife (JN), BRR e Taylor (TY), "Pesquisa de Condições de Vida - 1998", Região Metropolitana de Santos.

\begin{tabular}{lccc}
\hline VARIÁVEIS & JN/TY & JN/BRR & BRR/TY \\
\hline Famílias com vítimas de roubo ou furto & 1,001 & 1,002 & 0,999 \\
Famílias com portadores de dificuldades & 1,001 & 1,012 & 0,988 \\
Famílias em moradias auto-construídas & 1.001 & 0,994 & 1,007 \\
Famílias em moradias insalubres & 0,999 & 1,003 & 0,996 \\
Famílias sem acesso à pavimentação da rua & 1,001 & 1,003 & 0,998 \\
Famílias em dom não ligados à rede esgoto & 0,999 & 0,997 & 1,002 \\
\hline
\end{tabular}




\subsubsection{Técnicas de replicação aplicadas a estudos de associação em} inquéritos de saúde

Na pesquisa "Morbidade e utilização de serviços no município de Embu”, a procura por grupos de risco foi empreendida por meio da comparação entre os estratos. Nesse sentido, seguindo esquema de análise do relatório da FAPESP, foram comparados os percentuais referentes às características estudadas nos diferentes estratos, utilizando-se o teste qui-quadrado.

A hipótese de não associação entre variáveis foi testada sob dois delineamentos: Amostragem Aleatória Simples (AAS) e amostragem por conglomerados, que constituiu o delineamento real da pesquisa. Para a primeira das alternativas, foram aplicadas à expressão algébrica da estatística de Pearson, adotada na AAS, as proporções ponderadas de elementos das caselas da tabela de contingência. Sob amostragem por conglomerados, além dos pesos, foi considerado o efeito do delineamento, estimado por técnicas de replicação. Os níveis descritivos dos testes estão indicados na TABELA 23.

Quando foi considerada na análise a complexidade do delineamento, não foi rejeitada, para nenhuma das variáveis estudadas, a hipótese nula, de não associação. Embora o mesmo tenha ocorrido ao se adotar a suposição de aplicação da AAS, verifica-se que os níveis descritivos dos testes se alteraram. $\mathrm{Na}$ amostragem por conglomerados, esses níveis foram maiores do que na AAS, em função da existência do efeito do delineamento e conseqüente correção da estatística de Pearson. 
Tabela 23. Níveis descritivos dos testes de associação entre estrato e variáveis, segundo delineamento de amostragem. Pesquisa "Morbidade infantil e utilização de serviços de saúde no Município de Embu", 1996.

\begin{tabular}{lcc}
\hline VARIÁVEL & AAS & Del.complexo \\
\hline Pré-natal no Embu & 0,319 & 0,419 \\
Pré-natal $1^{\circ}$. trimestre & 0,698 & 0,721 \\
Cinco ou mais consultas & 0,809 & 0,816 \\
Exame das mamas & 0,650 & 0,469 \\
Parto cesariano & 0,268 & 0,345 \\
\hline
\end{tabular}

Na pesquisa "Morbidade referida e utilização de serviços de saúde na região sudoeste da Grande São Paulo", buscou-se avaliar diferenciais de morbidade por condição sócio-econômica familiar, optando por utilizar a escolaridade do chefe da família como sua expressão (CESAR 1997). Os níveis de escolaridade considerados foram: nenhum (analfabeto), $1^{0}$. grau I ( $1^{\mathrm{a}}$. à $4^{\mathrm{a}}$. série), $1^{\mathrm{o}}$. grau II $\left(5^{\mathrm{a}}\right.$. à $8^{\mathrm{a}}$. série), $2^{\mathrm{o}}$. grau e universidade, sendo admitidos graus completos e incompletos.

A existência de associação entre escolaridade do chefe familiar e a morbidade referida foi verificada por meio do teste qui-quadrado. Os níveis descritivos dos testes, determinados para as duas alternativas de delineamento, AAS e amostragem por conglomerados, estão indicados na TABELA 24, marcando-se com asterisco as estimativas que levariam à rejeição da hipótese de não associação entre as variáveis em estudo e a escolaridade do chefe. 
Tabela 24. Níveis descritivos dos testes de associação entre escolaridade e variáveis, segundo delineamento de amostragem. Pesquisa "Morbidade referida e utilização de serviços de saúde na região sudoeste da Grande São Paulo", 1989 e 1990.

\begin{tabular}{lcc}
\hline $\begin{array}{l}\text { VARIÁVEL } \\
\text { (apresentação de) }\end{array}$ & $\begin{array}{c}\text { Amostragem } \\
\text { Aleatória Simples }\end{array}$ & $\begin{array}{c}\text { Amostragem } \\
\text { de conglomerados }\end{array}$ \\
\hline Doença (qualquer) & 0,846 & 0,981 \\
Problema de nervosismo & $0,007^{*}$ & 0,219 \\
Hipertensão & $0,000^{*}$ & $0,000^{*}$ \\
Diabetes & $0,052^{*}$ & 0,092 \\
Doença cardíaca & $0,057^{*}$ & 0,263 \\
Doença respiratória & 0,543 & 0,873 \\
Dificuldade de ver & $0,000^{*}$ & $0,001^{*}$ \\
Surdez & $0,005^{*}$ & 0,060 \\
\hline
\end{tabular}

Para as variáveis "hipertensão" e "dificuldade de ver", os P-valores para testes em delineamentos complexos foram menores que 0,05 , indicando a existência de associação com o nível de escolaridade do chefe familiar. Caso fosse assumida a AAS, outras quatro variáveis seriam também consideradas associadas.

Os níveis descritivos dos testes realizados sob delineamentos complexos foram maiores que sob a AAS. Dessa forma, quando a hipótese de não associação não foi rejeitada para a AAS, também não o foi para a amostragem complexa. A recíproca não é verdadeira.

Esses testes foram realizados para o conjunto dos municípios pesquisados, ou seja, feitos com base em 180 setores censitários. Por razões de custo, raramente pesquisas da área de saúde pública utilizam tantas unidades primárias de amostragem. Nesse sentido, para aproximar os resultados à realidade das pesquisas, 
os teste de associação foram conduzidos também para as diversas áreas geográficas, que possuem em torno de 30 setores censitários.

As únicas variáveis que permitiram construir tabelas de contingência em que todas as caselas tivessem no mínimo cinco observações, foram "doença" e "dificuldade de ver". Os níveis descritivos dos testes de hipóteses, para cada área em scparado, estão indicados na TABELA 25. Os valores observados sob delineamento complexo foram maiores que aqueles relativos à AAS.

Tabela 25. Níveis descritivos dos testes de associação entre escolaridade e variáveis, segundo delineamento de amostragem. Pesquisa "Morbidade referida e utilização de serviços de saúde na região sudoeste da Grande São Paulo", 1989 e 1990.

\begin{tabular}{llccccccc}
\hline VARIÁVEL & DELIN. & \multicolumn{7}{c}{ ÁREA } \\
& AMOSTR. & 1 & 2 & 3 & 4 & 5 & 6 & Total \\
\hline Doença & AAS & 0,181 & 0,523 & 0,263 & 0,096 & 0,196 & 0,275 & 0,846 \\
& Am. congl. & 0,609 & 0,475 & 0,363 & 0,338 & 0,607 & 0,637 & 0,981 \\
\hline Dificuldade & AAS & 0,061 & $0,014^{*}$ & $0,000^{*}$ & 0,363 & 0,079 & 0,155 & $0,000^{*}$ \\
de ver & Am. congl. & 0,239 & $0,024^{*}$ & $0,011^{*}$ & 0,396 & 0,237 & 0,363 & $0,001^{*}$ \\
\hline
\end{tabular}

$\mathrm{Na}$ "Pesquisa de Condições de Vida - 1988" da Região Metropolitana de São Paulo, foi testada a associação das variáveis descritas com a renda das famílias, cujos niveis, de 1 a 4, definidos por seus quartis, foram: menor que 422 reais, entre 422 e 830 reais, entre 830 e 1646 reais e maior que 1646 reais. Os níveis descritivos dos testes estão indicados na TABELA 26, estando marcados por asterisco os menores que 0.05 , que levariam à rejeição da hipótese nula. 
A hipótese de ausência de associação não foi rejeitada para duas das variáveis: "família com vítimas de agressão física" e "família com portadores de dificuldades". É possivel observar que, ao se utilizar a correção de Rao-Scott, as probabilidades associadas ao teste aumentaram. Porém, a não rejeição ocorreu independentemente do delineamento considerado ao se fazerem os testes, uma vez que seus níveis descritivos já eram superiores a 0,05 com a AAS. Para todas as outras variáveis, os P-valores foram inferiores a 0,05 , sendo que, à exceção das variáveis "famílias com vítimas de agressão física" e "famílias portadoras de deficiências", as probabilidades foram inferiores a 0,0001 .

Tabela 26. Níveis descritivos dos testes de associação entre renda média familiar e variáveis, segundo delineamento de amostragem. "Pesquisa de Condições de Vida 1998”, Região Metropolitana de São Paulo.

\begin{tabular}{lcc}
\hline VARIÁVEIS & \multicolumn{2}{c}{ DELINEAMENTO } \\
\cline { 2 - 3 } & AAS & Am. de congl. \\
\hline Famílias com vítimas de agressão física & 0,388 & 0,464 \\
Famílias com portadores de deficiências & 0,474 & 0,487 \\
Famílias residentes em moradias auto-construídas & $0,002^{*}$ & $0,002^{*}$ \\
Famílias há menos de um ano na residência & $0,001^{*}$ & $0,001^{*}$ \\
\hline
\end{tabular}

O impacto provocado pela introdução do efeito do delineamento teria que ser avaliado pelas alterações na estatísticas de Pearson (TABELA 27). Após as correções, isto é, divisão da estatística pelo efeito médio do delineamento sugerido por Rao-Scott, as estatísticas de Pearson, com uma única exceção, tornaram-se 
menores. Valores menos elevados, para elas, significam maiores níveis descritivos dos testes. Foram também incluidas na tabela, as estimativas do deff para as proporções de famílias com as características listadas e as referentes ao deff médio, previsto pela correção de Rao-Scott para a estatística de Pearson.

Tabela 27. Estimativas do efeito do delineamento (deff) e estatísticas de Pearson, com e sem correção de Rao-Scott, para testes de associação entre renda média familiar e variáveis da "Pesquisa de Condições de Vida - 1998", Região Metropolitana de São Paulo.

\begin{tabular}{lcccc}
\hline VARIÁVEIS & Estatística de Pearson & \multicolumn{2}{c}{ deff } \\
& Sem & Com & Rao- & Total \\
& correção & correção & Scott & \\
\hline Familias com vítimas de roubo ou furto & 69,29 & 72,10 & 0,96 & 0,81 \\
Famílias com portadores de dificuldades & 24,91 & 23,87 & 1,04 & 1,24 \\
Famílias em domicílios com até 3 cômodos & 459,17 & 445,26 & 1,03 & 1,82 \\
Famílias residentes em favelas & 155,79 & 114,25 & 1,36 & 4,67 \\
Famílias residentes em cortiços & 43,06 & 40,43 & 1,06 & 1,56 \\
Famílias residentes domicílios invadidos & 153,34 & 105,97 & 1,45 & 4,99 \\
Fam. em dom. s/ estrutura urbana adequada & 144,09 & 92,97 & 1,55 & 4,76 \\
Famílias em moradias insalubres & 81,56 & 73,36 & 1,11 & 1,81 \\
Famílias sem acesso à pavimentação da rua & 164,43 & 107,83 & 1,52 & 5,55 \\
Famílias sem acesso à iluminação na rua & 120,43 & 66,02 & 1,82 & 5,02 \\
Familias sem acesso à coleta de lixo & 59,56 & 33,43 & 1,78 & 4,34 \\
Famílias em dom não ligados à rede esgoto & 159,81 & 106,85 & 1,49 & 5,09 \\
\hline
\end{tabular}

Os dados da pesquisa "Morbidade e utilização de serviços no município de Embu" permitiram o desenvolvimento de uma outra linha de investigação, presente na dissertação "Prevalência do aleitamento materno no município de Embu". 
referente à avaliação, para crianças menores de três anos, de fatores de risco associados ao desmame precoce, entendido como a introdução de alimentos, exceto água e chás, antes de 120 dias de vida das crianças.

Para a identificação desses fatores, foram utilizadas medidas de odds ratio, cujas estimativas e respectivos intervalos de confiança, para a AAS e a amostragem de conglomerados, constam na TABELA 28. Estão marcadas com asterisco as estimativas cujos intervalos de confiança não incluem a unidade.

Verificou-se que, quando a análise foi feita sob o delineamento complexo adotado, duas variáveis foram consideradas fatores de risco para o desmame precoce, por não incluírem a unidade em seus intervalos de confiança: "alta após cinco dias de vida" e "reside em favela". Ao se pressupor AAS, além dessas variáveis, duas outras também seriam consideradas fatores de risco.

Observou-se ainda que, como esperado, os intervalos de confiança para a amostragem por conglomerados foram mais amplos que os da AAS, em função de a variância ser estimada com menos graus de liberdade. 
Tabela 28. Estimativas de odds ratio para desmame precoce, dada a apresentação de características de interesse ${ }^{(1)}$, e intervalos de confiança $\left(\mathrm{IC}_{95 \%}\right)$, segundo delineamento de amostragem. Pesquisa "Morbidade infantil e utilização de serviços de saúde no Município de Embu”, 1996.

\begin{tabular}{|c|c|c|c|c|}
\hline \multirow[t]{2}{*}{ Característica } & \multicolumn{2}{|c|}{$\begin{array}{c}\text { Amostragem Aleatória } \\
\text { Simples }\end{array}$} & \multicolumn{2}{|c|}{$\begin{array}{l}\text { Amostragem de } \\
\text { conglomerados }\end{array}$} \\
\hline & $O r$ & $\mathrm{IC}_{95 \%}$ & $O r$ & $\mathrm{IC}_{95 \%}$ \\
\hline Reside em favela & $2,34^{*}$ & $1,50-3,67$ & $3,25^{*}$ & $1,82-5,82$ \\
\hline Renda p.c. $<1$ salário mínimo & 0,79 & $0,53-1,18$ & 0,73 & $0,21-2,57$ \\
\hline Mãe alfabetizada & 1,05 & $0,46-2,37$ & 0,31 & $0,08-1,17$ \\
\hline Chefe alfabetizado & $0,42 *$ & $0,18-0,96$ & 0,72 & $0,32-1,58$ \\
\hline Mãe $\operatorname{com} 4^{\text {a }}$. serie & 1,00 & $0,65-1,56$ & 1,14 & $0,60-2,19$ \\
\hline Chefe com $4^{a}$. serie & 0,85 & $0,49-1,47$ & 1,57 & $0,22-11,37$ \\
\hline Mãe chefe de família & 1,32 & $0,65-2,74$ & 0,62 & $0,14-2,86$ \\
\hline Mãe com 30 anos ou mais & 1,02 & $0,66-1,60$ & 1,58 & $0,98-2,53$ \\
\hline Óbito filho $<5$ anos & 1,05 & $0,52-2,16$ & 1,16 & $0,35-3,88$ \\
\hline Pré-natal realizado & 0.54 & $0,20-1,42$ & 0,26 & $0,01-4,86$ \\
\hline Mamas examinadas & 0,73 & $0,49-1,09$ & 0,37 & $0,13-1,03$ \\
\hline Inicio pré natal $1^{\circ}$. trimestre & 0,95 & $0,62-1,45$ & 0,79 & $0,36-1,72$ \\
\hline PN com 6 ou mais consultas & 0,81 & $0,53-1,23$ & 1,72 & $0,38-7,76$ \\
\hline Primeiro filho & 1,11 & $0,76-1,62$ & 1,36 & $0,69-2,71$ \\
\hline Baixo-peso ao nascer & 1,38 & $0,76-2,52$ & 1,40 & $0,47-4,15$ \\
\hline Parto cesária & 1,22 & $0,83-1,80$ & 1,01 & $0,46-2,23$ \\
\hline $1^{\mathrm{a}}$ mamada após 6 horas & 1,40 & $0,90-2,18$ & 1,19 & $0,26-5,47$ \\
\hline Recebeu orientação hospital & 1,33 & $0,89-2,00$ & 1,24 & $0,72-2,14$ \\
\hline Recebeu receita leite & $2,09 *$ & $1,08-4,12$ & 1,62 & $0,11-24,63$ \\
\hline Alta após 5 dias de vida & $3,09 *$ & $1,31-7,66$ & $5,76^{*}$ & $1,66-20,07$ \\
\hline Tem plano saúde & 1,07 & $0,71-1,61$ & 1,40 & $0,68-2,89$ \\
\hline
\end{tabular}

(1) chance de desmame precoce, dado que apresenta característica / chance de desmame precoce, dado que não apresenta a característica. 
Na pesquisa "Morbidade referida e utilização de serviços de saúde na região sudoeste da Grande São Paulo", foi estudada a associação entre morbidade e gênero, por meio da estimação de odds ratio, utilizando-se os dados de morbidade agrupados pela Classificação Internacional de Doenças (CID-9).

Para as proporções amostrais superiores a $1 \%$ (coeficientes de variação menores que $20 \%$ ) de pessoas que referiram determinada doença, as medidas da associação estão apresentadas na TABELA 29. Considerando como ilustração a variável "infecciosas", foi estimada a razão entre a chance de um entrevistado ter referido uma doença infecciosa nos 15 dias antecedentes à visita domiciliar, dado que é mulher, e a cliance de ter referido uma doença infecciosa, dado que é homem.

Foram identificadas com asterisco as estimativas de odds ratio que não incluem a unidade em seus intervalos de confiança. Verifica-se que as variáveis marcadas são as mesmas para os dois delineamentos, embora os intervalos de confiança tenham amplitudes distintas. São mais largos sob a amostragem de conglomerados do que sob a AAS. 
Tabela 29. Estimativas de odds ratio para doenças, dado o gênero ${ }^{(1)}$, e intervalos de confiança $\left(\mathrm{IC}_{95 \%}\right)$, segundo delineamento de amostragem. Pesquisa "Morbidade referida e utilização de serviços de saúde na região sudoeste da Grande São Paulo", 1989 e 1990.

\begin{tabular}{|c|c|c|c|c|}
\hline \multirow{2}{*}{ Doenças } & \multicolumn{2}{|c|}{ Amostragem Aleatória Simples } & \multicolumn{2}{|c|}{ Amostragem de conglomerados } \\
\hline & $o r$ & $\mathrm{IC}_{95 \%}$ & or & $\mathrm{IC}_{95 \%}$ \\
\hline Infecciosas & 0,95 & $0,70-1,28$ & 0,89 & $0,59-1,41$ \\
\hline Nervoso & 1,04 & $0,77-1,40$ & 1,17 & $0,74-1,84$ \\
\hline Circulatório & $1,67^{*}$ & $1,30-2,14$ & $1,58^{*}$ & $1,05-2,37$ \\
\hline Respiratório & 1,06 & $0,94-1,20$ & 1,19 & $0,97-1,46$ \\
\hline Digestivo & 1,08 & $0,85-1,38$ & 1,28 & $0,88-1,85$ \\
\hline Osteomuscular & $1,61^{*}$ & $1,32-1,98$ & $2,24^{*}$ & $1,62-3,10$ \\
\hline Mal definidas & $1,33^{*}$ & $1,20-1,48$ & $1,51^{*}$ & $1,29-1,77$ \\
\hline Lesões & 0,89 & $0,68-1,18$ & 0,94 & $0,66-1,35$ \\
\hline
\end{tabular}

(1) Chance de doença, dado que é mulher / chance de doença, dado que é homem 


\section{DISCUSSÃO}

Avaliar estimadores de variância diz respeito, fundamentalmente, a verificar se geram estimativas aceitáveis para a realização de inferências. Com base nas propriedades que têm sido consideradas relevantes para essa avaliação - a magnitude do vício das estimativas de variância, o grau de sua variabilidade e a capacidade de produzir intervalos de confiança que cubram o parâmetro populacional com uma probabilidade próxima do nível de confiança estabelécido (BEAN 1975, SÄRNDAL et al. 1992) - enfatizou-se, neste estudo, a comparação entre os estimadores de variância dos métodos de replicação, técnicas BRR e Jackknife, com o de linearização de Taylor.

Com base nas distribuições de amostragem dos estimadores de variância, verificou-se que a utilização de Jackknife resultou nos maiores valores esperados. Significa que com a técnica Jackknife, associou-se à razão $\mathrm{r}$, medidas de precisão menores. O estimador BRR apresentou o mesmo valor esperado que Taylor em um dos delineamentos e maior nos outros dois. Como esperado, as diferenças entre os resultados das técnicas foram mais acentuadas no primeiro delineamento, pelo qual foi sorteado um número pequeno de UPAs (16 unidades), deixando de existir ou tornando-se muito menores sob amostras de 32 ou 48 UPAs.

Em relação ao erro padrão das estimativas de variância, indicador da precisão e confiabilidade dos resultados obtidos (SILVA 1998), o padrão observado foi o mesmo: diferenças pequenas entre os estimadores, resultados semelhantes para BRR e Taylor e pior desempenho de Jackknife. 
Comparados por meio do coeficiente de variação da variância, BRR mostrouse superior a Taylor em dois delineamentos. Porém, as diferenças foram tão pequenas, que não apareceriam, caso o coeficiente de variação fosse calculado com somente duas casas decimais.

Por terem sido verificadas diferenças muito pequenas entre os estimadores, é dificil falar em presença de erros maiores para um ou outro estimador. No entanto, ao considerar que BRR teve desempenho semelhante a Taylor e superior a Jackknife, em relação à precisão, confirmam-se dados obtidos em alguns outros estudos.

BEAN (1975) conduziu investigação empírica sobre o comportamento dos mćtodos de estimação de variância, linearização de Taylor e replicação (dois estimadores BRR), utilizando cinco variáveis medidas no estudo "U. S. Health Interview Survey". A amostra desse inquérito foi tomada como a população de estudo, da qual foram sorteadas 900 amostras para avaliação dos estimadores, com 30 unidades primárias de amostragem e 8772 pessoas, em média, de 19 estratos. O autor observou alternância de melhores resultados entre BRR e Taylor, concluindo que este último apresentou variância ligeiramente menor.

KISH e FRANKELL (1974) estudaram estimadores BRR, Jackknife e Taylor, utilizando dados do inquérito "Current Population Survey" do "U. S. Bureau of the Census". Foram considerados no estudo cinco diferentes estimadores de primeira ordem e três distintos delineamentos: seleções pareadas em 6, 12 e 30 estratos, que resultaram em amostras de 70, 340 e 847 elementos. Foram retiradas 200 ou 300 amostras, dependendo do delineamento. Os autores concluíram que a variabilidade de Taylor foi menor, embora as diferenças em relação aos outros estimadores 
tivessem sido pequenas, em especial quando foram utilizados estimadores razão. Em termos de precisão, foi seguido do estimador Jackknife.

KOVAR et al. (1988) compararam estimadores Taylor, BRR, Jackknife e bootstrap em estudo de simulação, baseado em populações hipotéticas, construídas para se assemelharem à população do estudo "National Assessment of Educational Progress" e constituídas de 32 estratos. Os autores concluíram, em relação à precisão das estimativas de variância do estimador razão, que Taylor e Jackknife tiveram os melhores desempenhos, equivalentes entre si.

Os estimadores foram avaliados também quanto ao vício, tendo sido compsados por suas medidas de vício relativo. Essas medidas variaram entre 0,079 e 0,102 , para os estimadores por replicação, ficando muito próximas às de Taylor (entre 0,079 e 0,099). Diferenças tão pequenas impedem identificação de algum estimador como superior a outros, no que diz respeito à validade de suas estimativas.

Esses resultados coincidem com os observados por BEAN (1975), que concluiu pela não existência de padrão consistente de menor vício para algum dos estimadores avaliados, BRR e Taylor, tendo sido pequeno e tolerável para ambos. KISH e FRANKELL (1974) registraram, para a variância do estimador razão, vícios relativos entre 0,011 e 0,064 . Consideraram ainda que os vícios foram semelhantes para estimadores Taylor, BRR e Jackknife, e desprezíveis para todos.

À mesma conclusão chegaram KOVAR et al. (1988). Esses autores avaliaram o vício relativo em situações distintas. Para o sorteio de duas unidades primárias de amostragem por estrato, consideraram coeficientes de variação da média do denominador da razão $\mathrm{r}$ menores ou iguais e maiores que $10 \%$, e para o sorteio de cinco unidades, coeficientes de $1 \%, 4 \%$ e $9 \%$. Restringindo-se somente aos 
resultados referentes ao estimador razão, verificou-se, para seleções pareadas (duas UPAs por estrato) e coeficientes de variação baixos, que os estimadores de variância foram equivalentes e os vícios insignificantes. Porém, quando o coeficiente de variação da média do denominador aumentou, tornando-se maior que $10 \%$, BRR apresentou vício positivo substancial, e Jackknife e Taylor tenderam a subestimar levemente a verdadeira variância.

Por meio da razão de vício, observou-se que os vícios foram pequenos em relação ao erro padrão das estimativas de variância, para qualquer das técnicas. O valor máximo dessa razão foi $10,2 \%$. Esse fato leva à conclusão de que, nas condições em que foi feita esta avaliação, problemas de acurácia dos estimadores estão associados a problemas de precisão, mais intensamente do que a vícios. Indica, ainda. que em relação à comparação dos erros quadráticos médios dos estimadores, as conclusões são as mesmas que as obtidas com a comparação feita com base nas suas variâncias.

Para avaliar o nível de confiança real dos intervalos construídos com estimativas de variância por replicação, foi calculada a cobertura desses intervalos, verificando-se a pertinência da estimativa razão padronizada a intervalos pré-fixados. Quando o delineamento de amostragem e o procedimento de estimação resultam em estimadores complexos, a distribuição exata dessa razão padronizada é desconhecida (BEAN 1975). A avaliação da aplicabilidade de intervalos de confiança, que têm como base a curva normal ou t-Student, tem sido feita por estudos empíricos, em populações diversas, utilizando delineamentos e estimadores também diversos (KISH e FRANKELL 1974, BEAN 1975, BURKE e RUST 1995, CAMPBELL e MEYER 1978. KOVAR et al. 1988). 
Os autores desses estudos enfatizam esse aspecto como sendo de primordial importância na avaliação dos estimadores, devendo constituir-se no principal critério para orientar a opção por algum deles. Tal valorização se justifica pela importância que a inferência dos resultados para a população de estudo, feita por meio de intervalos de confiança, assume em inquéritos por amostragem. Estimativas intervalares são mais úteis que as pontuais, por incluírem informação sobre precisão.

Neste estudo, as coberturas dos intervalos de confiança foram inicialmente calculadas utilizando-se a distribuição t-Student para originar coeficientes aplicados ao erro padrão que refletissem os graus de liberdade utilizados. Os resultados indicaram desempenhos semelhantes das técnicas de estimação de variância, sendo que as pequenas diferenças entre elas não permitiram apontar alguma delas como superior.

Verificou-se ainda que os níveis de confiança observados foram menores que os fixados. Significa que, ao se construírem intervalos de confiança de parâmetros populacionais (médias e proporções) estimados sob delineamentos complexos, o nível de confiança estará superestimado.

Deve-se notar, porém, que as coberturas foram, para qualquer delineamento, superiores a 90\%, ficando entre 93,9 e 94,1\% para estimação com pelo menos 16 graus de liberdade. Tais alterações no nivel de confiança podem ser consideradas toleráveis (KISH e FRANKELL 1974, BEAN 1975), sendo importante que, ao fazerem inferências, o pesquisador esteja consciente de sua existência.

Para comparar as coberturas dos intervalos de confiança criados pelas diferentes técnicas de estimação de variância, foram também utilizados coeficientes referentes a percentis da distribuição Normal. Ao construir intervalos com 1,96 
desvios padrão, assume-se que o estimador de variância tem muitos graus de liberdade, o que, nesse contexto, é uma pressuposição inadequada. Como conseqüência esperada, as coberturas ficaram mais distantes do nível de confiança fixado de $95 \%$. Sob o primeiro delineamento, em que há poucos graus de liberdade, os resultados comprovam a afirmação de que a inferência com base na distribuição normal deve ser evitada, quando amostras são pequenas.

No entanto, tais coberturas foram calculadas para fins de comparação com resultados de outros estudos que avaliaram a aplicabilidade de intervalos de confiança com base na distribuição normal. Os resultados indicaram discreta superioridade da técnica BRR em dois delineamentos, sendo que essa observação é comum a vários outros trabalhos.

BEAN (1975) afirmou que as coberturas determinadas pela técnica BRR foram mais próximas aos valores normais correspondentes do que aquelas obtidas pelo Método de Linearização de Taylor. $\mathrm{O}$ autor verificou que, em relação ao percentual de individuos com atendimento médico, as coberturas foram superiores a $91 \%$, quando aplicado estimador BRR de erro padrão e superiores a $90 \%$, para Taylor. Também KISH e FRANKELL (1974) encontraram coberturas mais próximas de $95 \%$ para BRR (entre 90,4 e $94,4 \%$ ), depois para Jackknife (entre 89,4 e 94,3 ) e, por último. para Taylor (entre 88,8 e 92,0). KOVAR et al (1988) consideraram BRR e Jackknife equivalentes.

Os trabalhos citados concluíram também que os níveis de confiança estimados foram menores que os fixados, mas as diferenças foram consideradas toleráveis. Assim sendo, estimativas intervalares, em que técnicas Jackknife e BRR são utilizadas. podem ser feitas com razoável confiança. 
Em relação à cobertura dos intervalos de confiança, há duas conclusões, comuns aos trabalhos anteriormente citados, que coincidem com as do presente estudo: estimativas intervalares podem ser feitas com os estimadores Jackknife e BRR, e o nível de confiança real é menor que o nível nominal da distribuição normal.

Os resultados deste estudo enfatizam ainda a importância de considerar os graus de liberdade disponíveis para a estimação de variância, ao mostrar as conseqüências de se adotarem, indiscriminadamente, percentis da distribuição normal na construção de intervalos de confiança com amostras pequenas.

BURKE e RUST (1995) estudaram o desempenho do estimador Jackknife para amostras sistemáticas com número pequeno de UPAs, de 2 a 30 , calculando as coberturas dos intervalos de confiança construídos de duas formas: com coeficientes da distribuição normal $(t=1,96)$ e da distribuição $t$, com graus de liberdade relacionados ao número de replicações. A população do estudo foi constituída por 105 escolas que haviam participado do programa "National Assessment of Educational Progress" e a variável estudada foi a proficiência em leitura. Os autores mostraram como as coberturas dos intervalos de confiança melhoraram com a distribuição t-Student em relação à Normal. Os autores concluíram, também, que inferências válidas poderiam ser feitas com amostras de pelo menos seis unidades primárias, utilizando a técnica Jackknife.

Essa conclusão, de que inferências com estimadores por replicação são válidas com um número pequeno de UPAs, aplica-se também aos resultados deste estudo. A possibilidade de construir intervalos de confiança adequados, com poucas unidades, torna ainda mais atraente a aplicação das técnicas de replicação estudadas. Mesmo em inquéritos conduzidos com muitas unidades primárias de amostragem, 
pode acontecer que se tenha interesse em estudar subgrupos populacionais restritos a algumas dessas unidades. Isto ocorre com freqüência em inquéritos de saúde, levando à necessidade de se obterem estimativas intervalares com um número muito menor de unidades primárias do que aquelas com que o delineamento foi concebido.

Pelo que foi discutido até agora, observa-se que, em relação a outros trabalhos, realizados com outras populações, os resultados deste estudo coincidem cm muitos pontos e são discordantes em alguns poucos aspectos.

A discordância deve ser naturalmente aceita, uma vez que se trata de estudos empíricos, feitos com populações e delineamentos diferentes, com características próprias. Dessa forma, os resultados deste estudo podem dar contribuição importante à realização de inquéritos de saúde no Estado de São Paulo, poỉs alguns aspectos dos delineamentos adotados são extremamente freqüentes em pesquisas domiciliares por amostragem na área de saúde pública, tais como: utilização de sistemas de referências constituídos pelos setores censitários do IBGE; sorteio desses setores no primeiro estágio do processo amostral, seguido da seleção de outras unidades de amostragem e estimação de parâmetros populacionais, tais como médias e proporções, por meio de estimadores razão.

Entre os resultados apresentados destacam-se:

- $\quad$ BRR teve acurácia próxima à de Taylor (às vezes maior e às vezes menor);

- Jackknife apresentou acurácia menor que Taylor, mas diferenças foram pequenas;

- ambas tiveram coberturas de IC semelhantes a de Taylor. 
Conclui-se, com base nessas afirmações, que técnicas de replicação constituem uma alternativa adequada para estimação de variância em inquéritos de saúde.

Outro aspecto a ser salientado é o da consistência dos estimadores de variância em relação às propriedades avaliadas. À medida que aumenta o número de unidades primárias de amostragem, o vício e o erro padrão das estimativas de variância diminuem e a cobertura dos intervalos de confiança aproxima-se de $95 \%$, como esperado. Isso indica que, ao aumentar o número de unidades primárias de amostragem, além de se obterem estimativas mais acuradas, a escolha entre os distintos estimadores de variância passa a ter menor importância, uma vez que as diferenças entre eles tendem a diminuir.

Nos inquéritos de saúde avaliados neste estudo, é possivel verificar como isso ocorreu. Quando a comparação entre as estimativas Jackknife e Taylor foi feita com base em um número de unidades primárias de amostragem menor ou igual a 40, como nas pesquisas "Morbidade infantil e utilização de serviços de saúde no município de Embu" e "Produtividade dos habitats de Aedes aegypti", as diferenças ficaram entre 7 e 10\%. E nas pesquisas "Morbidade referida e utilização de serviços de saúde na região sudoeste da Grande São Paulo" e na "Pesquisa de Condições de Vida - 1998", em que o número de unidades primárias foi maior que 100 , essas diferenças foram inferiores a $0,3 \%$. Aspectos dos delineamentos das pesquisas constam no ANEXO 2.

O estudo das distribuições de amostragem dos estimadores de variância mostrou que, com amostras que tenham pelo menos 32 unidades primárias de amostragem, os métodos avaliados permitem a estimação de razões com precisão 
semelhante. Portanto, é no contexto de amostras pequenas que estimativas feitas por distintos métodos apresentam diferenças maiores.

A comparação entre os estimadores, feita nos quatro distintos inquéritos de saúde, confirmou esse resultado. Nos inquéritos em que foram aplicados Jackknife e Taylor, o primeiro resultou em estimativas de variância maiores, associando, portanto, menor precisão às proporções e médias estimadas e levando ao cálculo de intervalos de confiança mais amplos.

A comparação entre BRR e Taylor só pode ser feita na Pesquisa de Condições de Vida. realizada em Santos, na qual foi utilizado sorteio de pares de UPAs em cada estrato.

Os dados resultantes dessa comparação confirmaram a produção pela técnica BRR de estimativas de erro padrão próximas às de Taylor, indicando que seus desempenhos foram semelhantes na construção de intervalos de confiança. Essa observação foi feita com base no fato de que metade das estimativas BRR de erro padrão foi inferior às de Taylor e metade superior. Os resultados reafirmaram também o desempenho pior da técnica Jackknife.

Esses resultados apontam para a existência de vantagens na utilização da técnica $B R R$ em inquéritos de saúde. Além de suas propriedades, que se mostraram equivalentes ao método consagrado de estimação de variância, o de Linearização de Taylor, o delineamento exigido para a sua aplicação é conveniente à realização de inquéritos. Isto porque, ao se planejarem amostras, com freqüência surge a necessidade de dividir a população em um número grande de estratos, uma vez que se disponha, para as UPAs, de variáveis de estratificação adequadas. 
O delineamento sob o qual BRR é aplicada permite levar a estratificação ao seu limite máximo, sorteando-se somente duas unidades de amostragem em cada estrato. A possibilidade de utilização da técnica BRR deve se constituir em estímulo à utilização de delineamentos que considerem um número muito grande de estratos. Há situações em que esse procedimento facilita o planejamento da amostra e a operacionalização do trabalho de coleta de dados. Nesse sentido, uma maior divulgação da técnica BRR permitirá uma utilização mais intensa desse delineamento, que, em outros países, já tem ampla aplicação.

A técnica BRR constitui, ainda, alternativa à estimação de variância em amostras sistemáticas. Pode-se pressupor o uso desse delineamento, de pares de UPAs nos estratos, quando se estima a variância em amostras com grande número de unidades primárias, selecionadas sistematicamente. Caso a ordenação das unidades para o sorteio tenha relação com as estatísticas produzidas na pesquisa, pode-se criar estratos implícitos, de duas unidades cada, e aplicar BRR. As estimativas de variância refletirão, dessa forma, os ganhos advindos da seleção sistemática. Se a amostra fossa considerada aleatória simples, as estimativas de variância estariam superestimadas (WESTAT 2000).

Em relação ao estudo de associação por meio de técnicas de replicação, a discussão dos resultados assume outro caráter. Deixam de ser comparados estimadores de variância por replicação com algum estimador para delineamentos complexos já consagrado, e se passa a comparar os resultados da análise de associação em que técnicas de replicação são aplicadas, com os resultados que ignoram o delineamento de amostragem e adotam a Amostragem Aleatória Simples. Assumindo-se, portanto, que as técnicas de replicação geram estimativas de variância 
adequadas, verifica-se como elas podem ser utilizadas para avaliar a existência de associação entre variáveis e qual o efeito que sua utilização provoca.

$\mathrm{Na}$ "Pesquisa de Condições de Vida - 1998”, Região Metropolitana de São Paulo, os testes de associação conduzidos sob o delineamento utilizado e sob a Amostragem Aleatória Simples levaram às mesmas conclusões, no sentido de permitirem ou não a rejeição da hipótese nula. Porém, o aumento dos níveis descritivos dos testes mostra a influência do delineamento, uma vez que esses niveis tornaram-se maiores ao serem introduzidas as correções referentes ao efeito do delineamento.

Nos outros inquéritos em que foram feitos testes qui-quadrado de Pearson, verificou-se que com a Amostragem Aleatória Simples, a hipótese de não associação entre variáveis é rejeitada com freqüência maior que a dos delineamentos complexos. Desconsiderar que foram sorteados conglomerados leva, portanto, à rejeição da hipótese nula com freqüência superior à adequada.

$\mathrm{Na}$ amostragem por conglomerados, há quebra da independência entre os elementos, em função da possível existência de homogeneidade intraclasse existente. Ao corrigir a estatística de Pearson por uma medida de efeito do delineamento, considera-se a existência dessa homogeneidade na realização dos testes de associação.

Distorções ocorrem também na construção de intervalos de confiança para odds ratio. São mais amplos quando calculados com estimativas de erro padrão por replicação do que com as referentes à Amostragem Aleatória Simples, levando à inclusão da unidade com freqüência maior. 
É possivel verificar que algumas das variáveis que na análise bivariada sob a Amostragem Aleatória Simples seriam consideradas associadas, por não incluírem a unidade nos intervalos de confiança para odds ratio, deixam de sê-lo, quando a amostra é tratada adequadamente. Considerando que a análise bivariada é, muitas vezes, o primeiro passo na seleção de variáveis que devem compor a análise multivariada, equívocos como os apontados podem comprometer o modelo explicativo desenhado. Isso pode ocorrer na construção de modelos por meio da regressão logística, cujo uso, na área de saúde pública tem sido freqüente e crescente.

A utilização intensa de softwares em que a análise de dados é feita adotandose pressupostos da Amostragem Aleatória Simples (independência entre elementos e eqüiprobabilidade no sorteio) pode ser responsabilizada pela realização de inferências em que a ponderação das unidades de amostragem e a correlação intraclasse são ignoradas.

Faz-se necessário, portanto, que se passe a utilizar softwares "especializados", voltados para a análise de dados coletados sob delineamentos complexos. Inúmeras alternativas surgiram nas últimas décadas (LEPKOWSKI e BOWLES 1996), bastando para o seu uso que o arquivo de dados originados no inquérito contenha informações referentes a aspectos do delineamento. Tais aspectos podem ser "ignorados", caso o arquivo inclua os pesos de réplicas criadas para a estimação de variância. A prática de considerar o delineamento efetivamente empregado na coleta de dados depende, em grande medida, da divulgação das técnicas existentes para esse fim, bem como dos softwares especializados que as contemplam. 


\section{CONCLUSÕES}

Adotando-se o estimador de Taylor como referência, os estimadores por replicação, BRR e Jackknife, mostraram-se adequados à estimação de erros de amostragem de proporções e médias, em inquéritos domiciliares. Apresentaram vícios semelhantes e coberturas dos intervalos de confiança igualmente próximos dos niveis de confiança estabelecidos pela distribuição t-Student. Em termos de precisão, BRR e Taylor apresentaram resultados superiores àqueles determinados por Jackknife, sendo, porém, que as diferenças foram muito pequenas.

Nos quatro inquéritos de saúde estudados, os intervalos de confiança para médias e proporções foram mais amplos para a técnica Jackknife do que para Taylor, para amostras compostas por menos de 40 unidades primárias de amostragem. Entretanto, passaram a ter amplitudes semelhantes com amostras maiores. Os intervalos calculados com estimativas por BRR tiveram a mesma amplitude que os de Taylor.

Conclui-se com base nesses resultados, que para amostras com menos de 40 unidades primárias de amostragem, BRR constitui alternativa tão adequada quanto Taylor para a realização de inferências. Para amostras maiores, também Jackknife equiparou-se a Taylor.

Nesse sentido, a utilização de técnicas de replicação em análise de dados de inquéritos de saúde deve ser recomendada. E, ainda, a possibilidade de utilização da técnica BRR deve se constituir em estímulo à utilização de delineamentos de 
amostragem que considerem um número muito grande de estratos, o que pode facilitar o planejamento da amostra.

A aplicação de estimativas de variância por replicação na determinação de intervalos de confiança para o odds ratio, permitiu a identificação de fatores de risco ou de proteção, levando em consideração o delineamento efetivamente utilizado nos inquéritos. Como conseqüência do efeito do delineamento, os intervalos foram mais amplos, incluindo a unidade com maior freqüência em relação à amostragem aleatória simples.

O efeito do delineamento estimado por técnicas de replicação também alterou, em relação à Amostragem Aleatória Simples, os resultados dos testes de associação entre variáveis expressas por tabelas de contingência, que mostraram menor tendência em rejeitar a hipótese de não associação entre fatores considerados.

Admitir a Amostragem Aleatória Simples como sendo o real delineamento da amostra é um procedimento amplamente difundido, cuja adoção pode facilmente levar a conclusões incorretas. Nesse sentido, devem ser divulgadas as técnicas disponíveis de estimação de variância sob delineamentos complexos, bem como, os softwares que adotem procedimentos de inferência estatística adequados a dados provenientes de inquéritos domiciliares. 


\section{REFERÊNCIAS BIBLIOGRÁFICAS}

1. Alves MCGP, Gurgel S de M, Almeida $M$ do CRR de. Plano amostral para cálculo de densidade larvária de Aedes aegypti e Aedes albopictus no Estado de São Paulo, Brasil. Rev Saúde Pública 1991; 25(4): 251-6.

2. Alves MCGP, Mantegazza E, Wanderley DMV, Meneguetti LC, Buralli GM, Yasamaru S, Scandar SA. Controle da doença de Chagas na região de Sorocaba, São Paulo, Brasil. In: Anais da VI Reunião Anual de Pesquisa Aplicada em Doença de Chagas; 1989 nov 2-4; Uberaba, Brasil; p. 125

3. Bean JA. Distribution and properties of variance estimators for complex multistage probability samples. An empirical distribution. Rockville, $\mathrm{Md}$; 1975. National Center for Health Statistics - Vital and Health Statistics Serie 2, $65)$.

4. Brick JM, Morganstein D, Valliant R. Analysis of complex samples using replication. Rockville: Westat. [technical papers on line]. Avaliable from: <URL: http://www.westat.com./wesvar/techpapers/ACS-Replication.pdf $>$ [2001 Mar 05].

5. Burke J, Rust K. On the performance of Jackknife variance estimation for systematic samples with small numbers of primary sampling units. In: Proc Amer Statist Assoc Survey Res Methods Sec, Washinton DC: ASA; 1995, p. $321-5$.

6. Bussab WO e Dini NP. Regiões homogêneas na Grande São Paulo. Revista da Fundação SEADE. São Paulo, 1995;1(3).

7. Bussab WO, Morettin PA. Estatística básica. $4^{\mathrm{a}}$. ed. São Paulo: Atual; 1987. 
8. Campbell C, Meyer M. Some properties of $\mathrm{T}$ confidence intervals for survey data. In: Proc Amer Statist Assoc Survey Res Methods Sec, Washinton, DC: ASA; 1978, p. 437-42.

9. Carlson BL. Software for statistical analysis of sample survey data. In: Encyclopedia of biostatistics, Armitage P, Colton T, editors; 1998. [serial on line] Avaliable from: URL: <http://www.fas.harvard.edu/ stats/surveysoft/blv eob.html> [2001 Mar 25].

10. Carvalheiro JR. Investigação epidemiológica e entrevistas domiciliárias. Rev. Saúde Pública 1981; (15)5: 543-50.

11. [CDC] Center for Disease Control. World Health Organization. Epi Info, Epidemiologia em microcomputadores: um sistema de processamento de texto, banco de dados e estatísticas [programa de computador]. Atlanta: OPAS/ WHO; 1995.

12. Cesar CLG, Figueiredo GM, Westphal MF, Cardoso MRA, Costa MZ de A, Gattás VL. Morbidade referida e utilização de serviços de saúde em localidades urbanas brasileiras: metodologia. Rev. Saúde Pública 1996; 30(2):153-60.

13. Cesar CLG. Morbidade referida e utilização de serviços de saúde na Grande São Paulo. O perfil da desigualdade em saúde. São Paulo, 1997. [Tese de livre-docência - Faculdade de Saúde Pública da Universidade de São Paulo].

14. Chow LL. Statistical significance. London: Sage Publications; 1996. (Sage University Paper: Quantitative Applications in the Social Sciences).

15. Cochran WG. Sampling techniques. New York: John Wiley \& Sons; 1977.

16. Deming WE. On simplifications of sampling design through replication with equal probabilities and without stages. J Amer Statist Assoc 1956; 51: 24-53.

17. Fellegi IP. Approximate tests of independence and goodness of fit based on stratified multistage samples. J Amer Statist Assoc 1980; 75(370): 261-8. 
18. Flayer P, Rust $K$, Morganstein D. Complex survey variance estimation and contingency table analysis using replications. In: Proc Amer Statist Assoc Survey Res Methods Sec; Washington, D.C: ASA; p.110-9

19. Fleiss JL. Statistical methods for rates and proportions. New York: John Wiley \& Sons; 1981.

20. Freeman Jr DH. Applied categorical data analysis. New York: Marcel Dekker; 1987.

21. Frei F. Análise de agrupamentos: estudo metodológico e aplicações em epidemiologia. São Paulo, 1998. [Dissertação de mestrado - Faculdade de Saúde Pública da Universidade de São Paulo].

22. Fundação SEADE. Pesquisa de Emprego e Desemprego - Conceitos, Metodologia e Operacionalização. São Paulo; 1995.

23. Fundação SEADE. Pesquisa de Emprego e Desemprego - Base de Indicadores de Famílias e Domicílios. [CD Rom]. São Paulo; 2000.

24. Gurney M, Jewett RS. Constructing orthogonal replications for variance estimation. J Amer Statist Assoc 1975; 70 (352): 819-21.

25. Hansen MH, Hurwitz WN, Madow WG. Sampling survey methods and theory. New York: John Wiley \& Sons; 1953. 1v.

26. Henkel RE. Tests of significance. Beverly Hills: Sage Publications; 1986. (Sage University Paper: Quantitative Applications in the Social Sciences).

27. Kahn HA, Sempos CT. Statistical methods in epidemiology. New York: Oxford University Press; 1989. (Brian MacMahon: Monographs in Epidemiology and Biostatistics).

28. Kalton G. Practical methods for estimating surveys sampling errors. Bull Int Stat Inst $1977 ; 47(3): 495-514$. 
29. Kalton G. Compensating for missing survey data. Ann Arbor: The University of Michigan; 1983. (Resarch Report Series, Institute for Social Research).

30. Kish L. Survey sampling. New York: John Wiley \& Sons; 1965.

31. Kish L, Frankel MR. Inference from complex samples. J R Statist Soc 1974; Series B, 36: 1-37.

32. Kovar JG, Rao JNK, Wu CFJ. Bootstrap and other methods to measure errors in survey estimates. Can J Stat 1998; 16(Suppl): 25-45.

33. Kroeger A. Health interview surveys in developing countries: a review of the methods and results. Int J Epidemiol 1983; 12(4): 465-81.

34. Lebrão ML, Carandini L, Magaldi C. Análise das condiçöes de saúde e de vida da população urbana de Botucatu, São Paulo (Brasil). IV - Morbidade referida em entrevistas domiciliárias, 1993-1984. Rev Saúde Públ 1991; 25(6): 452 - 60.

35. Lepkowski J e Bowles J. Sampling error software for personal computers. Surv Stat 1996; 35: 10-7. [serial on line]. Avaliable from: UDR: <http://www.fas.harvard.edu/ stats/survey-soft/iass.html> [2001 .07.20]

36. McCarthy PJ. Replication - An approach to the analysis of data from complex surveys. Rockville, Md; 1966. (National Center for Health Statisitcs Vital and Health Statistic Series 2, No. 14).

37. Mulry MH, Wolter KM. The effect of Fisher's z-transformation on confidence intervals for the correlation coefficient. In: Proc Amer Statist Assoc Survey Res Methods Sec. Washington, D.C.; 1981, p. 601-6.

38. Pedroso GC. Prevalência de aleitamento materno no município de Embu (São Paulo), no ano de 1996. São Paulo; 1999. [Dissertação de mestrado Escola Paulista de Medicina da Universidade Federal de São Paulo]. 
39. Pereira M. Produtividade e habitats larvários de Aedes aegypti em Santos, Estado de São Paulo. São Paulo, 2001. [Tese de Doutorado - Faculdade de Saúde Pública da Universidade de São Paulo].

40. Pessoa DGC, Nascimento-Silva PL. Análise de dados amostrais complexos. São Paulo: Associação Brasileira de Estatística; 1998.

41. Plackett RL, Burman PJ. The design of optimum multi-factorial experiments Biometrika 1946; 83: 305-25.

42. Rust K. Efficient replicated variance estimation. In: Proc Amer Statist Assoc Survey Res Methods Sec. Washington, D. C.; 1986, p. 81-7.

43. Särndal CE, Swensson B, Wretman JH. Model assisted survey sampling. New York: Springer-Verlag; 1992.

44. Silva NN da, Puccini RF, Araújo NS, Pedroso GC, Gomes MT, Furlani WJ, Soares FS. Morbidade e utilização de serviços no município de Embu: estudo epidemiológico na área de saúde infantil. São Paulo, 1997. [Relatório Processo FAPESP 95/3438-7].

45. Silva NN da. Amostragem probabilística: um curso introdutório. São Paulo: Editora da Universidade de São Paulo; 1998.

46. Skinner CJ, Holt D, Smith TMF. Analysis of complex surveys. Chichester: John Wiley \& Sons; 1989.

47. Tukey JW. Bias and confidence in not-quite large samples. Abstract. Ann Math Statist 1958; 29:614.

48. United Nations. National Household Survey Capability Programm. Sampling errors in household surveys. New York; 1993.

49. Westat. WesVar ${ }^{\mathrm{TMI}}$ 4.0 User's guide. Rockville, 2000.

50. Westat. WesVar ${ }^{\mathrm{TM}} 4.0$ [programa de computador]. Rockville: Westat; 2000. 
51. White KL. Health Surveys: Who, why and what? Rapp Trimest Statist Mond $1985 ; 38: 2-14$.

52. [WHO] World Health Organization. A system of world-wide survillance for vectors. Wkly Epidemiol Rec 1972, 47: 73-84.

53. Wolter KM. Introduction to variance estimation. New York: Spring-Velag; 1985. 


\section{ANEXO 1}

\section{Esquema do sorteio da amostra}

$1^{\circ}$.) Foi construído um arquivo com dados originais da Pesquisa de Emprego e Desemprego, cada registro correspondendo a um domicílio, segundo modelo constante no QUADRO 7.

Quadro 7. Modelo do Arquivo 1, com dados da Pesquisa de Emprego e Desemprego, por domicílio.

\begin{tabular}{ccccc}
\hline ESTRATO & SETOR & DOMICÍLIO & RENDA & $\begin{array}{c}\text { PESO } \\
\mathrm{M}_{\mathrm{h}} / 10\end{array}$ \\
\hline 1 & 1 & 1 & $\mathrm{Y}_{1}$ & $\mathrm{M}_{1} / 10$ \\
1 & 1 & 2 & $\mathrm{Y}_{2}$ & $\mathrm{M}_{1} / 10$ \\
$\vdots$ & $\vdots$ & $\vdots$ & $\vdots$ & $\vdots$ \\
1 & 2 & & & $\mathrm{M}_{1} / 10$ \\
1 & 2 & & $\mathrm{M}_{1} / 10$ \\
$\vdots$ & $\vdots$ & & & \\
2 & 1 & $\mathrm{M}_{1}+1$ & $\mathrm{M}_{2} / 10$ \\
2 & 1 & $\mathrm{M}_{1}+2$ & & $\mathrm{M}_{2} / 10$ \\
2 & 2 & $\vdots$ & & $\mathrm{M}_{2} / 10$ \\
2 & 2 & & & $\mathrm{M}_{2} / 10$ \\
$\vdots$ & $\vdots$ & & & $\vdots$ \\
\hline
\end{tabular}

$\mathrm{Mh}$ - número de domicílios no estrato h.

$2^{0}$ ) A partir dos dados do Arquivo 1, foi criado arquivo com registros correspondentes a setores censitários. Para isso, em cada estrato:

- foram somados os domicílios por setor e foi feita a soma acumulada dos números de domicílios por setor (QUADRO 8); 
- foi sorteado um número aleatório entre 0,1 e $\mathrm{Mh} / 2$ ( $1^{\circ}$. número sorteado). Acrescentou-se $\mathrm{Mh} / 2$ a esse número ( $2^{\circ}$. número sorteado).

- foram identificados os setores censitários cujo tamanhos acumulados fossem exatamente superiores a esses números. Esses setores (UPAs) foram incluídos na amostra;

- em cada UPA, foram sorteados 5 números, entre 1 e $M_{h r x}$, não repetidos, correspondentes aos domicílios sorteados.

Quadro 8. Modelo do Arquivo 2, com dados da Pesquisa de Emprego e Desemprego, por setor censitário.

\begin{tabular}{ccccc}
\hline $\begin{array}{c}\text { Estrato } \\
(\mathrm{h})\end{array}$ & $\begin{array}{c}\text { Setor } \\
(\alpha)\end{array}$ & $\begin{array}{c}\text { Dom/setor } \\
\left(M_{h \alpha}\right)\end{array}$ & $\begin{array}{c}\text { No.acum. } \\
\text { Dom/setor }\end{array}$ & $\begin{array}{c}\text { setores } \\
\text { sorteados }\end{array}$ \\
\hline 1 & 10 & 5 & 5 & \\
1 & 2 & 15 & 20 & $\mathrm{x}$ \\
1 & 23 & 18 & 38 & $\mathrm{x}$ \\
$\vdots$ & $\vdots$ & $\vdots$ & $\vdots$ & \\
2 & 11 & 4 & 4 & $\mathrm{x}$ \\
2 & 20 & 16 & 20 & \\
2 & 22 & 4 & 24 & \\
$\vdots$ & $\vdots$ & $\vdots$ & $\vdots$ & \\
\hline
\end{tabular}

$3^{\circ}$.) Foi construído o arquivo final, em que cada registro correspondeu a um domicílio sorteado. Constou desse arquivo, para cada domicílio, os dados correspondentes a: estrato, UPA, peso e renda familiar. 


\section{ANEXO 2}

\section{Criação de réplicas - Técnica JACKKNIFE}

Para cada uma das 2000 amostras sorteadas, foram construídas 8 réplicas, retirando-se uma UPA (a segunda) de cada estrato. Como exemplo, a primeira réplica contém somente a primeira UPA do primeiro estrato e as duas UPAs dos estratos restantes.

Os domicílios da UPA que não foi incluída na amostra recebem peso nulo e os domicílios da outra UPA do mesmo estrato, têm seu peso dobrado. Para os demais estratos, os domicílios têm os mesmos pesos com que estão incluídos na "amostramãe".

A TABELA 30 foi construida com os dados de uma das 2000 amostras sorteadas com o $1^{\circ}$. delineamento (8 estratos - 16 UPAs). Estão indicados os pesos de cada domicilio nas 8 réplicas criadas pela técnica Jackknife.

O estimador da renda média em cada réplica $i$ foi: $r_{i}=\frac{\sum_{i}^{n_{i}} w_{i j} y_{i j}}{\sum_{j}^{n_{i}} w_{i j}}$,

sendo $w_{i j}$ e $y_{i j}$, respectivamente, o peso e a renda do elemento $\mathrm{j}$ da réplica $\mathrm{i}$.

O estimador do desvio padrão foi: $d p(r)=\sqrt{\sum\left(r_{i}-r\right)^{2}}$, sendo r o estimador da renla médià na amostra-mãe.

As estimativas de $r$, em cada réplica, foram: 


$$
\begin{aligned}
& r_{1}=\frac{12580145.6}{8592}=1464.16965 \\
& r_{2}=1501.64298 \\
& r_{3}=1446.82078 \\
& r_{4}=1421.84139 \\
& r_{5}=1489.27363 \\
& r_{6}=1489.09846 \\
& r_{7}=1495.53524 \\
& r_{8}=1528.71755
\end{aligned}
$$

A estimativa do erro padrão foi:

$$
d p(r)=\sqrt{\sum\left(r_{i}-1461.153864\right)^{2}}=1103.52741
$$


Tabela 30 . Dados da amostra e pesos das réplicas criadas pela técnica Jackknife.

\begin{tabular}{|c|c|c|c|c|c|c|c|c|c|c|c|}
\hline \multicolumn{4}{|c|}{ Amostra } & \multicolumn{8}{|c|}{ Réplicas - pesos } \\
\hline estrato & UPA & renda & Peso & 1 & 2 & 3 & 4 & 5 & 6 & 7 & 8 \\
\hline 1 & 1 & 628 & 181.2 & 362.4 & 181.2 & 181.2 & 181.2 & 181.2 & 181.2 & 181.2 & 181.2 \\
\hline 1 & 1 & 780 & 181.2 & 362.4 & 181.2 & 181.2 & 181.2 & 181.2 & 181.2 & 181.2 & 181.2 \\
\hline 1 & 1 & 594 & 181.2 & 362.4 & 181.2 & 181.2 & 181.2 & 181.2 & 181.2 & 181.2 & 181.2 \\
\hline 1 & 1 & 940 & 181.2 & 362.4 & 181.2 & 181.2 & 181.2 & 181.2 & 181.2 & 181.2 & 181.2 \\
\hline 1 & 1 & 200 & 181.2 & 362.4 & 181.2 & 181.2 & 181.2 & 181.2 & 181.2 & 181.2 & 181.2 \\
\hline 1 & 2 & 0 & 181.2 & 0 & 181.2 & 181.2 & 181.2 & 181.2 & 181.2 & 181.2 & 181.2 \\
\hline 1 & 2 & 250 & 181.2 & 0 & 181.2 & 181.2 & 181.2 & 181.2 & 181.2 & 181.2 & 181.2 \\
\hline 1 & 2 & 1519 & 181.2 & 0 & 181.2 & 181.2 & 181.2 & 181.2 & 181.2 & 181.2 & 181.2 \\
\hline 1 & 2 & 1230 & 181.2 & 0 & 181.2 & 181.2 & 181.2 & 181.2 & 181.2 & 181.2 & 181.2 \\
\hline 1 & 2 & 0 & 181.2 & 0 & 181.2 & 181.2 & 181.2 & 181.2 & 181.2 & 181.2 & 181.2 \\
\hline 2 & 1 & 530 & 135.1 & 135.1 & 270.2 & 135.1 & 135.1 & 135.1 & 135.1 & 135.1 & 135.1 \\
\hline 2 & 1 & 2601 & 135.1 & 135.1 & 270.2 & 135.1 & 135.1 & 135.1 & 135.1 & 135.1 & 135.1 \\
\hline 2 & 1 & 1053 & 135.1 & 135.1 & 270.2 & 135.1 & 135.1 & 135.1 & 135.1 & 135.1 & 135.1 \\
\hline 2 & 1 & 427 & 135.1 & 135.1 & 270.2 & 135.1 & 135.1 & 135.1 & 135.1 & 135.1 & 135.1 \\
\hline 2 & 1 & 653 & 135.1 & 135.1 & 270.2 & 135.1 & 135.1 & 135.1 & 135.1 & 135.1 & 135.1 \\
\hline 2 & 2 & 480 & 135.1 & 135.1 & 0 & 135.1 & 135.1 & 135.1 & 135.1 & 135.1 & 135.1 \\
\hline 2 & 2 & 300 & 135.1 & 135.1 & 0 & 135.1 & 135.1 & 135.1 & 135.1 & 135.1 & 135.1 \\
\hline 2 & 2 & 538 & 135.1 & 135.1 & 0 & 135.1 & 135.1 & 135.1 & 135.1 & 135.1 & 135.1 \\
\hline 2 & 2 & 991 & 135.1 & 135.1 & 0 & 135.1 & 135.1 & 135.1 & 135.1 & 135.1 & 135.1 \\
\hline 2 & 2 & 380 & 135.1 & 135.1 & 0 & 135.1 & 135.1 & 135.1 & 135.1 & 135.1 & 135.1 \\
\hline 3 & 1 & 195 & 40.9 & 40.9 & 40.9 & 81.8 & 40.9 & 40.9 & 40.9 & 40.9 & 40.9 \\
\hline 3 & 1 & 0 & 40.9 & 40.9 & 40.9 & 81.8 & 40.9 & 40.9 & 40.9 & 40.9 & 40.9 \\
\hline 3 & 1 & 386 & 40.9 & 40.9 & 40.9 & 81.8 & 40.9 & 40.9 & 40.9 & 40.9 & 40.9 \\
\hline 3 & 1 & 195 & 40.9 & 40.9 & 40.9 & 81.8 & 40.9 & 40.9 & 40.9 & 40.9 & 40.9 \\
\hline 3 & 1 & 200 & 40.9 & 40.9 & 40.9 & 81.8 & 40.9 & 40.9 & 40.9 & 40.9 & 40.9 \\
\hline 3 & 2 & 1500 & 40.9 & 40.9 & 40.9 & 0 & 40.9 & 40.9 & 40.9 & 40.9 & 40.9 \\
\hline 3 & 2 & 900 & 40.9 & 40.9 & 40.9 & 0 & 40.9 & 40.9 & 40.9 & 40.9 & 40.9 \\
\hline 3 & 2 & 550 & 40.9 & 40.9 & 40.9 & 0 & 40.9 & 40.9 & 40.9 & 40.9 & 40.9 \\
\hline 3 & 2 & 240 & 40.9 & 40.9 & 40.9 & 0 & 40.9 & 40.9 & 40.9 & 40.9 & 40.9 \\
\hline 3 & 2 & 797 & 40.9 & 40.9 & 40.9 & 0 & 40.9 & 40.9 & 40.9 & 40.9 & 40.9 \\
\hline 4 & 1 & 1050 & 59.3 & 59.3 & 59.3 & 59.3 & 118.6 & 59.3 & 59.3 & 59.3 & 59.3 \\
\hline 4 & 1 & 15500 & 59.3 & 59.3 & 59.3 & 59.3 & 118.6 & 59.3 & 59.3 & 59.3 & 59.3 \\
\hline 4 & 1 & 460 & 59.3 & 59.3 & 59.3 & 59.3 & 118.6 & 59.3 & 59.3 & 59.3 & 59.3 \\
\hline 4 & 1 & 0 & 59.3 & 59.3 & 59.3 & 59.3 & 118.6 & 59.3 & 59.3 & 59.3 & 59.3 \\
\hline 4 & 1 & 7000 & 59.3 & 59.3 & 59.3 & 59.3 & 118.6 & 59.3 & 59.3 & 59.3 & 59.3 \\
\hline 4 & 2 & 2500 & 59.3 & 59.3 & 59.3 & 59.3 & 0 & 59.3 & 59.3 & 59.3 & 59.3 \\
\hline 4 & 2 & 1800 & 59.3 & 59.3 & 59.3 & 59.3 & 0 & 59.3 & 59.3 & 59.3 & 59.3 \\
\hline 4 & 2 & 5000 & 59.3 & 59.3 & 59.3 & 59.3 & 0 & 59.3 & 59.3 & 59.3 & 59.3 \\
\hline 4 & 2 & 2406 & 59.3 & 59.3 & 59.3 & 59.3 & 0 & 59.3 & 59.3 & 59.3 & 59.3 \\
\hline 4 & 2 & 18000 & 59.3 & 59.3 & 59.3 & 59.3 & 0 & 59.3 & 59.3 & 59.3 & 59.3 \\
\hline
\end{tabular}


continuação da Tabela 30

\begin{tabular}{|c|c|c|c|c|c|c|c|c|c|c|c|}
\hline \multicolumn{4}{|c|}{ Amostra } & \multicolumn{8}{|c|}{ Réplicas - pesos } \\
\hline Estrato & UPA & renda & Peso & 1 & 2 & 3 & 4 & 5 & 6 & 7 & 8 \\
\hline 5 & 1 & 1000 & 65.0 & 65.0 & 65.0 & 65.0 & 65.0 & 130.0 & 65.0 & 65.0 & 65.0 \\
\hline 5 & 1 & 1605 & 65.0 & 65.0 & 65.0 & 65.0 & 65.0 & 130.0 & 65.0 & 65.0 & 65.0 \\
\hline 5 & 1 & 640 & 65.0 & 65.0 & 65.0 & 65.0 & 65.0 & 130.0 & 65.0 & 65.0 & 65.0 \\
\hline 5 & 1 & 2009 & 65.0 & 65.0 & 65.0 & 65.0 & 65.0 & 130.0 & 65.0 & 65.0 & 65.0 \\
\hline 5 & 1 & 300 & 65.0 & 65.0 & 65.0 & 65.0 & 65.0 & 130.0 & 65.0 & 65.0 & 65.0 \\
\hline 5 & 2 & 537 & 65.0 & 65.0 & 65.0 & 65.0 & 65.0 & 0 & 65.0 & 65.0 & 65.0 \\
\hline 5 & 2 & 750 & 65.0 & 65.0 & 65.0 & 65.0 & 65.0 & 0 & 65.0 & 65.0 & 65.0 \\
\hline 5 & 2 & 550 & 65.0 & 65.0 & 65.0 & 65.0 & 65.0 & 0 & 65.0 & 65.0 & 65.0 \\
\hline 5 & 2 & 0 & 65.0 & 65.0 & 65.0 & 65.0 & 65.0 & 0 & 65.0 & 65.0 & 65.0 \\
\hline 5 & 2 & 0 & 65.0 & 65.0 & 65.0 & 65.0 & 65.0 & 0 & 65.0 & 65.0 & 65.0 \\
\hline 6 & 1 & 2215 & 112.5 & 122.5 & 122.5 & 122.5 & 122.5 & 122.5 & 245.0 & 122.5 & 122.5 \\
\hline 6 & 1 & 5670 & 122.5 & 122.5 & 122.5 & 122.5 & 122.5 & 122.5 & 245.0 & 122.5 & 122.5 \\
\hline 6 & 1 & 1645 & 122.5 & 122.5 & 122.5 & 122.5 & 122.5 & 122.5 & 245.0 & 122.5 & 122.5 \\
\hline 6 & 1 & 750 & 122.5 & 122.5 & 122.5 & 122.5 & 122.5 & 122.5 & 245.0 & 122.5 & 122.5 \\
\hline 6 & 1 & 1630 & 122.5 & 122.5 & 122.5 & 122.5 & 122.5 & 122.5 & 245.0 & 122.5 & 122.5 \\
\hline 6 & 2 & 4200 & 112.5 & 122.5 & 122.5 & 122.5 & 122.5 & 122.5 & 0 & 122.5 & 122.5 \\
\hline 6 & 2 & 2900 & 122.5 & 122.5 & 122.5 & 122.5 & 122.5 & 122.5 & 0 & 122.5 & 122.5 \\
\hline 6 & 2 & 350 & 122.5 & 122.5 & 122.5 & 122.5 & 122.5 & 122.5 & 0 & 122.5 & 122.5 \\
\hline 6 & 2 & 500 & 122.5 & 122.5 & 122.5 & 122.5 & 122.5 & 122.5 & 0 & 122.5 & 122.5 \\
\hline 6 & 2 & 2000 & 122.5 & 122.5 & 122.5 & 122.5 & 122.5 & 122.5 & 0 & 122.5 & 122.5 \\
\hline 7 & 1 & 500 & 161.6 & 161.6 & 161.6 & 161.6 & 161.6 & 161.6 & 161.6 & 323.2 & 161.6 \\
\hline 7 & 1 & 1640 & 161.6 & 161.6 & 161.6 & 161.6 & 161.6 & 161.6 & 161.6 & 323.2 & 161.6 \\
\hline 7 & 1 & 1720 & 161.6 & 161.6 & 161.6 & 161.6 & 161.6 & 161.6 & 161.6 & 323.2 & 161.6 \\
\hline 7 & 1 & 2700 & 161.6 & 161.6 & 161.6 & 161.6 & 161.6 & 161.6 & 161.6 & 323.2 & 161.6 \\
\hline 7 & 1 & 1640 & 161.6 & 161.6 & 161.6 & 161.6 & 161.6 & 161.6 & 161.6 & 323.2 & 161.6 \\
\hline 7 & 2 & 500 & 161.6 & 161.6 & 161.6 & 161.6 & 161.6 & 161.6 & 161.6 & 0 & 161.6 \\
\hline 7 & 2 & 350 & 161.6 & 161.6 & 161.6 & 161.6 & 161.6 & 161.6 & 161.6 & 0 & 161.6 \\
\hline 7 & 2 & 3360 & 161.6 & 161.6 & 161.6 & 161.6 & 161.6 & 161.6 & 161.6 & 0 & 161.6 \\
\hline 7 & 2 & 1122 & 161.6 & 161.6 & 161.6 & 161.6 & 161.6 & 161.6 & 161.6 & 0 & 161.6 \\
\hline 7 & 2 & 1040 & 161.6 & 161.6 & 161.6 & 161.6 & 161.6 & 161.6 & 161.6 & 0 & 161.6 \\
\hline 8 & 1 & 4000 & 93.6 & 93.6 & 93.6 & 93.6 & 93.6 & 93.6 & 93.6 & 93.6 & 187.2 \\
\hline 8 & 1 & 520 & 93.6 & 93.6 & 93.6 & 93.6 & 93.6 & 93.6 & 93.6 & 93.6 & 187.2 \\
\hline 8 & 1 & 1800 & 93.6 & 93.6 & 93.6 & 93.6 & 93.6 & 93.6 & 93.6 & 93.6 & 187.2 \\
\hline 8 & 1 & 3650 & 93.6 & 93.6 & 93.6 & 93.6 & 93.6 & 93.6 & 93.6 & 93.6 & 187.2 \\
\hline 8 & 1 & 960 & 93.6 & 93.6 & 93.6 & 93.6 & 93.6 & 93.6 & 93.6 & 93.6 & 187.2 \\
\hline 8 & 2 & 1620 & 93.6 & 93.6 & 93.6 & 93.6 & 93.6 & 93.6 & 93.6 & 93.6 & 0 \\
\hline 8 & 2 & 1117 & 93.6 & 93.6 & 93.6 & 93.6 & 93.6 & 93.6 & 93.6 & 93.6 & 0 \\
\hline 8 & 2 & 879 & 93.6 & 93.6 & 93.6 & 93.6 & 93.6 & 93.6 & 93.6 & 93.6 & 0 \\
\hline 8 & 2 & 1112 & 93.6 & 93.6 & 93.6 & 93.6 & 93.6 & 93.6 & 93.6 & 93.6 & 0 \\
\hline 8 & 2 & 0 & 93.6 & 93.6 & 93.6 & 93.6 & 93.6 & 93.6 & 93.6 & 93.6 & 0 \\
\hline
\end{tabular}




\section{Criação de réplicas - Técnica BRR}

Foram construídas 8 réplicas, incluindo uma UPA de cada estrato em cada uma delas, segundo esquema da Matriz Hadamard, ilustrada no quadro 9.

Quadro 9. Modelo da Matriz Hadamard (8x8)

\begin{tabular}{lllllllll}
\hline estrato & \multicolumn{7}{c}{ réplica } \\
& 1 & 2 & 3 & 4 & 5 & 6 & 7 & 8 \\
\hline 1 & + & + & + & + & + & + & + & + \\
2 & + & - & + & - & + & - & + & - \\
3 & + & - & - & + & + & - & - & + \\
4 & + & + & - & - & + & + & - & - \\
5 & + & + & + & + & - & - & - & - \\
6 & + & - & + & - & - & + & - & + \\
7 & + & - & - & + & - & + & + & - \\
8 & + & + & - & - & - & - & + & + \\
\hline
\end{tabular}

O sinal + indica a inclusão da $1^{\mathrm{a}}$. UPA e o sinal - , da $2^{\mathrm{a}}$. UPA.

Em cada réplica, os pesos dos domicílios da UPA excluida passam a ser zero e os outros domicílios recebem o mesmo peso com que foram sorteados na amostramãe.

Considerando a mesma amostra utilizada na tabela anterior, estão indicados na TABELA 31 os pesos em cada réplica da técnica BRR.

As estimativas da renda média obtidas em cada réplica i $(i=1,8)$ foram:

$$
\begin{aligned}
& r_{1}=\frac{\sum w_{i} y_{i}}{\sum w_{i}}=\frac{6912361.2}{4296}=1609.02263 \\
& r_{2}=1432.15861 \\
& r_{3}=1512.42363 \\
& r_{4}=1415.65277 \\
& r_{5}=1293.00377
\end{aligned}
$$




$$
\begin{aligned}
& r_{6}=1365.34367 \\
& r_{7}=1604.18503 \\
& r_{8}=1481.66706 .
\end{aligned}
$$

A estimativa do desvio padrão de $\mathbf{r}$ foi:

$$
d p(r)=\sqrt{\frac{\sum\left(r_{i}-1464.153864\right)^{2}}{8}}=1103.52741
$$


Tabela 31. Dados da amostra e pesos das réplicas criadas pela técnica BRR.

\begin{tabular}{|c|c|c|c|c|c|c|c|c|c|c|c|}
\hline \multicolumn{4}{|c|}{ Amostra } & \multicolumn{8}{|c|}{ Réplicas - pesos } \\
\hline estrato & UPA & renda & Peso & 1 & 2 & 3 & 4 & 5 & 6 & 7 & 8 \\
\hline 1 & 1 & 628 & 181.2 & 181.2 & 181.2 & 181.2 & 181.2 & 181.2 & 181.2 & 181.2 & 181.2 \\
\hline 1 & 1 & 780 & 181.2 & 181.2 & 181.2 & 181.2 & 181.2 & $1,81.2$ & 181.2 & 181.2 & 181.2 \\
\hline 1 & 1 & 594 & 181.2 & 181.2 & 181.2 & 181.2 & 181.2 & 181.2 & 181.2 & 181.2 & 181.2 \\
\hline 1 & 1 & 940 & 181.2 & 181.2 & 181.2 & 181.2 & 181.2 & 181.2 & 181.2 & 181.2 & 181.2 \\
\hline 1 & 1 & 200 & 181.2 & 181.2 & 181.2 & 181.2 & 181.2 & 181.2 & 181.2 & 181.2 & 181.2 \\
\hline 1 & 2 & 0 & 181.2 & 0 & 0 & 0 & 0 & 0 & 0 & 0 & 0 \\
\hline 1 & 2 & 250 & 181.2 & 0 & 0 & 0 & 0 & 0 & 0 & 0 & 0 \\
\hline 1 & 2 & 1519 & 181.2 & 0 & 0 & 0 & 0 & 0 & 0 & 0 & 0 \\
\hline 1 & 2 & 1230 & 181.2 & 0 & 0 & 0 & 0 & 0 & 0 & 0 & 0 \\
\hline 1 & 2 & 0 & 181.2 & 0 & 0 & 0 & 0 & 0 & 0 & 0 & 0 \\
\hline 2 & 1 & 530 & 135.1 & 135.1 & 0 & 135.1 & 0 & 135.1 & 0 & 135.1 & 0 \\
\hline 2 & 1 & 2601 & 135.1 & 135.1 & 0 & 135.1 & 0 & 135.1 & 0 & 135.1 & 0 \\
\hline 2 & 1 & 1053 & 135.1 & 135.1 & 0 & 135.1 & 0 & 135.1 & 0 & 135.1 & 0 \\
\hline 2 & 1 & 427 & 135.1 & 135.1 & 0 & 135.1 & 0 & 135.1 & 0 & 135.1 & 0 \\
\hline 2 & 1 & 653 & 135.1 & 135.1 & 0 & 135.1 & 0 & 135.1 & 0 & 135.1 & 0 \\
\hline 2 & 2 & 480 & 135.1 & 0 & 135.1 & 0 & 135.1 & 0 & 135.1 & 0 & 135.1 \\
\hline 2 & 2 & 300 & 135.1 & 0 & 135.1 & 0 & 135.1 & 0 & 135.1 & 0 & 135.1 \\
\hline 2 & 2 & 538 & 135.1 & 0 & 135.1 & 0 & 135.1 & 0 & 135.1 & 0 & 135.1 \\
\hline 2 & 2 & 991 & 135.1 & 0 & 135.1 & 0 & 135.1 & 0 & 135.1 & 0 & 135.1 \\
\hline 2 & 2 & 380 & 135.1 & 0 & 135.1 & 0 & 135.1 & 0 & 135.1 & 0 & 135.1 \\
\hline 3 & 1 & 195 & 40.9 & 40.9 & 0 & 0 & 40.9 & 40.9 & 0 & 0 & 40.9 \\
\hline 3 & 1 & 0 & 40.9 & 40.9 & 0 & 0 & 40.9 & 40.9 & 0 & 0 & 40.9 \\
\hline 3 & 1 & 386 & 40.9 & 40.9 & 0 & 0 & 40.9 & 40.9 & 0 & 0 & 40.9 \\
\hline 3 & 1 & 195 & 40.9 & 40.9 & 0 & 0 & 40.9 & 40.9 & 0 & 0 & 40.9 \\
\hline 3 & 1 & 200 & 40.9 & 40.9 & 0 & 0 & 40.9 & 40.9 & 0 & 0 & 40.9 \\
\hline 3 & 2 & 1500 & 40.9 & 0 & 40.9 & 40.9 & 0 & 0 & 40.9 & 40.9 & 0 \\
\hline 3 & 2 & 900 & 40.9 & 0 & 40.9 & 40.9 & 0 & 0 & 40.9 & 40.9 & 0 \\
\hline 3 & 2 & 550 & 40.9 & 0 & 40.9 & 40.9 & 0 & 0 & 40.9 & 40.9 & 0 \\
\hline 3 & 2 & 240 & 40.9 & 0 & 40.9 & 40.9 & 0 & 0 & 40.9 & 40.9 & 0 \\
\hline 3 & 2 & 797 & 40.9 & 0 & 40.9 & 40.9 & 0 & 0 & 40.9 & 40.9 & 0 \\
\hline 4 & 1 & 1050 & 59.3 & 59.3 & 59.3 & 0 & 0 & 59.3 & 59.3 & 0 & 0 \\
\hline 4 & 1 & 15500 & 59.3 & 59.3 & 59.3 & 0 & 0 & 59.3 & 59.3 & 0 & 0 \\
\hline 4 & 1 & 460 & 59.3 & 59.3 & 59.3 & 0 & 0 & 59.3 & 59.3 & 0 & 0 \\
\hline 4 & 1 & 0 & 59.3 & 59.3 & 59.3 & 0 & 0 & 59.3 & 59.3 & 0 & 0 \\
\hline 4 & 1 & 7000 & 59.3 & 59.3 & 59.3 & 0 & 0 & 59.3 & 59.3 & 0 & 0 \\
\hline 4 & 2 & 2500 & 59.3 & 0 & 0 & 59.3 & 59.3 & 0 & 0 & 59.3 & 59.3 \\
\hline 4 & 2 & 1800 & 59.3 & 0 & 0 & 59.3 & 59.3 & 0 & 0 & 59.3 & 59.3 \\
\hline 4 & 2 & 5000 & 59.3 & 0 & 0 & 59.3 & 59.3 & 0 & 0 & 59.3 & 59.3 \\
\hline 4 & 2 & 2406 & 59.3 & 0 & 0 & 59.3 & 59.3 & 0 & 0 & 59.3 & 59.3 \\
\hline 4 & 2 & 18000 & 59.3 & 0 & 0 & 59.3 & 59.3 & 0 & 0 & 59.3 & 59.3 \\
\hline
\end{tabular}


continuação da Tabela 32

\begin{tabular}{|c|c|c|c|c|c|c|c|c|c|c|c|}
\hline \multicolumn{4}{|c|}{ Amostra } & \multicolumn{8}{|c|}{ Réplicas - pesos } \\
\hline estrato & UPA & Renda & Peso & 1 & 2 & 3 & 4 & 5 & 6 & 7 & 8 \\
\hline 5 & 1 & 1000 & 65.0 & 65.0 & 65.0 & 65.0 & 65.0 & 0 & 0 & $\overline{0}$ & 0 \\
\hline 5 & 1 & 1605 & 65.0 & 65.0 & 65.0 & 65.0 & 65.0 & 0 & 0 & 0 & 0 \\
\hline 5 & 1 & 640 & 65.0 & 65.0 & 65.0 & 65.0 & 65.0 & 0 & 0 & 0 & 0 \\
\hline 5 & 1 & 2009 & 65.0 & 65.0 & 65.0 & 65.0 & 65.0 & 0 & 0 & 0 & 0 \\
\hline 5 & 1 & 300 & 65.0 & 65.0 & 65.0 & 65.0 & 65.0 & 0 & 0 & 0 & 0 \\
\hline 5 & 2 & 537 & 65.0 & 0 & 0 & 0 & 0 & 65.0 & 65.0 & 65.0 & 65.0 \\
\hline 5 & 2 & 750 & 65.0 & 0 & 0 & 0 & 0 & 65.0 & 65.0 & 65.0 & 65.0 \\
\hline 5 & 2 & 550 & 65.0 & 0 & 0 & 0 & 0 & 65.0 & 65.0 & 65.0 & 65.0 \\
\hline 5 & 2 & 0 & 65.0 & 0 & 0 & 0 & 0 & 65.0 & 65.0 & 65.0 & 65.0 \\
\hline 5 & 2 & 0 & 65.0 & 0 & 0 & 0 & 0 & 65.0 & 65.0 & 65.0 & 65.0 \\
\hline 6 & 1 & 2215 & 112.5 & 112.5 & 0 & 112.5 & 0 & 0 & 112.5 & 0 & 112.5 \\
\hline 6 & 1 & 5670 & 122.5 & 122.5 & 0 & 122.5 & 0 & 0 & 122.5 & 0 & 122.5 \\
\hline 6 & 1 & 1645 & 122.5 & 122.5 & 0 & 122.5 & 0 & 0 & 122.5 & 0 & 122.5 \\
\hline 6 & 1 & 750 & 122.5 & 122.5 & 0 & 122.5 & 0 & 0 & 122.5 & 0 & 122.5 \\
\hline 6 & 1 & 1630 & 122.5 & 122.5 & 0 & 122.5 & 0 & 0 & 122.5 & 0 & 122.5 \\
\hline 6 & 2 & 4200 & 112.5 & 0 & 112.5 & 0 & 112.5 & 112.5 & 0 & 112.5 & 0 \\
\hline 6 & 2 & 2900 & 122.5 & 0 & 122.5 & 0 & 122.5 & 122.5 & 0 & 122.5 & 0 \\
\hline 6 & 2 & 350 & 122.5 & 0 & 122.5 & 0 & 122.5 & 122.5 & 0 & 122.5 & 0 \\
\hline 6 & 2 & 500 & 122.5 & 0 & 122.5 & 0 & 122.5 & 122.5 & 0 & 122.5 & 0 \\
\hline 6 & 2 & 2000 & 122.5 & 0 & 122.5 & 0 & 122.5 & 122.5 & 0 & 122.5 & 0 \\
\hline 7 & 1 & 500 & 161.6 & 161.6 & 0 & 0 & 161.6 & 0 & 161.6 & 161.6 & 0 \\
\hline 7 & 1 & 1640 & 161.6 & 161.6 & 0 & 0 & 161.6 & 0 & 161.6 & 161.6 & 0 \\
\hline 7 & 1 & 1720 & 161.6 & 161.6 & 0 & 0 & 161.6 & 0 & 161.6 & 161.6 & 0 \\
\hline 7 & 1 & 2700 & 161.6 & 161.6 & 0 & 0 & 161.6 & 0 & 161.6 & 161.6 & 0 \\
\hline 7 & 1 & 1640 & 161.6 & 161.6 & 0 & 0 & 161.6 & 0 & 161.6 & 161.6 & 0 \\
\hline 7 & 2 & 500 & 161.6 & 0 & 161.6 & 161.6 & 0 & 161.6 & 0 & 0 & 161.6 \\
\hline 7 & 2 & 350 & 161.6 & 0 & 161.6 & 161.6 & 0 & 161.6 & 0 & 0 & 161.6 \\
\hline 7 & 2 & 3360 & 161.6 & 0 & 161.6 & 161.6 & 0 & 161.6 & 0 & 0 & 161.6 \\
\hline 7 & 2 & 1122 & 161.6 & 0 & 161.6 & 161.6 & 0 & 161.6 & 0 & 0 & 161.6 \\
\hline 7 & 2 & 1040 & 161.6 & 0 & 161.6 & 161.6 & 0 & 161.6 & 0 & 0 & 161.6 \\
\hline 8 & 1 & 4000 & 93.6 & 93.6 & 93.6 & 0 & 0 & 0 & 0 & 93.6 & 93.6 \\
\hline 8 & 1 & 520 & 93.6 & 93.6 & 93.6 & 0 & 0 & 0 & 0 & 93.6 & 93.6 \\
\hline 8 & 1 & 1800 & 93.6 & 93.6 & 93.6 & 0 & 0 & 0 & 0 & 93.6 & 93.6 \\
\hline 8 & 1 & 3650 & 93.6 & 93.6 & 93.6 & 0 & 0 & 0 & 0 & 93.6 & 93.6 \\
\hline 8 & 1 & 960 & 93.6 & 93.6 & 93.6 & 0 & 0 & 0 & 0 & 93.6 & 93.6 \\
\hline 8 & 2 & 1620 & 93.6 & 0 & 0 & 93.6 & 93.6 & 93.6 & 93.6 & 0 & 0 \\
\hline 8 & 2 & 1117 & 93.6 & 0 & 0 & 93.6 & 93.6 & 93.6 & 93.6 & 0 & 0 \\
\hline 8 & 2 & 879 & 93.6 & 0 & 0 & 93.6 & 93.6 & 93.6 & 93.6 & 0 & 0 \\
\hline 8 & 2 & 1112 & 93.6 & 0 & 0 & 93.6 & 93.6 & 93.6 & 93.6 & 0 & 0 \\
\hline 8 & 2 & 0 & 93.6 & 0 & 0 & 93.6 & 93.6 & 93.6 & 93.6 & 0 & 0 \\
\hline
\end{tabular}




\section{ANEXO 3}

\section{Delineamentos de Amostragem dos Inquéritos de Saúde}

\section{"Morbidade e utilização de serviços no município de Embu"}

A população objeto de investigação foi composta das crianças menores de cinco anos e suas famílias, residentes no município de Embu, em 1996.

Para sorteio da amostra, os setores censitários do município foram agrupados em quatro estratos, segundo condições de moradia e situação financeira das famílias. Em cada estrato, foram sorteados dez setores censitários, com probabilidade proporcional ao tamanho, definido pelo número de domicílios existentes. Dentro dos setores, por meio do sorteio de segmentos de aproximadamente dez domicílios, 150 domicílios foram sorteados para compor a amostra de menores de um ano, e 50 domicílios, para o grupo de crianças de um a quatro anos. (SILVA et al. 1996).

A fração de amostragem utilizada em cada estrato foi:

$f=f_{1} \cdot f_{2}$

$f_{1}=\frac{10 \cdot D_{i}}{\sum_{i} D_{i}}$ é a probabilidade de sorteio do i-ésimo setor censitário, calculada em função de $D i$, número de domicílios existentes no mesmo; $f_{2}=\frac{d_{i}}{D_{i}}$ é a probabilidade de sorteio dos domicílios no setor censitário $\mathrm{i} ; \mathrm{di}=150$ para menores de um ano e $d i=50$ para crianças de um a quatro anos. 
A atualização em campo dos tamanhos dos setores censitários, fez com que a fração de amostragem do segundo estágio, caso o número de domicílios encontrados fosse diferente do esperado, se tornasse: $f_{2}=\frac{d_{i} \frac{D_{i}^{\prime}}{D_{i}}}{D_{i}^{\prime}}$, sendo que $D_{i}^{\prime}$ é o número de domicílios encontrado em campo.

As informações do questionário foram tratadas como variáveis categóricas e os estimadores foram da forma:

$$
r=\frac{\sum_{\alpha}^{n} w_{\alpha} \cdot y_{\alpha}}{\sum_{\alpha}^{\prime \prime} w_{\alpha} \cdot x_{\alpha}}
$$

$y_{\alpha}=1$, se criança $\alpha$ apresentou a característica em estudo e $y_{\alpha}=0$ caso contrário;

$x_{\alpha}=1$, para toda criança da amostra;

$w_{\alpha}=1 / f_{\alpha}$, peso igual ao inverso da fração de amostragem;

n é o número de crianças na amostra.

Os pesos foram introduzidos para compensar diferenças de probabilidade ( $f$ ) de qualquer criança da população pertencer à amostra sorteada, provocadas pela atualização em campo dos tamanhos dos setores censitários e sorteio de número igual de domicílios por estrato.

O número total de famílias da amostra foi de 941 , tendo sido pesquisadas 487 crianças menores de um ano e 617 crianças de um a quatro anos. 


\section{"Morbidade referida e utilização de serviços de saúde da região sudoeste da Grande São Paulo".}

A população alvo constituiu-se da população residente em oito municípios da Região Metropolitana de São Paulo: Taboão da Serra, Embú, Itapecerica da Serra, São Lourenço da Serra, Embú-Guaçú, Juquitiba, Cotia e Vargem Grande Paulista, durante o período do levantamento, realizado nos anos de 1989 e 1990.

Os setores censitários desses municípios foram agrupados em estratos, segundo grupos de municípios (seis áreas) e densidade de domicílios por setor (dois níveis), num total de 12 estratos.

A amostra foi sorteada em dois estágios (setor censitário e domicílio) ou três (setor censitário, quarteirão e domicílio), dependendo do estrato. Em cada área, houve o sorteio de 30 setores, totalizando 180 unidades primárias de amostragem. Ainda em cada área, a distribuição das unidades de amostragem pelos dois estratos, definidos pelos níveis de densidade populacional, foi feita por partilha proporcional ao número de domicílios de cada estrato.

Planejou-se o sorteio de 250 indivíduos, em sete subgrupos populacionais distintos, definidos por sexo e idade: menores de um ano, de 1 a 6 anos, de 7 a 19 anos, de 20 a 49 anos (sexos feminino e masculino), 50 ou mais anos de idade (sexos masculino e feminino). Os tamanhos de amostra planejados foram iguais, em função do interesse em se obter estimativas que atendessem ao critério fixado de precisão, em cada um dös subgrupos.

Com base na média de indivíduos por domicílio, foram estimados os números de domicílios que deveriam ser visitados, para se obter 250 entrevistas, por subgrupo 
populacional, sendo que, em função do grupo mais raro, definiu-se o tamanho da amostra (amostra principal). A partir dessa amostra principal, foram tomadas subamostras de domicílios suficientes para atingir o número previsto de entrevistas em cada subgrupo, utilizando-se fração $f r_{\alpha}$ de domicílios, $\alpha$ correspondendo ao subgrupo populacional $\alpha$.

As frações de amostragem estão descritas no QUADRO 10.

Quadro 10. Frações de amostragem por estrato (área e nível de densidade populacional) e estágio de seleção. Pesquisa "Morbidade referida e utilização de serviços de saúde na região sudoeste da Grande São Paulo".

\begin{tabular}{l|c|cccc}
\hline \multirow{A}{*}{ REA } & NÍVEL & $1^{\circ}$ & ESTÁGIO & $2^{\circ}$ & TOTAL \\
& DENS. & $1^{\circ}$ & \\
\hline $1-2-3$ & I & $a M_{i} / M$ & $b M_{i j} / M_{i}$ & $c / M_{i j}$ & $a b c / M$ \\
& II & $a^{\prime} M_{i} / M$ & $b^{\prime} M_{i j} / M_{i}$ & - & $a^{\prime} b^{\prime} / M$ \\
$4-5$ & I & $a M_{i} / M$ & $b / M_{i}$ & & $a b / M$ \\
& II & $a^{\prime} M_{i} / M$ & $b^{\prime} / M_{i}$ & & $a^{\prime} b^{\prime} / M$ \\
6 & I & $a M_{i} / M$ & $b M_{i j} / M_{i}$ & $c / M_{i j}$ & $a b c / M$ \\
\hline
\end{tabular}

No quadro acima, nos estratos em que foram utilizados três estágios de sorteio, $(a, b, c)$ corresponderam, respectivamente, aos números de setores censitários, quarteirões e domicílios sorteados e $\left(M, M_{i}, M_{i j}\right)$ corresponderam, respectivamente, aos números de domicílios existentes no município, no setor censitário e quarteirão sorteados. Com dois estágios de seleção, $\left(a^{\prime}, b^{\prime}\right)$ corresponderam aos números de setores e domicílios sorteados.

A definição de amostras de igual tamanho, nas seis áreas e nos sete subgrupos populacionais, introduziu probabilidades distintas de sorteio, refletidas no peso dos 
elementos. Dentro de cada área, a partição da amostra pelos estratos de densidade populacional por ser proporcional ao número de domicílios, não gerou alterações nas frações de amostragem.

Pela pós-estratificação, os estimadores utilizados nessa pesquisa foram ajustados para sexo e idade, segundo dados do censo de 1991, sendo da forma:

$r=\frac{\sum a_{i j} \cdot w_{i j} \cdot y_{i j}}{\sum a_{i j} \cdot w_{i j} \cdot x_{i j}}$

$w_{i j}=\left(1 / f_{i j}\right) \cdot\left(1 / f r_{i j}\right)$ é o peso do indivíduo $\mathrm{ij}$, inverso da probabilidade de seleção $f_{i j} f r_{i j} ; a_{i j}=N_{i j}^{\prime} / \sum \sum w_{i j}$ é o ajuste para sexo e idade e $N_{i j}^{\prime}$ é a população no domínio j, estrato i, para o censo de 1991.

O número total de entrevistas realizadas foi de 10199. 
"Produtividade dos habitats de Aedes aegypti", Santos, 2000.

A pesquisa foi realizada com o objetivo de estudar os recipientes domésticos que retém água e podem se tornar criadouros do vetor da dengue, Aedes aegypti, avaliando-os quanto à produção de larvas e pupas do mosquito. Foram visitadas edificações em três bairros do município de Santos: Vila São Jorge, Macuco e Boqueirão, nos meses de janeiro, fevereiro e março de 2000. Para cada bairro e mês, foi sorteada uma amostra por conglomerados.

No Boqueirão, adotou-se amostragem em dois estágios, tendo o quarteirão como unidade primária e edificação, como secundária. Metade das edificações de cada setor sorteado foi incluída na amostra. Nos outros bairros, foi adotado sorteio em estágio único, pesquisando-se todas as edificações nos quarteirões da amostra.

As frações de amostragem foram:

- para estágio único: $f=a / A ; a=n / \bar{B}$

- para dois estágios: $f=(a / A) \cdot(1 / 2) ; a=2 n / \bar{B}$

sendo (n,N) os números de edificações na amostra e no bairro;

$(\mathrm{a}, \mathrm{A})$ os números de quarteirões na amostra e no bairro;

$\bar{B}=N / A$, número médio de edificações por quarteirão do bairro.

Os número de edificações e quarteirões pesquisados estão indicados na Tabela 32. 
Tabela 32. Unidades de amostragem, quarteirões e edificações, na pesquisa "Produtividade dos habitats de Aedes aegypti", Município de Santos, 2000.

\begin{tabular}{llcc}
\hline MÊS & BAIRRO & EDIFICAÇÕES & QUARTEIRÕES \\
\hline Janeiro & Vila São Jorge & & 11 \\
& Macuco & 988 & 18 \\
& Boqueirão & 1109 & 11 \\
Fevereiro & Vila São Jorge & 883 & 12 \\
& Macuco & 826 & 15 \\
& Boqueirão & 740 & 15 \\
& Vila São Jorge & 623 & 10 \\
& Macuco & 805 & 15 \\
& Boqueirão & 426 & 15 \\
\hline
\end{tabular}

Embora o objetivo do estudo realizado em Santos não tenha sido avaliar densidade larvária de Aedes aegypti, o Índice de Breteau foi estimado para contextualizar as discussões sobre produtividade de criadouros do mosquito. $O$ estimador do Índice de Breteau é definido pela expressão:

$I \hat{B}=100 \sum y_{i} / \sum x_{i}$

$y_{i}$ é o número de recipientes positivos no quarteirão $\mathrm{i}$;

$x_{i}$ é o número de edificações sorteadas no quarteirão i 


\section{"Pesquisa de Condições de Vida - 1998"}

Na Região Metropolitana de São Paulo, a amostra da "Pesquisa de Condições de Vida - 1988" (PCV) foi retirada das amostras da Pesquisa de Emprego e Desemprego (PED) dos meses de agosto a novembro desse ano. Incluiu todos os setores da PED e a metade dos domicílios de cada setor. A população alvo é composta pelas famílias moradoras na área urbana da Região Metropolitana de São Paulo (RMSP).

Os municípios da RMSP e distritos do Município de São Paulo foram agrupados em cinco estratos, criados com base em estudo que divide a RMSP em regiões homogêneas. $O$ número de unidades de amostragem em cada estrato foi determinado em proporcionalidade ao seu número de domicílios, adotando-se, portanto, estratificação com partilha proporcional.

A fração de amostragem em cada estrato foi:

$$
\begin{aligned}
& f=f_{P E I D} / 2 \\
& f_{P E I I}=\frac{508 \cdot D_{i}}{\sum D_{i}} \cdot \frac{9}{D_{i}}
\end{aligned}
$$

sendo que $f_{P l E D}$ é a fração de amostragem da Pesquisa de Emprego e Desemprego.

Essa fração refere-se ao sorteio de setores censitários com probabilidade proporcional ao tamanho, $D i$, correspondente ao número de domicílios particulares ocupados do setor i. Prevê amostra de 4500 domicílios, distribuídos em 508 setores censitários, implicando no sorteio de nove domicílios, em média, por setor.

Na PED, a amostra necessária para que as estimativas atendam à precisão desejada não é sorteada, por razões de custo, em um único mês. São sorteadas amostras independentes em três meses consecutivos e as estimativas calculadas com 
base nessas três amostras. Conseqüentemente, na PCV as estimativas foram feitas também dessa forma.

Os estimadores utilizados na pesquisa são do tipo razão, corrigidos pela não resposta e ajustados pela pós-estratificação, para a população estimada de julho de 1998. As expressões algébricas que os definem são:

$r=\frac{\sum_{i} w_{i} \sum_{j} y_{i j}}{\sum_{i} w_{i}^{*} \sum_{j} x_{i j}}$

$w_{i}^{*}=w_{i} \cdot \frac{P}{\sum_{i} w_{i}} \quad ; \quad w_{i}=\frac{1}{f}\left(1+\frac{d s r_{i}}{v a l_{i}}\right)$

$P$ é a projeção populacional para julho de 1998;

$d s r_{i}$ é o total de domicílios sem resposta (fechados, com recusa, com entrevistas incompletas) e $v a l_{i}$ é o total de domicílios com entrevistas válidas no setor censitário i.

$y_{i j}$ corresponde à observação do elemento $\mathrm{j}$ do setor $\mathrm{i}$;

$x_{i j}=1$, para todo elemento $\mathrm{j}$ do setor $\mathrm{i}$.

Na Região Metropolitana de Santos, adotou-se também amostragem em dois estágios: setor censitário e domicílio. Foram criados dois estratos nos quais foram aplicadas frações de amostragem distintas: município de Santos e demais municípios.

As unidades primárias de amostragem foram sorteadas com probabilidade proporcional ao seu tamanho - número de domicílios particulares ocupados, utilizando-se o procedimento de seleções pareadas. Para tanto, com os setores ordenados segundo renda média dos chefes, foram criadas a/2 zonas de sorteio, com 
números iguais de domicílios ocupados. Em cada zona, acumulando-se os conglomerados segundo seu tamanho, foram sorteados, sem reposição e de forma aleatória, dois conglomerados.

A fração global de amostragem é descrita por:

$f=f_{1} \cdot f_{2}$

$f_{1}=\frac{2 D_{i}}{M} ; M=\frac{\sum D_{i}}{a / 2}$

$f_{2}=\frac{b}{D_{i}}$

sendo que $D_{i}$ é o número de domicílios do setor i; $M$ é o tamanho das zonas de sorteio; a/2 é o número de zonas de sorteio; b é o número de domicílios a serem sorteados no conglomerado.

Foram sorteados 120 setores censitários, após a criação, portanto, de 60 zonas de sorteio.

Os estimadores foram:

$r=\frac{\sum_{h} \sum_{i} w^{*}{ }_{h i} \sum_{j} y_{h i j}}{\sum_{h} \sum_{i} w^{*}{ }_{h i} \sum_{j} x_{h i j}}$

$w^{*} h_{i i}=w_{l i} \cdot \frac{P_{l h}}{\sum_{i} w_{l i}} ; \quad w_{h i}=\frac{1}{f_{h}}\left(1+\frac{d s r_{h i}}{v a l_{h i}}\right)$

$P_{h}$ é a projeção populacional do estrato h, para julho de 1998

$d s r_{h i}$ é o total de domicílios sem resposta (fechados, com recusa, com entrevistas incompletas)

$v a l_{h i}$ é o total de domicílios com entrevistas válidas no setor censitário i, estrato h. 